\title{
De la ferme gauloise à la villa romaine, le site du Grand-Coudray à Bonchamp-lès-Laval (Mayenne)
}

From Gallic farm to Roman villa: the site of Grand-Coudray at Bonchamp-lèsLaval (Mayenne)

Vom latènezeitlichem Gehöft zur römischen Villenanlage: Der Fundplatz von Grand-Coudray bei Bonchamp-lès-Laval (Mayenne)

Desde la granja galo hasta la villa romana: el sitio de Grand-Coudray en Bonchamp-lès-Laval (Mayenne)

\section{Gérard Guillier, Emmanuelle Coffineau, Valérie Deloze et Stéphanie Raux}

\section{OpenEdition}

Journals

Édition électronique

URL : https://journals.openedition.org/rao/2554

DOI : $10.4000 /$ rao. 2554

ISBN : 978-2-7535-4053-8

ISSN : $1775-3732$

\section{Éditeur}

Presses universitaires de Rennes

\section{Édition imprimée}

Date de publication : 15 décembre 2014

Pagination : 199-250

ISBN : 978-2-7535-4051-4

ISSN : 0767-709X

Référence électronique

Gérard Guillier, Emmanuelle Coffineau, Valérie Deloze et Stéphanie Raux, « De la ferme gauloise à la villa romaine, le site du Grand-Coudray à Bonchamp-lès-Laval (Mayenne) », Revue archéologique de I'Ouest [En ligne], 31 | 2014, mis en ligne le 15 décembre 2016, consulté le 22 août 2022. URL : http:// journals.openedition.org/rao/2554; DOI : https://doi.org/10.4000/rao.2554 


\title{
De la ferme gauloise à la villa romaine, le site du Grand-Coudray à Bonchamp-lès-Laval (Mayenne)

\author{
From Gallic Farm to Roman Villa: The Site of Grand-Coudray \\ at Bonchamp-lès-Laval (Mayenne)
}

\author{
Gérard Guillier*, Emmanuelle Coffineau**, \\ Valérie Deloze ${ }^{* * *}$ et Stéphanie Raux ${ }^{* * * *}$
}

\begin{abstract}
Résumé : La fouille partielle d'un site laténien et antique localisé au nord-est de la ville de Laval a mis en évidence deux systèmes d'enclos gaulois successifs, bordés au sud par un petit cheminement. Le principal intérêt de cette modeste fouille réside dans la présence de près de vingt bâtiments sur poteaux plantés. Le mobilier céramique est juste suffisant pour permettre une première accroche chronologique; en revanche l'instrumentum a révélé quelques objets inhabituels, un lingot de fer et un fragment de vase en lignite. L'époque antique est caractérisée par le creusement de structures se superposant exactement aux précédentes. La dernière phase de l'occupation, au début du II ${ }^{\mathrm{e}}$ s. apr. J.-C., est définie par l'angle sudouest de la pars rustica d'une villa romaine. La céramique modelée antique, caractéristique du site, présente un pourcentage régionalement assez inhabituel avec près de $60 \%$ des vases.
\end{abstract}

\begin{abstract}
The partial excavation of a site from the La Tene and Gallo-Roman periods located to the north east of the town of Laval has revealed two successive Gallic enclosures, bordered to the south by a minor route marked by a ditch parallel to the southern angles of the enclosures. The main point of interest is the presence of almost 20 postholed buildings. The pottery is not very abundant, but is suffcient to enable an initial chronology; however, the instrumentum included a number of unusual objects, including an iron ingot and a fragment of lignite vase. The Gallo-Roman period is characterised by the digging of structures that superimpose exactly over the previous ones. The last occupation phase, in the early 2nd century A.D., saw the construction of a Roman villa, of which the south west angle of the pars rustica has been excavated. The Gallo-Roman modelled pottery presents a rather unusual regional character, with almost $60 \%$ being vases.
\end{abstract}

Mots clés : Diablintes, Mayenne, La Tène, Enclos gaulois, bâtiments sur poteaux, portails, Haut-Empire, habitat, villa, céramique, instrumentum.

Keywords: Diablintes, Mayenne, La Tène, Gallic enclosures, post-hole buildings, portal, Roman Empire, villa, habitation, ceramics, smal finds.

\section{INTRODUCTION}

L'intervention archéologique au lieu-dit Le GrandCoudray sur la commune de Bonchamp-lès-Laval est localisée au cœur du département de la Mayenne (fig. 1), à cinq kilomètres au nord-nord-est de Laval, au sein de l'ancienne cité gauloise et gallo-romaine des Aulerques Diablintes (Naveau, 1992, 1997). Elle jouxte au sud l'aire de service Laval-Bonchamp sur le tracé de l'autoroute Le Mans-Rennes (A81) (fig. 2). Cette fouille déterminée par la menace de destruction due à l'aménagement de la ligne à grande vitesse Le Mans - Rennes, a été confiée à l'Inrap par Eiffage Rail

* Institut national de recherches archéologiques préventives (Inrap Grand-Ouest), UMR 8546 CNRS/ENS Paris. (gerard.guillier@inrap.fr)

** Inrap Grand-Ouest.

*** Inrap Grand-Ouest, UMR 6566 - CReAAH Rennes 1.

**** Inrap/UMR 5140 Montpellier-Lattes «Archéologie des Sociétés Méditerranéennes ». 

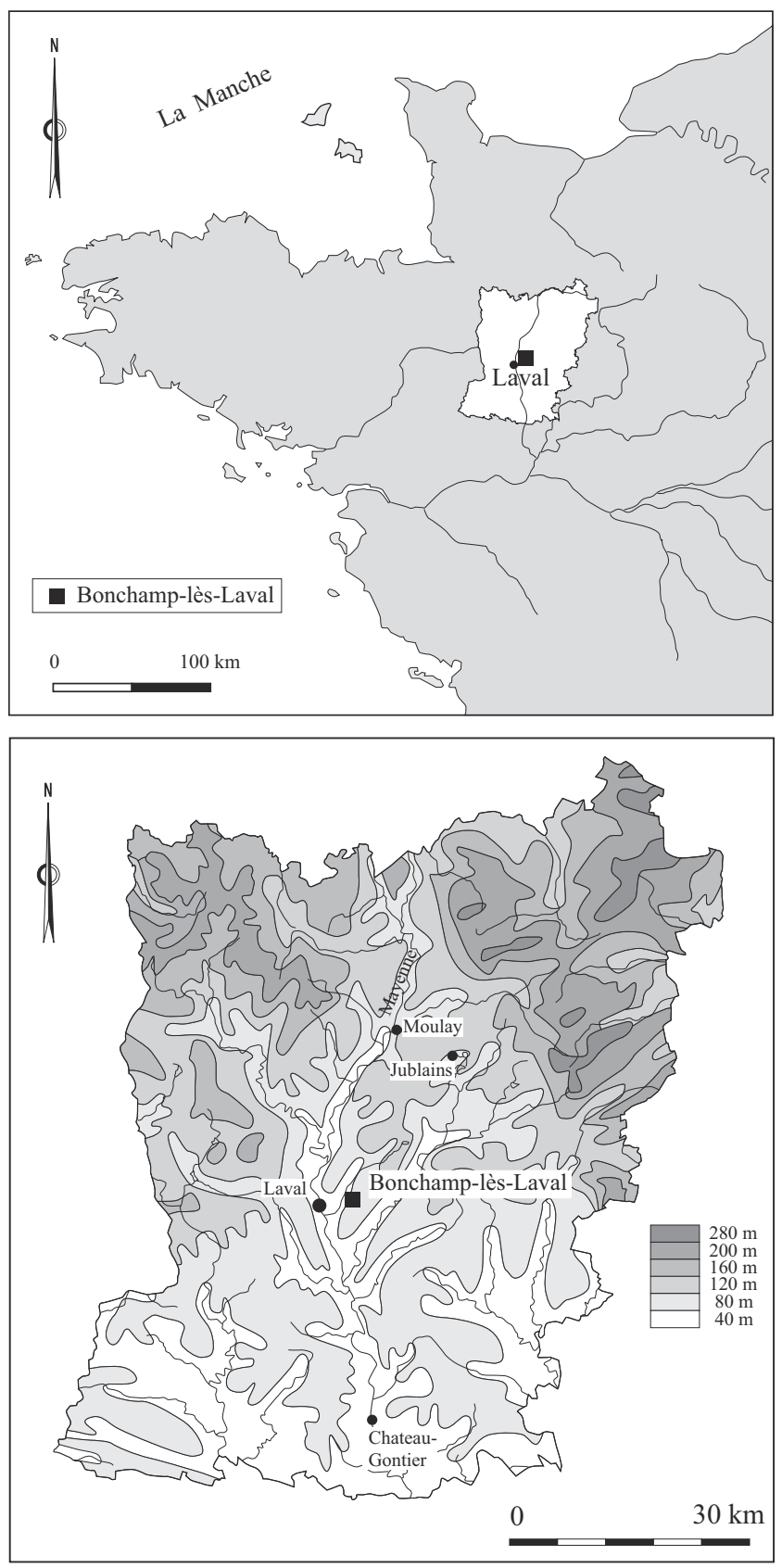

Figure 1 : Localisation de Bonchamp-lès-Laval (Mayenne - 53). Figure 1: Location of Bonchamp-lès-Laval (Mayenne, 53).

Express. Le numéro de site archéologique dans la base de données Patriarche est EA 530340016 (parcelle ZC 47p). Le site a été découvert lors d'une phase de diagnostic archéologique préalable à la construction de la ligne LGV (Guicheteau, 2011) et sa fouille a été réalisée de janvier à mars 2012 (Guillier, 2014b); ces données sont ponctuellement complétées par les résultats d'un diagnostic réalisé en mars 2014 et dont l'emprise jouxte à l'est l'intervention de 2012 (Guillier, 2014a) (fig. 3).

\section{État des connaissances avant l'opération}

Le site se situe hors du champ chronologique de l'environnement archéologique reconnu qui couvre essentiellement la préhistoire et le Moyen Âge (fig. 2). L'époque antique tardive est représentée par une inhumation découverte en 1884 à Argentré (Naveau, 1992); mentionnons au nord du Grand-Coudray, au-delà de l'A81, un toponyme potentiellement antique : Martigné. Les voies anciennes dans le secteur sont attestées par les travaux de J. Naveau (1992; fig. 2). La voie 1 correspond à l'un des tracés de la voie Le Mans - Corseul. La voie 2 s'embranche sur la voie 1, mais n'est pas datée : elle pourrait être romaine tandis que la voie 3, probablement romaine, vient de Montsûrs et se dirige vers le gué antique de Laval (informations : J. Naveau). Enfin, la voie 4 est une hypothèse récente de L. Schmitt (Inrap), ce serait une variante de la voie 1 .

\section{Le contexte géologique local (V.D.)}

La commune de Bonchamp-lès-Laval, localisée dans la partie centre-ouest de la Mayenne, s'intègre dans le "synclinal de Laval ", constitué de formations sédimentaires du Cambrien au Carbonifère. Le site occupe un faible bombement, à une altitude de $+96 \mathrm{~m} \mathrm{NGF}$ (fig. 3). Le substrat constitué des schistes de Laval carbonifères est surmonté de formations superficielles (épaisses de 0,3 à 0,5 mètre). Enfin, signalons qu'au nord de l'autoroute A81 affleurent, de Louverné à Soulgé-sur-Ouette (Mary et al., 1989), les calcaires carboniferes de Sablé.

À partir de la stratigraphie, du mobilier archéologique et des relations spatiales visibles en plan, nous proposons l'hypothèse suivante de mise en phase chronologique du site :

- la phase 1 : la première occupation structurée du site, datée de La Tène C2/D1;

- la phase 2 : le creusement d'un nouvel enclos, à La Tène D1/D2;

- la phase 3 : d'Auguste au début des Antonins, avec la phase 3a, un enclos dans la continuité de la période gauloise et la phase $3 \mathrm{~b}$ qui marque un changement dans l'organisation du site;

- la phase 4 : où apparaît l'extrémité sud d'une villa antique.

Enfin, les données altimétriques sont données après le décapage mécanique des formations superficielles recouvrant le site. 


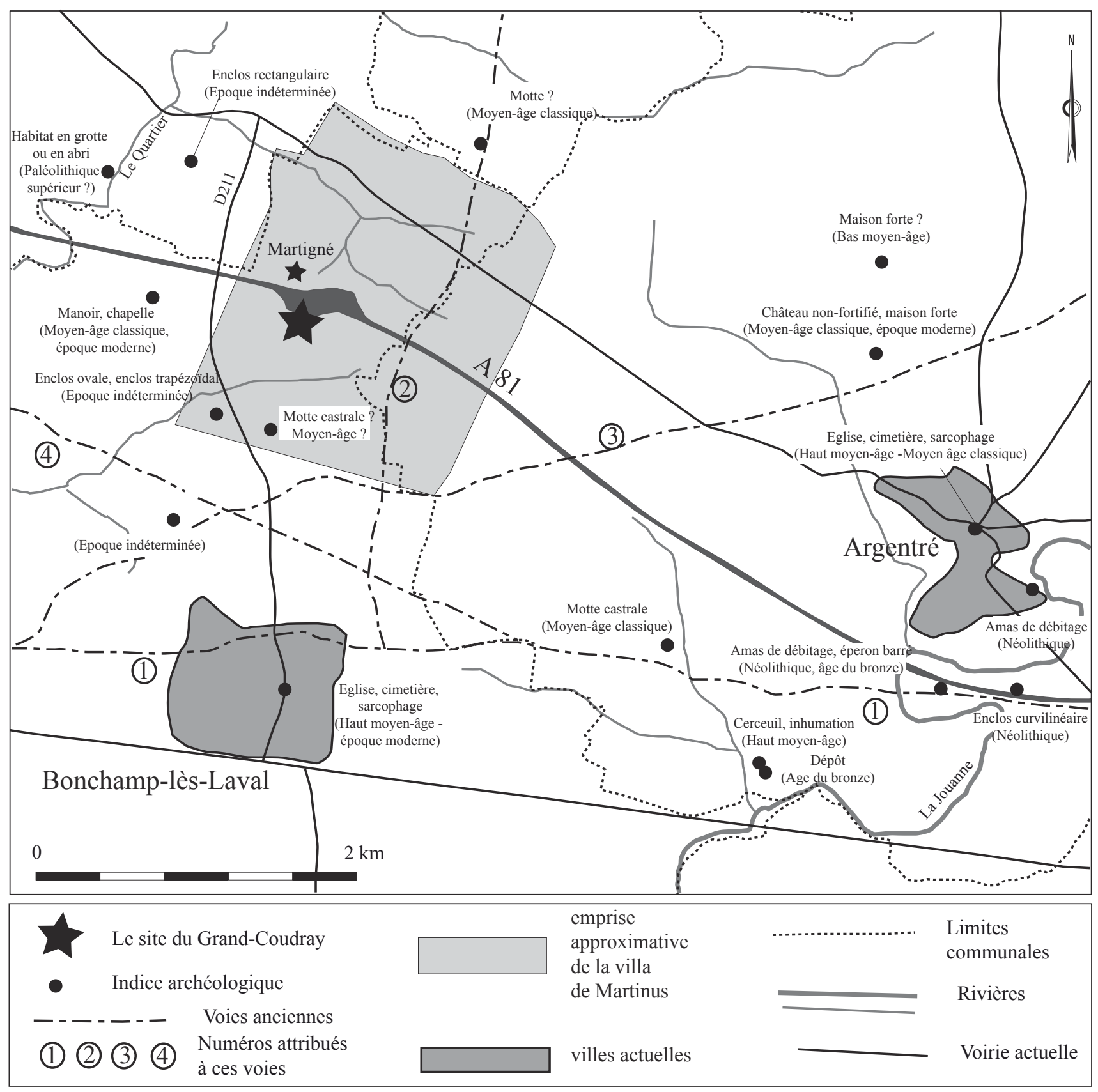

Figure 2 : Bonchamp-lès-Laval (53), localisation du site du Grand-Coudray et carte archéologique du secteur. Figure 2: Location of the site of Grand-Coudray and archaeological map of the sector.

\section{L'OCCUPATION GAULOISE : LES STRUCTURES ET LE MOBILIER}

\section{La phase 1 : la première occupation structurée du site, La Tène C2/D1}

L'enclos interne St 1152/1003 enserre quelques bâtiments sur poteaux plantés (fig. 4 et 5). Au sud et à l'est et parallèle- ment à ce premier enclos St 1152/1003, se situe un second enclos, externe, matérialisé d'une part au sud par le fossé, St $1211=1195=1229=5$ (distant du premier enclos de 6 à 6,5 mètres) et qui limite vraisemblablement un axe de circulation, et d'autre part à l'est par son retour vers le nord (distant du premier enclos de 70 mètres), matérialisé par les fossés St 6-7, où l'interruption les séparant est marquée par un portail d'accès monumental. 


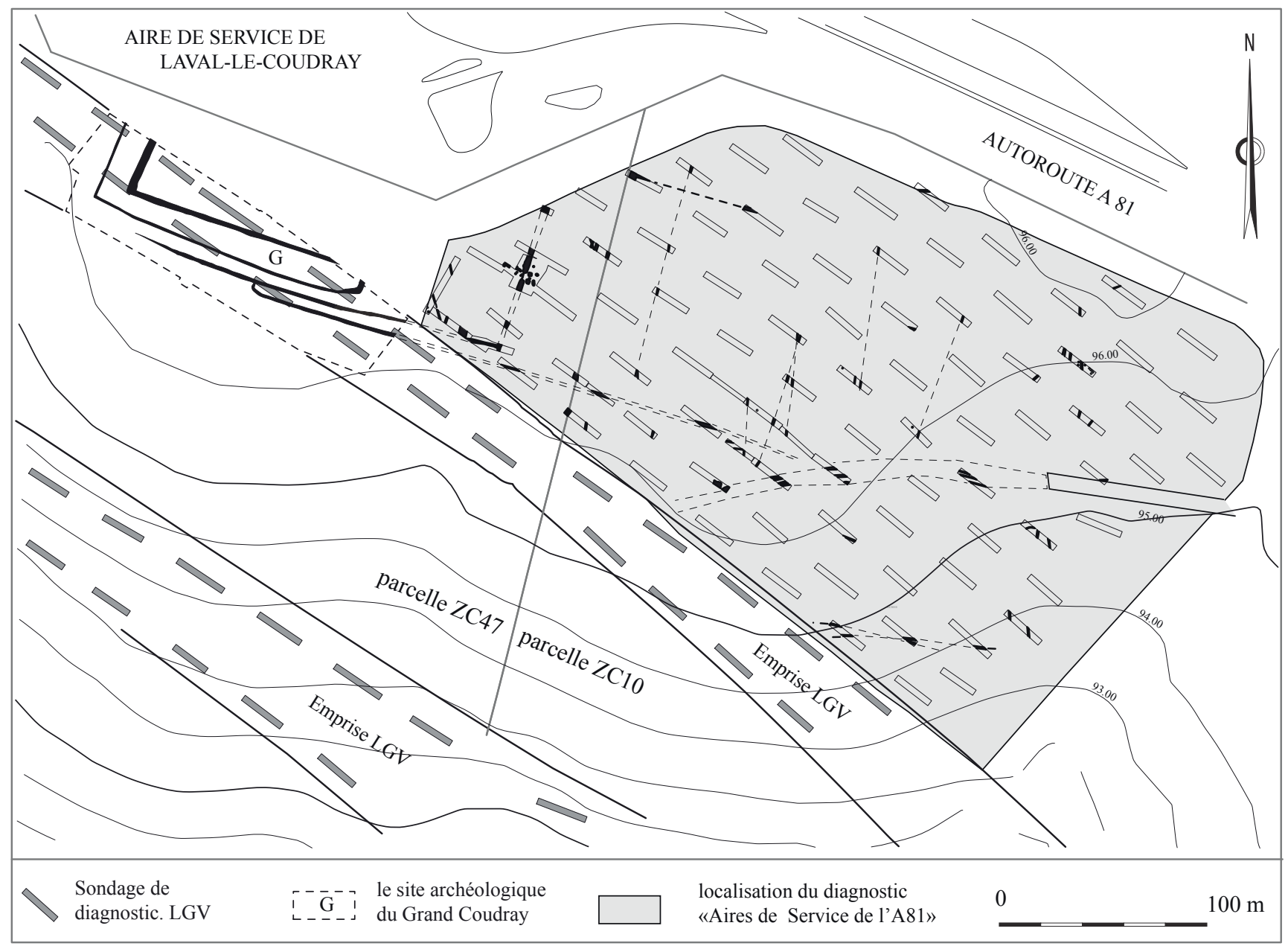

Figure 3 : Bonchamp-lès-Laval (53), localisation du diagnostic " Aires de Service de l'A81 » et de la fouille du site du Grand-Coudray (l'équidistance des courbes est de 1 mètre).

Figure 3: Location of the "A81 service station" test area and of the excavation of the site of Grand-Coudray (the contour interval is $1 \mathrm{~m}$ ).

\section{Un fossé d'enclos peu profond: St 1152/1003}

Le fossé d'enclos St 1152/1003 a été mis au jour sur une longueur de 124 mètres (étape 1/a), portée dans un second temps à 134,5 mètres par un léger grandissement à l'est (étape 1/b) (fig. 5). L'étape 1/a (St 1152/1003/1253) est caractérisée par un fossé (largeur : de 1 à $1,2 \mathrm{~m}$; profondeur : 0,45 à 0,65 mètre) dont le creusement est trapézoïdal à l'origine ou en " $U$ " plus ou moins ouvert. Son comblement, lessivé, présente à sa base une prédominance de plaquettes de schiste, signant un mode de fonctionnement ouvert et une dégradation des parois, puis un profil de stabilisation du fossé et, enfin, un apport de sédiments signant l'obturation du fossé. Le mobilier archéologique, issu de la partie médiane du comblement, est quasi absent des couches les plus profondes.
L'étape $1 / \mathrm{b}$ se distingue par un agrandissement vers l'est de l'enclos de l'ordre de 10 mètres. Le nouveau fossé, St 1044, est deux fois plus large et deux fois plus profond que St 1152. Les niveaux relevés sur le fond du fossé St 1152 déterminent une double pente, à partir du point haut, situé au niveau du sondage sd 65 : de 1,14\% vers l'ouest et de $0,66 \%$ à l'est, conformément à la topographie. Le mobilier exhumé de ce fossé comporte de rares tessons de céramique, une currency bar [7] et un fragment de vase en lignite [29].

Une division interne matérialisée par le fossé St 1205, délimite à l'ouest un espace de 20 mètres de largeur (fig. 5). Ce fossé est rectiligne (longueur : $36,5 \mathrm{~m}$; largeur : 0,95 à $1 \mathrm{~m}$; profondeur : 0,4 à 0,5 mètre). Les profils relevés sont

1. Les appels aux objets sont figurés entre crochets : $[\mathrm{N}]$ et renvoient aux figures 23 et 31 . 


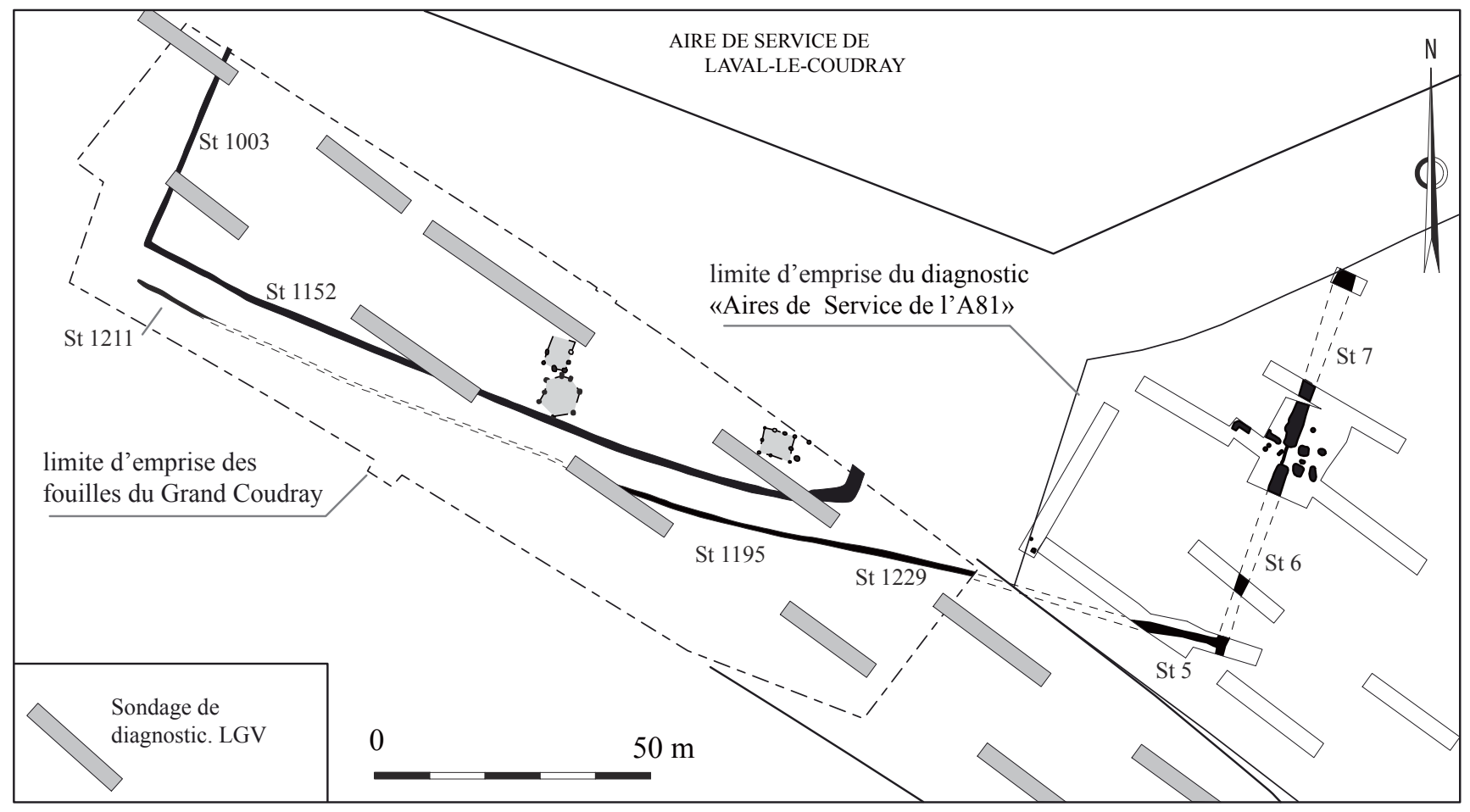

Figure 4 : Bonchamp-lès-Laval (53), phase 1, plan d'ensemble des vestiges.

Figure 4: Phase 1, overall plan of the remains.

trapézoïdaux et bien marqués (sd 37) ou en forme de " $U$ ", plus ou moins ouvert (sd 103). Les niveaux relevés sur le fond de ce fossé déterminent une pente à peu près nulle. Il présente une accumulation d'un sédiment gris à verdâtre recelant des plaquettes de schiste : des dépôts hydromorphes de type gley (hydromorphie profonde permanente). Le mobilier est réduit : un fragment de panse de céramique de datation indéterminée.

\section{Le fossé sud St $1211=1195=1229=5$}

Le fossé sud de l'enclos externe se développe sur une longueur de 220 mètres, mais un fossé antique s’y superpose sur plus de 70 mètres. Son tracé, légèrement incurvé, est parallèle au côté sud de l'enclos St 1152. Son extrémité ouest, St 1211, est définie par un brusque arrêt vertical dans l'axe du fossé St 1003. À l'est, le fossé sud est matérialisé par le fossé St 5 du diagnostic (fig. 4). Ce fossé, distant de 6 à 6,5 mètres du côté sud de l'enclos, est plus profond à l'est (fig. 5) qu'à l'ouest, avec des profils trapézoïdaux à l'est et en " $U$ ». À l'ouest, ce fossé s'apparente à un cheminement ou un accès (à l'enclos). Le mobilier constitué de soixantetreize tessons de céramique, regroupés dans la moitié est du fossé, se rapporte à la phase ancienne du site; mais en surface, quelques tessons antiques indiquent une longue durée d'utilisation. Les altitudes observées sur le fond du fossé sud dessinent une pente vers l'ouest de $2,73 \%$ et une seconde vers l'est, de 1,02\%, marquant l'adéquation de son implantation à la topographie du site, à l'image de St 1152/1003.

\section{Les fossés est : les structures St 6 et 7}

Ces segments de fossés St 6 et 7 ont été découverts lors du diagnostic archéologique de 2014 (ils sont longs respectivement de 35 et 34 mètres, une interruption de 3,50 mètres de largeur les sépare). Chacun de ces segments a fait l'objet d'une coupe et d'un relevé stratigraphique (fig. 6).

Le fossé St 6, recoupé au niveau du sondage SD16 présente un profil en " $U$ » (fig. 6; largeur : 2,35 m; profondeur : $1,70 \mathrm{~m}$ ), plus ou moins trapézoïdal et un fond plat. La base du comblement signe un mode de fonctionnement ouvert avec une nette dégradation des parois et écoulement des matériaux formant talus.

Le fossé St 7, recoupé au niveau du sondage SD85 (fig. 6; largeur : $3 \mathrm{~m}$; profondeur : 1,75 mètre), présente un profil nettement trapézoïdal. La stratigraphie est plus complexe, on y décèle des US de dégradation des parois (US 5 et 6 ) constituées très essentiellement de plaquettes de schiste, une argile grise, hydromorphe traduisant éventuellement un profil de stabilisation (US 4) et enfin des US de comblement de surface, où il est noté quelques tessons et fragments de tuiles antiques. 


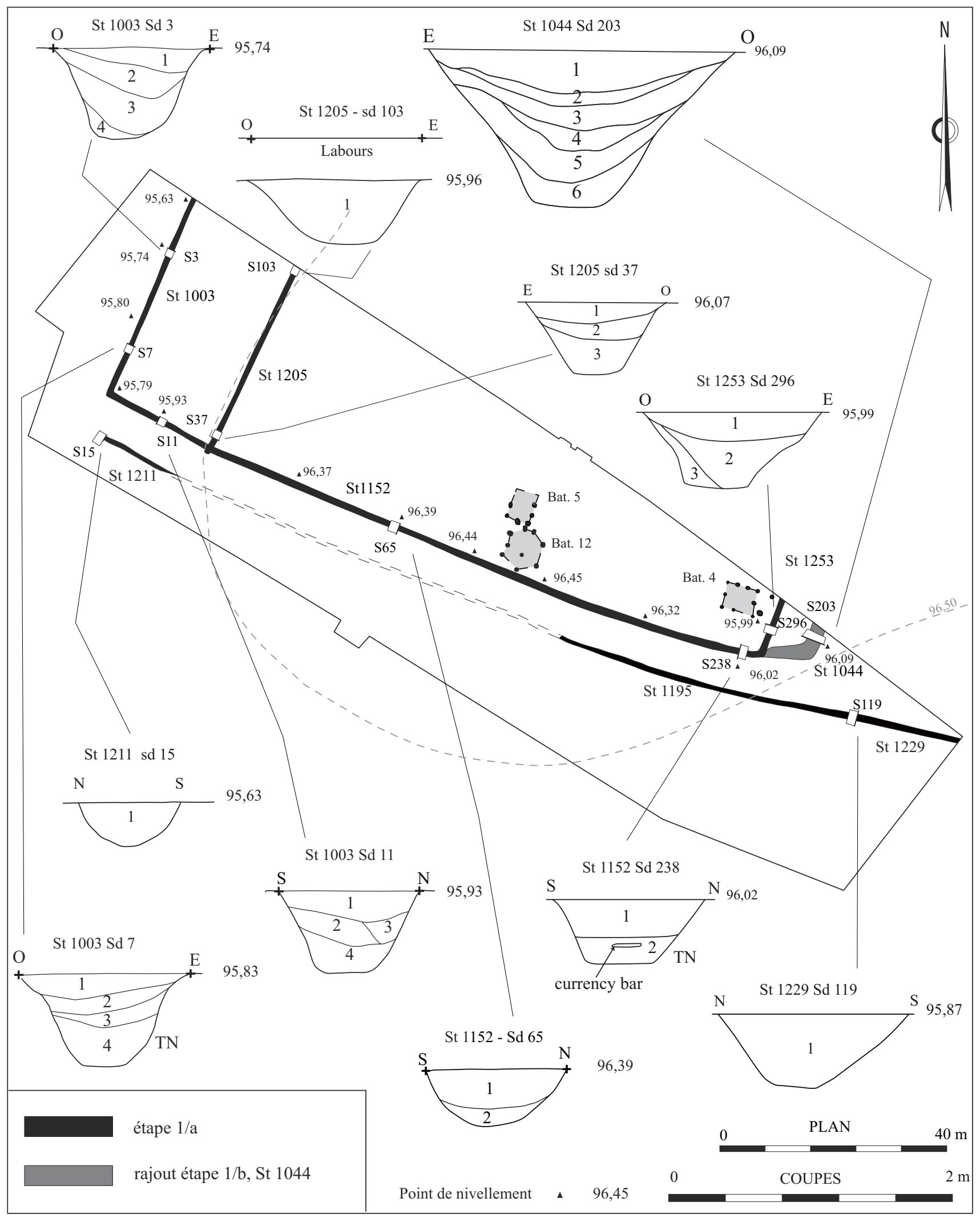

Figure 5 : Bonchamp-lès-Laval (53), phase 1, plans des fossés St 1003/1152, St 1211/1195/1229 et St 1205 et choix de relevés de coupe effectués dans ces fossés.

Figure 5: Phase 1, plans of ditches St 1003/1152, St 1211/1195/1229 and St 1205 and choice of sections carried out in these ditches. 


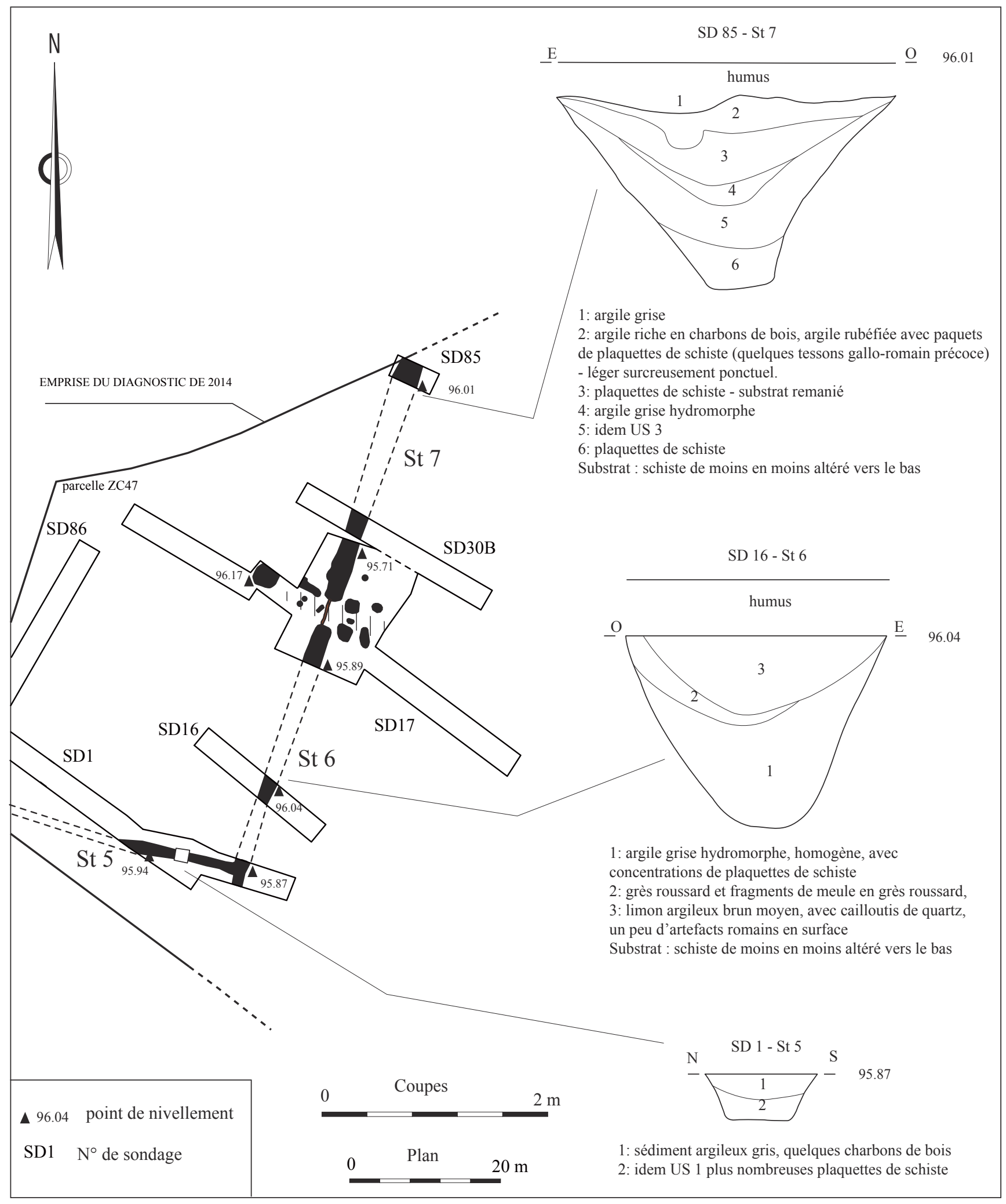

Figure 6 : Bonchamp-lès-Laval (53), phase 1, plan des structures laténiennes mises au jour lors du diagnostic de 2014 et relevés des coupes des fossés St 5, 6 et 7 .

Figure 6: Phase 1, plan of La Tène structures revealed during the 2014 test excavations and sections of ditches St 5, 6 and 7. 


\section{Le portail monumental est}

Le secteur où a été mis au jour ce portail monumental lors du diagnostic archéologique de 2014 (Guillier, 2014a; fig. 7) est caractérisé par une interruption entre les fossés St 6 et 7 et souligné par de nombreuses structures :

- plusieurs poteaux et fosses de petites dimensions : St 1 , $12,13,14$ et 16 ;

- l'extrémité orientale du fossé St 15, non exploré;

- un empierrement de blocs de calcaire : St 17;

- une petite structure fossoyée peu profonde localisée au niveau de l'interruption entre les fossés St 6 et 7 : St 11;

- quatre gros poteaux, St 2 et 8 (structure B22) d'une part et St 3 et 4 (structure B23) d'autre part, formant deux portails successifs.

Les extrémités nord du fossé St 6 et sud du fossé St 7, nettement arrondies, déterminent une ouverture large de 3,50 mètres. Des irrégularités dans le tracé de St 7 (au nord), pourraient marquer la présence de recreusements. Des poteaux et fosses de petites dimensions, St 1, 12, 13, 14 et 16, seule la première a fait l'objet d'un sondage manuel (fig. 7). Cette structure St 1 présente un calage de petits blocs de quartz qui détermine un fantôme de poteau (largeur : 0,40 mètre).

Des blocs de calcaire de Sablé, St 17, marquent un cheminement (largeur : 2 mètres environ), sensiblement orienté est-ouest. St 17 est plus ou moins altéré par les labours puisque apparaissant de 0,20 à 0,25 mètre de profondeur sous la surface du sol actuel. À l'ouest, il est constitué d'un lit de blocs (de 0,10 à 0,20 mètre de côté), serrés les uns contre les autres; au niveau de l'entrée, les blocs étaient de plus grandes dimensions (de 0,20 à 0,30 mètre de côté). Dans St 17, il a été mis au jour un lissoir [36] et un broyon [37]. Enfin, sur ou dans St 17, il n'a été mis en évidence aucun artefact antique que ce soit (fragment de tuile, tesson de céramique...), élément qui nous inciterait assez fortement à lier ce cheminement à l'époque laténienne et non à la période romaine.

Au niveau de l'interruption entre les fossés St 6 et $S 7$, il a été mis au jour les rejoignant la petite structure fossoyée St 11 (profondeur : 0,06 mètre; largeur : 0,26 mètre; longueur : 3,5 mètres). Son tracé est légèrement sinueux et présente un profil trapézoïdal à fond plat.

Enfin, quatre gros poteaux, appariés deux à deux, en fonction de leurs dimensions, de leurs profondeurs, de leurs plans ainsi que de la nature de leurs comblements, nettement différenciés, St 2 et 8 (structure B22) d'une part et St 3 et 4 (structure B23) d'autre part (tabl. 1), marquent deux portails d'entrée successifs à l'est des fossés St 6 et 7 .

2. Nous distinguons le portail matérialisé par deux fosses, d'un porche, lui élevé sur quatre poteaux.
Les structures St 2 et 8 (B22) sont espacées de 2,50 mètres et distantes des fossés de l'enclos de 3,50 à 4 mètres, tandis que St 3 et 4 (B23), espacées de 1,80 mètre sont distantes de ces fossés de seulement 0,70 à 0,90 mètre. Il est possible d'envisager que ces portails correspondent à deux états marqués par les irrégularités (re-creusements) observées sur le tracé de St 7. Ces portails B22 et B23 marquent théoriquement l'axe supposé d'un talus et déterminent une entrée monumentale à l'est des enclos de la phase 1 .

\section{Quelques bâtiments sur poteaux plantés}

D'après l'agencement topographique des dix-huit bâtiments et structures sur poteaux laténiens, deux lots se distinguent. Le lot 1 correspond aux structures localisées entre le fossé St 1037 et le fossé St 1152 qui marque le côté sud de l'enclos caractérisant la phase 1 (fig. 5), tandis que le lot 2 regroupe les bâtiments localisés au nord du fossé St 1037, qui relèvent de la phase 2 . C'est le premier qui nous intéresse ici : les bâtiments B4, B5 et B12.

Les petits bâtiments B4 et B5

De plan rectangulaire et régulier, le bâtiment B4 (4,5 x 5,5 mètres; surface : 25 mètres carrés; fig. 8) est dessiné par trois rangées de poteaux ${ }^{3}$ parallèles marquant au sol un plan à deux nefs, les poteaux axiaux St 1156 et 1159 matérialisent l'axe de la faitière. Sont relevés deux fantômes de poteau dans St 1039 et 1040 (d'environ 0,2 mètre de diamètre); des particules d'argile rubéfiée sont notées dans St 1155, 1156 et 1157. Le bâtiment B5 est recoupé au nord par l'enclos St 1037 (phase 2; fig. 8). Il s'agit de l'extrémité sud d'un petit bâtiment où les poteaux dessinent un plan rectangulaire à deux nefs (largeur : 4,2 mètres; longueur subsistante : 3,5 mètres); des deux poteaux axiaux, seul subsiste le poteau sud St 1135. Dans les comblements des trous de poteau sont relevés deux, voire trois fantômes (de 0,3 à 0,4 mètre de diamètre). De l'argile rubéfiée est notée dans St 1134, 1137 et 1138 . De petits fragments de granite indiquent la présence d'une meule (St 1281).

\section{Le bâtiment sur module porteur B12}

Cette structure de plan losangique (largeur : 6,3 m, longueur : 7 mètres), est constituée de neuf trous de poteau (fig. 9). Sont relevés deux ou trois fantômes (de 0,3 à 0,4 mètre de diamètre). De l'argile rubéfiée est mentionnée dans St 1259. C'est un bâtiment sur plan centré matérialisé par quatre trous de poteau formant un module porteur de plan rectangulaire (de 4 x 6,5 mètres de côté; fig. 9). La présence du couple de poteaux St 1139 et 1176 au nord,

3. Les trous de poteau, toutes phases confondues, sauf exception, appellent peu de commentaires. Ils présentaient des comblements constitués de limons bruns, recelant de nombreuses inclusions de plaquettes de schiste. 


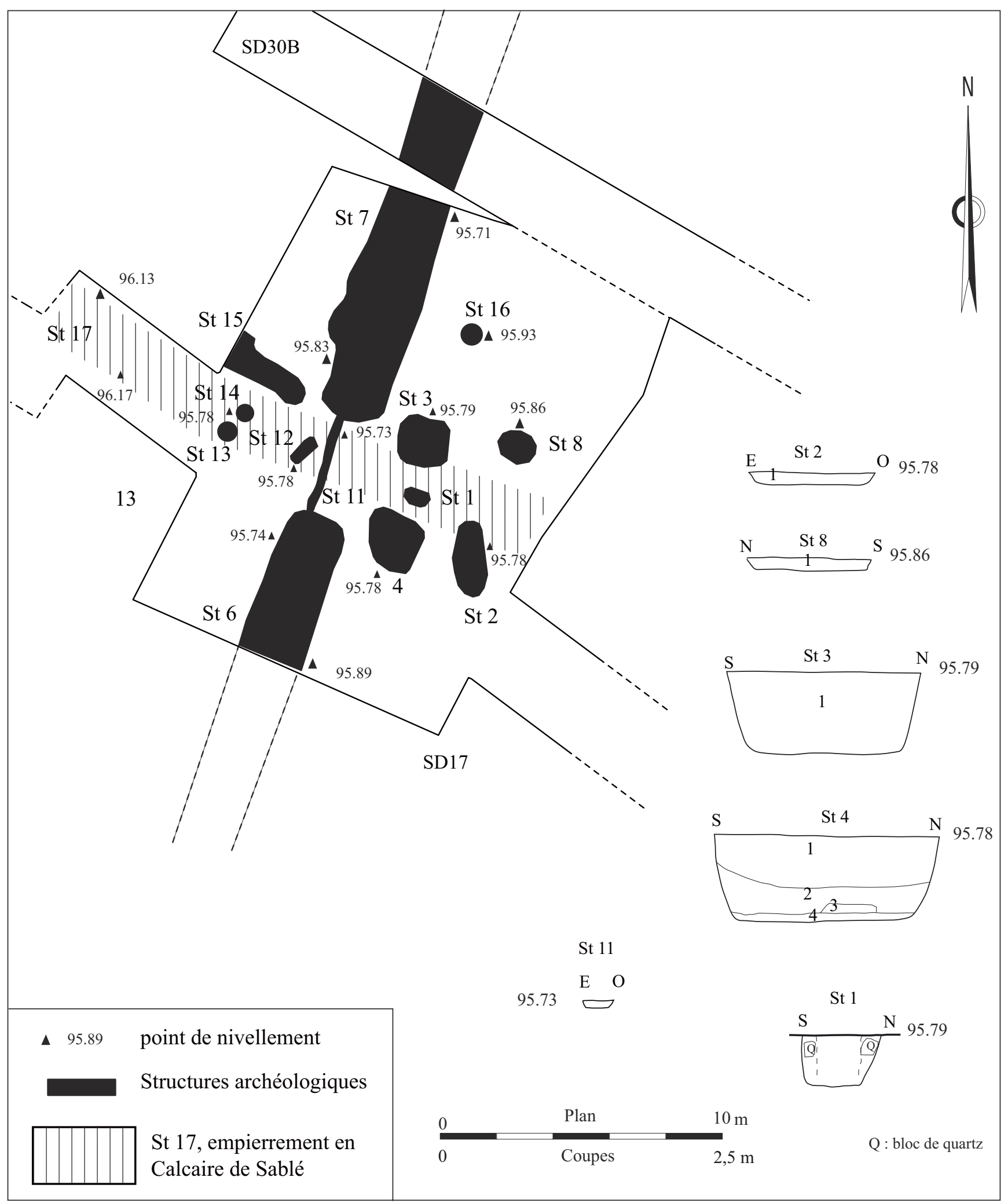

Figure 7 : Bonchamp-lès-Laval (53), phase 1, plan détaillé de la zone des portails et relevés des coupes de quelques structures choisies. Figure 7: Phase 1, detailed plan of the area of the portals and sections of a selection of structures. 


\begin{tabular}{|c|c|c|c|c|c|}
\hline & Largeur & Longueur & Profondeur & Plan & Comblement, remarques \\
\hline \multicolumn{6}{|c|}{ État $1, \mathrm{~B} 22$} \\
\hline St. 2 & 1,15 & 2,70 & 0,10 & allongé & $\begin{array}{l}\text { Argile grise, plaquettes de schiste, rares parti- } \\
\text { cules d'argile rubéfiée }\end{array}$ \\
\hline St. 8 & 1,06 & 1,35 & 0,10 & ovale & $\begin{array}{l}\text { Argile grise, plaquettes de schiste, rares parti- } \\
\text { cules d'argile rubéfiée }\end{array}$ \\
\hline \multicolumn{6}{|c|}{ État 2, B23 } \\
\hline St. 3 & 1,80 & 1,80 & 0,74 & $\begin{array}{l}\text { quadrangulaire aux } \\
\text { angles arrondis }\end{array}$ & $\begin{array}{l}\text { Sédiment riche en argile et torchis rubéfiés. } \\
\text { Deux tessons d'amphore Dressel } 1\end{array}$ \\
\hline St. 4 & 1,80 & 1,90 & 0,76 & $\begin{array}{l}\text { quadrangulaire irré- } \\
\text { gulier }\end{array}$ & $\begin{array}{c}\text { Stratifié, avec en surface un sédiment riche en } \\
\text { argile et torchis rubéfiés }\end{array}$ \\
\hline
\end{tabular}

Tableau 1 : Bonchamp-lès-Laval (53), «Aire de service de l'A81 » : quelques données relatives aux structures St 2 et 8 (B22) et St 3 et 4 (B23) (les mesures sont exprimées en mètres).

Table 1: "A81 service station": data relating to structures St 2 and 8 (B22) and St 3 and 4 (B23) (the data are expressed in metres).

et du poteau St 1173 au sud, tous placés sur l'axe nordsud du bâtiment à une distance de 1,5 mètre du module porteur, localisent à ces endroits la paroi située en périphérie du module porteur central et définissent sensiblement à une même distance les tracés des parois est et ouest. Au nord, les structures St 1139 et 1176, matérialiseraient l'accès au bâtiment (la surface de B12 serait d'approximativement 70 mètres carrés).

Le mobilier archéologique de la phase 1:

fin de La Tène moyenneldébut de

La Tène finale, II s. av. J.-C. (E. C.)

Le mobilier céramique de la phase 1 a été recueilli dans les fossés de l'enclos interne St 1003, 1044, 1152 et 1253 ainsi que dans l'enclos externe St 1229, 5, 6 et 7 : ce sont cent vingt-six fragments de poteries dont seize bords (fig. 10). Le répertoire est celui habituellement trouvé dans les contextes de consommation de type habitat de La Tène C2/D1 (180100 av. J.-C.). Ces céramiques sont modelées et régularisées à la tournette. Elles présentent une pâte siliceuse noire à cœur orange comportant de nombreuses inclusions de quartz et de mica. Leur surface est lissée.

Le corpus composé de neuf écuelles, de quatre pots, d'un vase de stockage (fig. 10, vase 1), d'une grande jatte et d'une assiette est accompagné d'un bord (vase 2 ) et de vingt-neuf tessons de panse d'amphores de type Dressel 1A.

Les formes basses sont variées, avec des écuelles à pâte fine d'un diamètre à l'ouverture inférieur à $20 \mathrm{~cm}$ et de grandes jattes au diamètre égal ou supérieur à $30 \mathrm{~cm}$. Quatre ont un bord épaissi rentrant, dont le haut de la panse est orné d'incisions (fig. 10, vases 3 à 8). Notons une grande jatte à lèvre déversée et panse hémisphérique (vase 9). Ces productions caractéristiques sont présentes à La Tène moyenne et finale en Sarthe et en Mayenne. De grandes jattes associées à des écuelles ornées d'incisions sont mentionnées au second âge du Fer en Mayenne : sur l'oppidum du Mesnil (Valais, 2005), sur le site du Panveau à Aron (Mortreau, 2007), et enfin, plus au sud de Laval, à La Carie 2 à Entrammes (Guillier et al., 2012) et à La Chesnaie à La Selle-Craonnaise (Coffineau, 2006a). Les autres écuelles offrent des profils variés (vases 10 à 12), sont à lèvre déversée à profil « en esse " et ont une panse peu galbée et plus hémisphérique de type Gaudine 6A et 8B (Guillier et al., 2006), décorées d'incisions avec un cordon sur la panse (vase 10) et à l'intérieur de la lèvre (vases 10 et 12). Ces mêmes décors se retrouvent sur les pots à panse ovoïde (vases 13 à 15). L'assiette tournée à pâte fine grise et aux surfaces noires (vase 16) imite la forme campanienne Lamboglia.

La répartition spatiale du mobilier de la phase 1 se fonde sur peu d'éléments. Si quelques tessons, dont un fragment de col d'amphore, un éclat de silex (St 1152, non représenté) et un cerclage en fer (St 1152) [26] sont présents à l'ouest du site, la majorité provient de sa partie est. S'y remarquent un fragment d'un récipient en lignite [29] et une currency bar [7] (St 1152, Sondage 238). Enfin, de petits fragments de granite, matériau exogène au site, liés au bâtiment B5, témoignent de la présence d'une meule. Cette modeste concentration de mobilier, déterminerait une zone de rejets, signant la proximité d'une zone d'accès à l'enclos, où il a été mis au jour un lissoir aménagé sur une plaquette de grès à grain fin, de teinte grise à verdâtre, et recelant de nombreuses et fines particules de mica [36] (St 17), un vraisemblable broyon en grès à grain fin, de teinte rouge, compact [37] (St 17) ainsi que $60 \%$ des tessons découverts sur toute d'étendue de la fouille.

Les quelques objets de la phase 1 ont été associés pour leur étude à ceux de la phase 2 constituant ainsi pour la période gauloise un corpus intéressant ( $c f$. infra), mais modeste. 


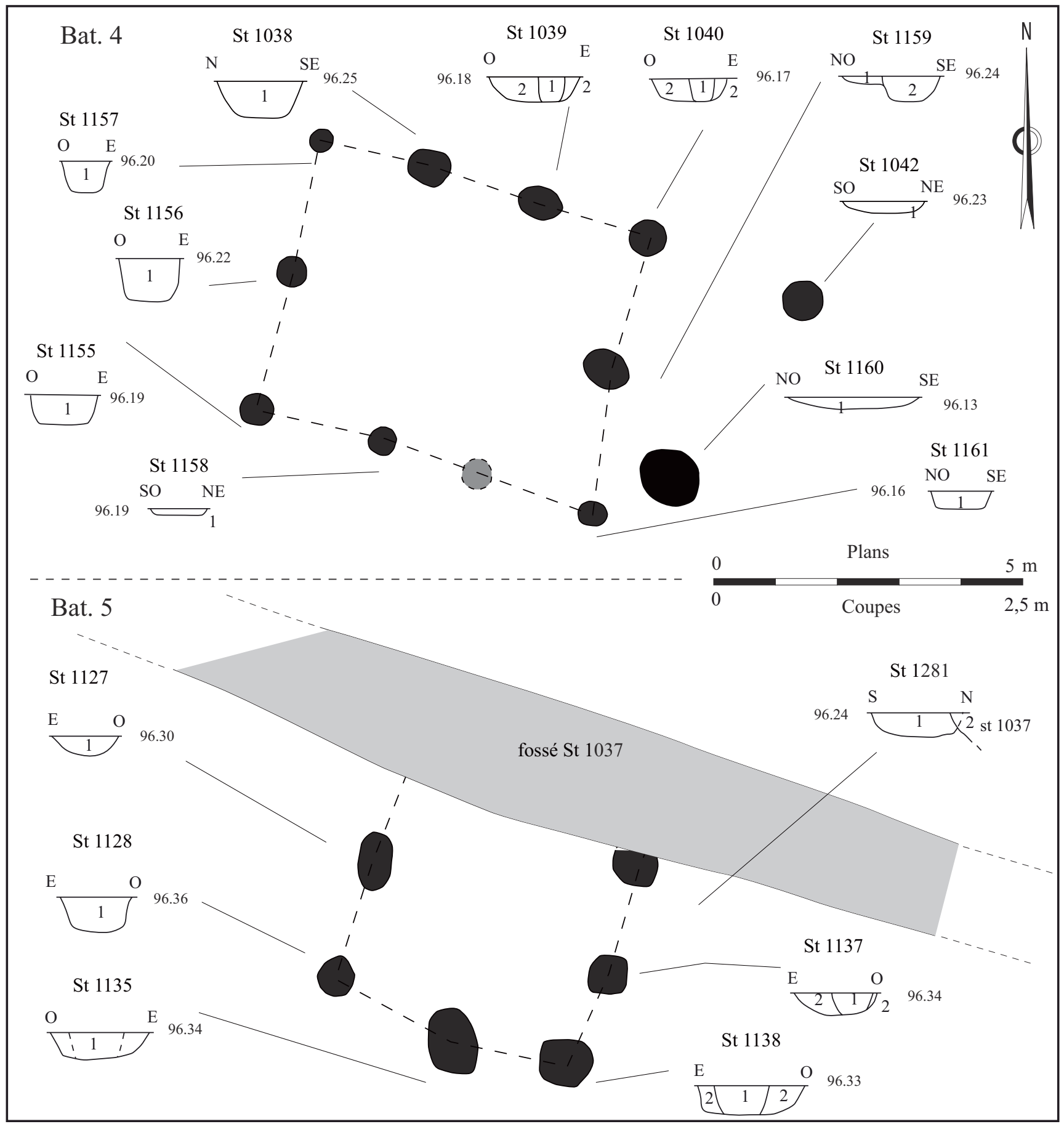

Figure 8 : Bonchamp-lès-Laval (53), plans détaillés des bâtiments B4 (haut) et B5 (bas) et relevés des coupes des trous de poteau les constituant.

Figure 8: Detailed plans of buildings B4 (top) and B5 (bottom) and sections of post holes constituting them.

\section{La phase 2 : le creusement} d'un nouvel enclos à La Tène D1/D2

Cette phase 2 se caractérise par le creusement d'un nouveau fossé d'enclos (fig. 11) et par l'édification d'un nombre élevé de bâtiments sur poteaux au sein de cet enclos (fig. 12). Le fossé St 1211 = 1195 = 1229, encore en fonctionnement d'après le mobilier qui y a été découvert, marque toujours un axe de circulation au sud de l'enclos. 


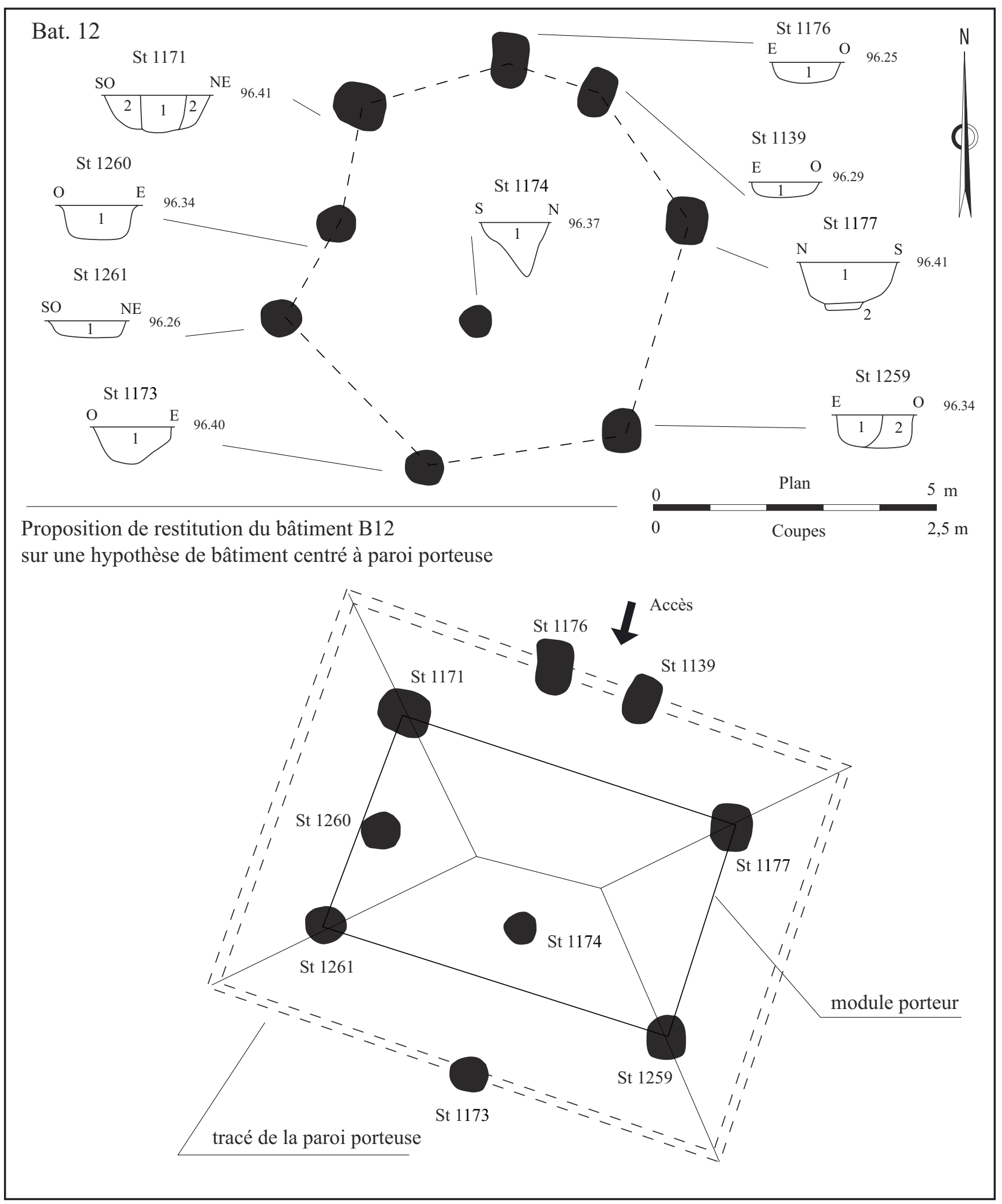

Figure 9 : Bonchamp-lès-Laval (53), le bâtiment B12, plan détaillé, relevés des coupes des trous de poteau le constituant, proposition de restitution sur une hypothèse de bâtiment centré à paroi porteuse.

Figure 9: Building B12, detailed plan, sections of the post holes constituting it, suggested reconstruction employing a hypothesis of a centred building with load-bearing walls. 


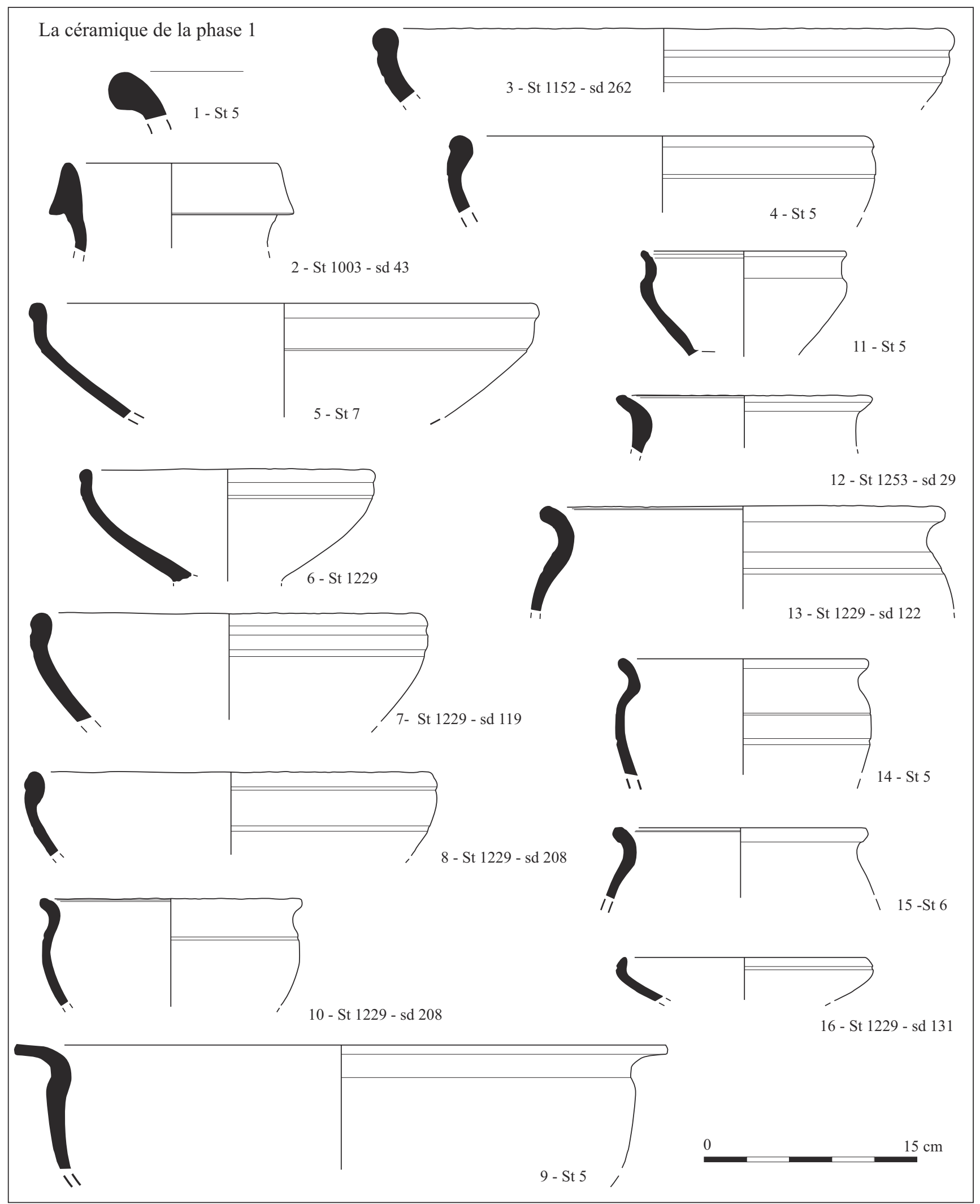

Figure 10 : Bonchamp-lès-Laval (53), la céramique de la phase 1.

Figure 10: The phase 1 pottery. 


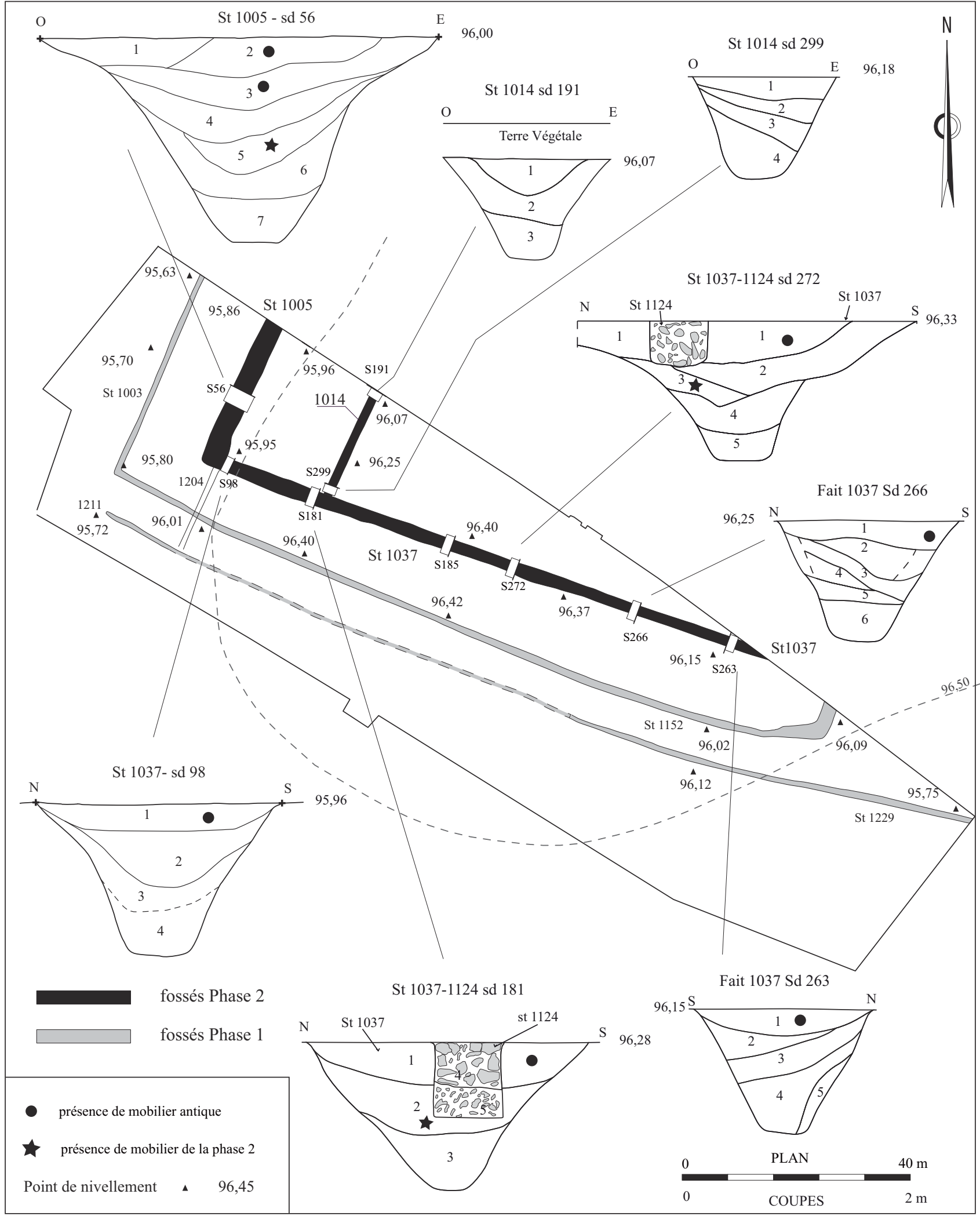

Figure 11 : Bonchamp-lès-Laval (53), phase 2, les fossés St 1005/1037 et St 1014, plan et présentation d'un choix de coupes (les bâtiments ne sont pas figurés).

Figure 11: Phase 2, ditches St 1005/1037 and St 1014, plan and presentation of a choice of sections (buildings are not represented). 

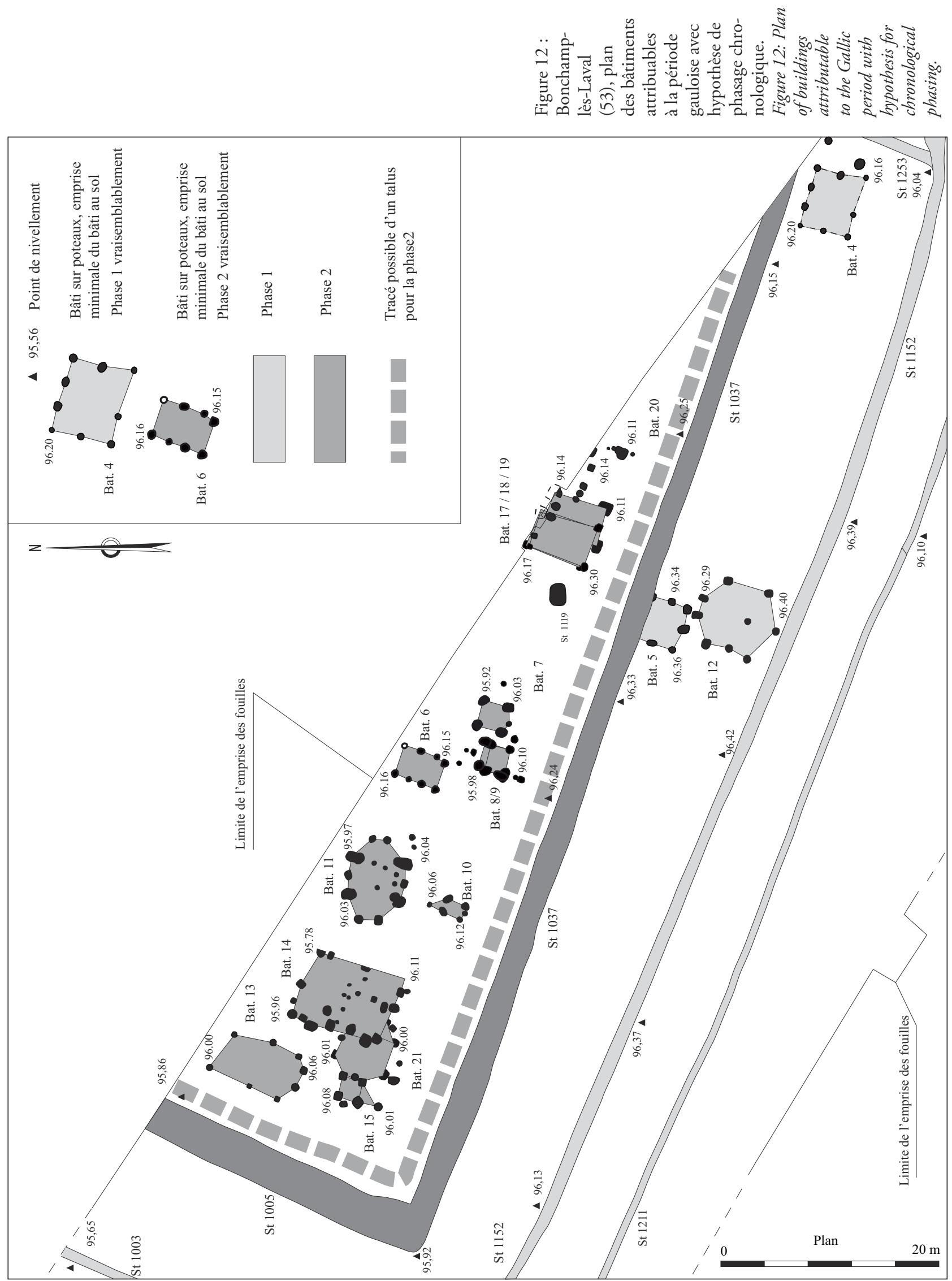


\section{Le nouvel enclos St 1005/1037}

Cet enclos St 1005/1037 est creusé à l'intérieur de l'aire définissant l'enclos de la phase précédente dont il reprend l'orientation. Son côté ouest (St 1005) a été mis au jour sur 28 mètres de long tandis que son côté sud l'a été sur 110 mètres de long. Sur la base minimale d'un enclos de 70 à 100 mètres de côté, nous n'en avons mis au jour qu'environ $20 \%$. Cet enclos (fig. 11) se démarque du précédent (fig. 5) par ses fossés imposants. Son côté ouest, St 1005 (largeur : 3,5 m; profondeur : $2 \mathrm{~m}$ ) présente un creusement au profil trapézoïdal à fond plat, surtout visible sur sa moitié inférieure, tandis que les niveaux supérieurs des parois sont dégradés. Au sud, St 1037 nous est parvenu sous la forme d'un fossé plus large et plus profond à l'ouest qu'à l'est. Les profils relevés sont trapézoïdaux; dans deux cas seulement, ils tendent vers le « $U$ » (sd 181 et 185).

Le mobilier de la phase 2 provient de la partie médiane du comblement du fossé : céramique, fragments de plaquesfoyères et torchis rubéfié. Cet horizon détermine une période de stabilisation du profil du fossé, qui n'évolue dès lors que lentement. Le tiers supérieur de son comblement est antique comme l'atteste le mobilier mis au jour. La base du comblement signe un mode de fonctionnement ouvert avec une très nette dégradation des parois et d'écoulements des matériaux formant talus; il recèle de rares tessons de la phase 2, les couches occultant le fond du fossé sont constituées exclusivement de plaquettes de schiste.

La division interne St 1014 au tracé rectiligne, isole un espace de 19 mètres de largeur à l'ouest de l'enclos (fig. 11; largeur : 1,5 à 1,8 m; profondeur : 1,05 à 1,2 m). Les profils de St 1014, trapézoïdaux, sont bien marqués (sd 191) ou un peu érodés (sd 299). Les niveaux relevés sur le fond de ce fossé déterminent une faible déclivité qui descend du sud vers le nord, contraire à la pente naturelle du terrain. La stratigraphie présente un sédiment composé de plaquettes de schiste, avec un limon brun interstitiel. Le mobilier s'y limite à douze tessons datés entre le milieu du $\mathrm{II}^{\mathrm{e}}$ et le milieu du Ir siècle av. J.-C.

\section{Les bâtiments sur poteaux plantés, associés à la phase 2}

Ces bâtiments sont localisés au nord du fossé St 1037 et portent les numéros suivants : B6, B7, B8/9, B10, B11, B13, B14, B15, B17/18, B19, B20 et B21 (fig. 12). Leur ordonnancement régulier à une distance de 4 mètres environ au nord de St 1037 et à l'est de St 1005, est un argument qui les démarque de ceux de la phase $1:$ cette aire vierge de toute structure marque un talus aujourd'hui disparu.

\section{Le petit bâtiment $\mathrm{B} 6$}

Ce bâtiment $\mathrm{B} 6$ au plan rectangulaire, où deux rangées de poteaux parallèles dessinent au sol un plan à une nef ( $4 \mathrm{x}$ 2,6 m; surface : 10,5 mètres carrés; fig. 13), est matérialisé par sept trous de poteau, le huitième est restitué dans son angle nord-est.

Le grenier à plancher surélevé B7

De plan carré (fig. 13), le bâtiment B7 est matérialisé par quatre forts trous de poteau et par trois petits poteaux annexes (2,5 mètres de côté; surface : 6,25 mètres carrés). Les quatre gros trous de poteau sont sensiblement comparables et des fantômes de poteaux y ont été relevés (de 0,3 à 0,36 mètre de diamètre). Des particules d'argile rubéfiée sont notées dans St 1112.

Les greniers à plancher surélevé B8/9

Ces deux structures aux plans rectangulaires sont matérialisées au sol par quatre forts trous de poteau (fig. 14; B8 et B9 mesurent 2,4 × 2,5 mètres et $2 \times 2,5$ mètres de côté; leurs surfaces sont de 6 et 5 mètres carrés). Le grenier B9 est une reconstruction sur place de B8. Un fantôme de poteau est noté dans St 1288 (de 0,5 mètre de diamètre). De l'argile rubéfiée est relevée dans St 1279, 1288 et 1312, tandis que cinq fragments de plaque foyère sont issus de St 1278.

\section{Le petit grenier à plancher surélevé B10}

Ce bâtiment B10 est de plan rectangulaire ( 2 x 1,5 mètre de côté; surface : 3 mètres carrés; fig. 14). Il est accompagné de deux petits trous de poteau annexes. Des fantômes de poteau (de 0,4 à 0,5 mètre de diamètre), ont été relevés dans trois des quatre poteaux qui matérialisent l'ossature de B10. Des particules d'argile rubéfiée sont notées dans St 1096.

\section{Le bâtiment sur module porteur B11}

Ce bâtiment B11 est constitué de nombreux trous de poteau souvent de fortes dimensions, disposés selon un plan en amande (7,5 x 5 m; fig. 15). Les trous de poteau, St 1298 et 1297, ont fait l'objet d'un recreusement sur place, c'est un second état qui modifie peu l'ensemble. Des distinctions s'observent selon que les structures se rapportent aux poteaux formant le module porteur ou non. Ceux qui s'y rapportent sont de forte dimension (de 1,2 à 1,8 mètre de long), seul St 1297 est plus petit. Deux ou trois fantômes de poteau (de 0,25 à 0,45 mètre de diamètre), y ont été mis en évidence. De l'argile rubéfiée est notée dans St 1297. Quelques tessons sont relevés dans St 1061, 1066 et 1068; une scorie de forge dans St 1016 et un lissoir en grès dans St 1066 [5]. Le bâtiment B11 est un bâtiment sur plan centré matérialisé par 


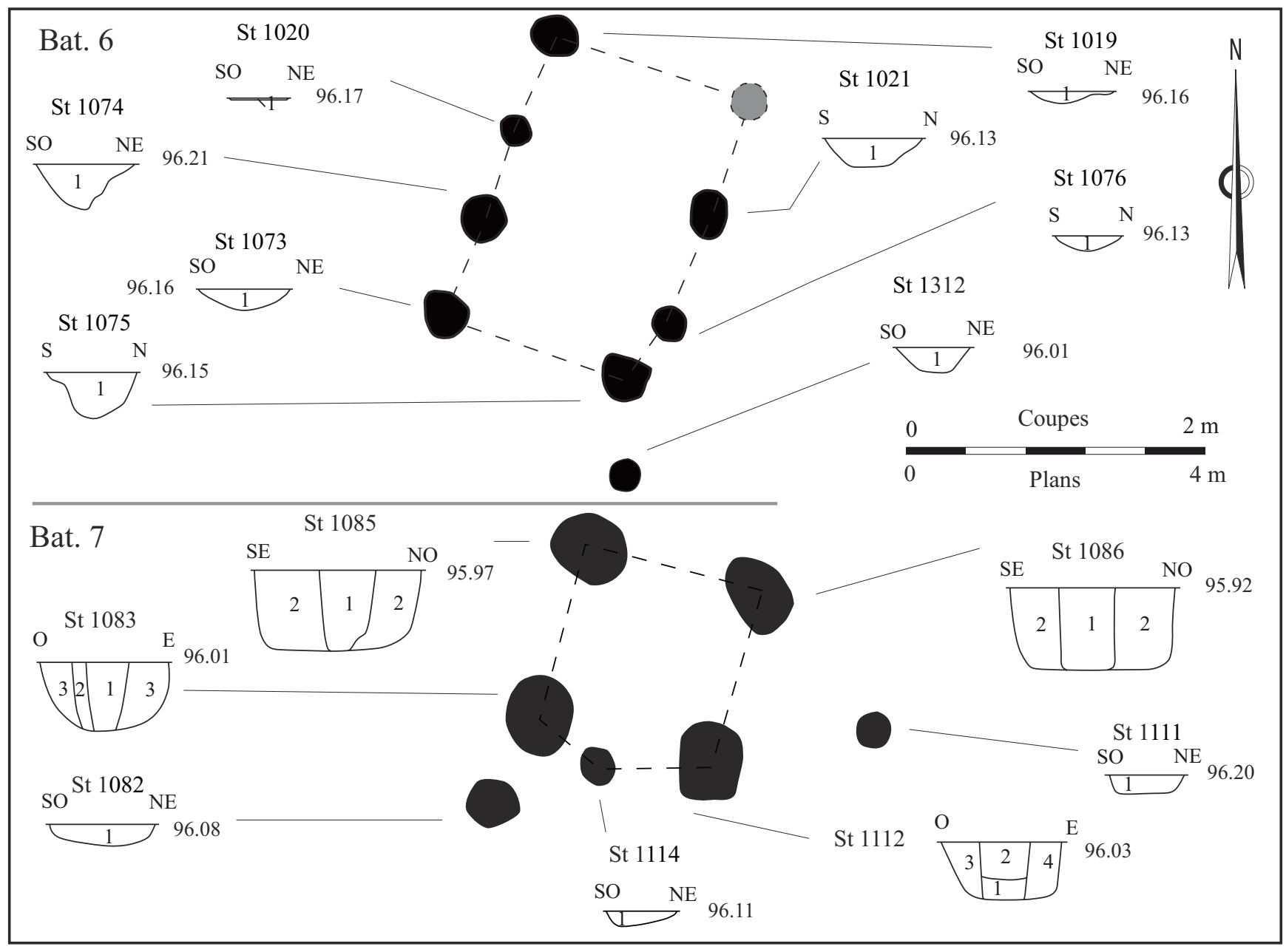

\begin{tabular}{|llllll|}
\hline $\begin{array}{l}\text { structure } \\
\text { archéologique }\end{array} 1085$ & $\begin{array}{l}\text { numéro de } \\
\text { structure }\end{array}$ & 95.97 & point coté & $\begin{array}{l}\text { Emplacement } \\
\text { restitué d'un } \\
\text { trou de poteau }\end{array}$ \\
\hline
\end{tabular}

Figure 13 : Bonchamp-lès-Laval (53), plans détaillés des bâtiments B6 et B7 et relevés des coupes des trous de poteau les constituant. Figure 13: Detailed plans of buildings B6 and B7 and sections of post holes constituting them.

quatre trous de poteau formant un module porteur de plan rectangulaire (de 3,5 x 5 mètres de côté; fig. 15). Les deux paires de poteaux St 1066 et 1067 à l'est, St 1324 et 1327 à l'ouest, placées sur un même axe est-ouest déterminent l'emplacement de la paroi périphérique et les accès est et ouest à B11. Le tracé de la paroi périphérique nord et sud est basé sur le même espace large de 2 mètres que celui qui a été observé entre le module porteur et les porches (la surface de B11 serait d'approximativement 64 mètres carrés).

\section{L'hypothétique bâtiment B13}

Ce pourrait être un petit bâtiment à pans coupés au sud (largeur : 4 à $4,5 \mathrm{~m}$; longueur : $7 \mathrm{~m}$; surface : 30 mètres carrés; fig. 16). L’asymétrie observée dans son l'angle nord-est marquerait une seconde hypothèse basée sur un module porteur matérialisé par les seuls poteaux St 1246, 1247, 1289 et 1290 ( $2,8 \times 4,4$ mètres de côté) et le couple de poteaux St 1250 et 1291, formant le porche d'entrée. Sur ces nouvelles bases, la surface de B13 peut être estimée à environ 34 mètres carrés.

\section{Le grand bâtiment B14}

Le plan du bâtiment B14 présenté (fig. 17) est indicatif : les poteaux matérialisant son côté est sont recoupés par le fossé St 1014, attribuable à une étape tardive de la phase 2 (à moins que B14 ne relève de la phase 1). Quoi qu'il en soit, B14 est une structure constituée de trous de poteau de forte dimension, disposés selon un plan quadrangulaire 


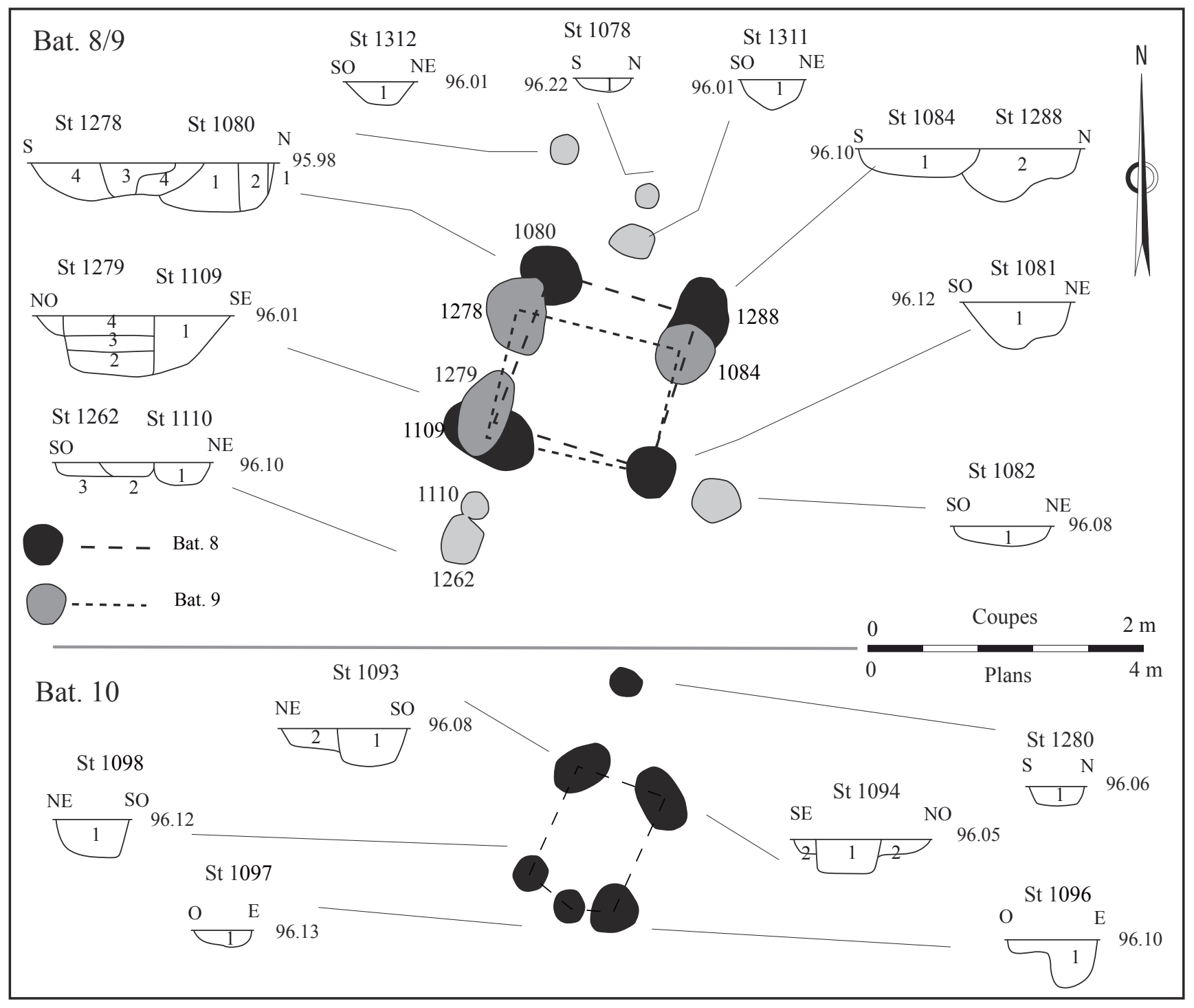

Figure 14 : Bonchamp-lès-Laval (53), plans détaillés des bâtiments B8/9 et B10, et relevés des coupes des trous de poteau les constituant. Figure 14: Detailed plans of buildings B8/9 and B10 and sections of post holes constituting them.

(7,3 x 9,4 m; surface : 68,5 mètres carrés). Certains poteaux, proches les uns des autres, marqueraient des remaniements ou des réparations. L'hypothèse de restitution émise se base sur un module de plan rectangulaire auquel sont adjoints les deux poteaux St 1054 et 1268, au nord et au sud. Les poteaux situés aux angles de la construction, St 1245 et 1293, peu profondément fondés peuvent marquer le tracé de la paroi et supporter une partie des pannes. Enfin, les poteaux St 1241 et 1242, centrés sur le côté ouest de B14, espacés de $1,1 \mathrm{~m}$, évoquent un accès en léger retrait. Les structures se rapportant au module porteur, St 1243 et St 1277, de fort diamètre, présentent des fantômes de poteaux (de 0,5 à 0,6 mètre de diamètre). Les structures ne se rapportant, ni au module porteur, ni aux structures précédentes, qui parsèment l'espace central de $\mathrm{B} 14$ sont de dimensions bien moindres (à l'exception de St 1340). Ces petites structures, alignées sur un axe est-ouest, correspondraient à des aménagements internes, cloisons... De l'argile rubéfiée est mentionnée dans plusieurs structures (St 1241, $1243,1268,1269,1277$ et 1293$)$.

\section{Le grenier à plancher surélevé B15}

Ce bâtiment B15 est révélé par quatre forts trous de poteau, dessinant un plan carré (de 2 mètres de côté) (fig. 18). Il est accompagné de trois trous de poteau annexes, peu profondément implantés, aux profils en « $U$ » ouvert. Le mobilier archéologique est constitué de deux tessons de céramique du milieu du II $^{\mathrm{e}}$ ou du début du I ${ }^{\text {er }}$ siècle av. J.-C. (St 1238). 


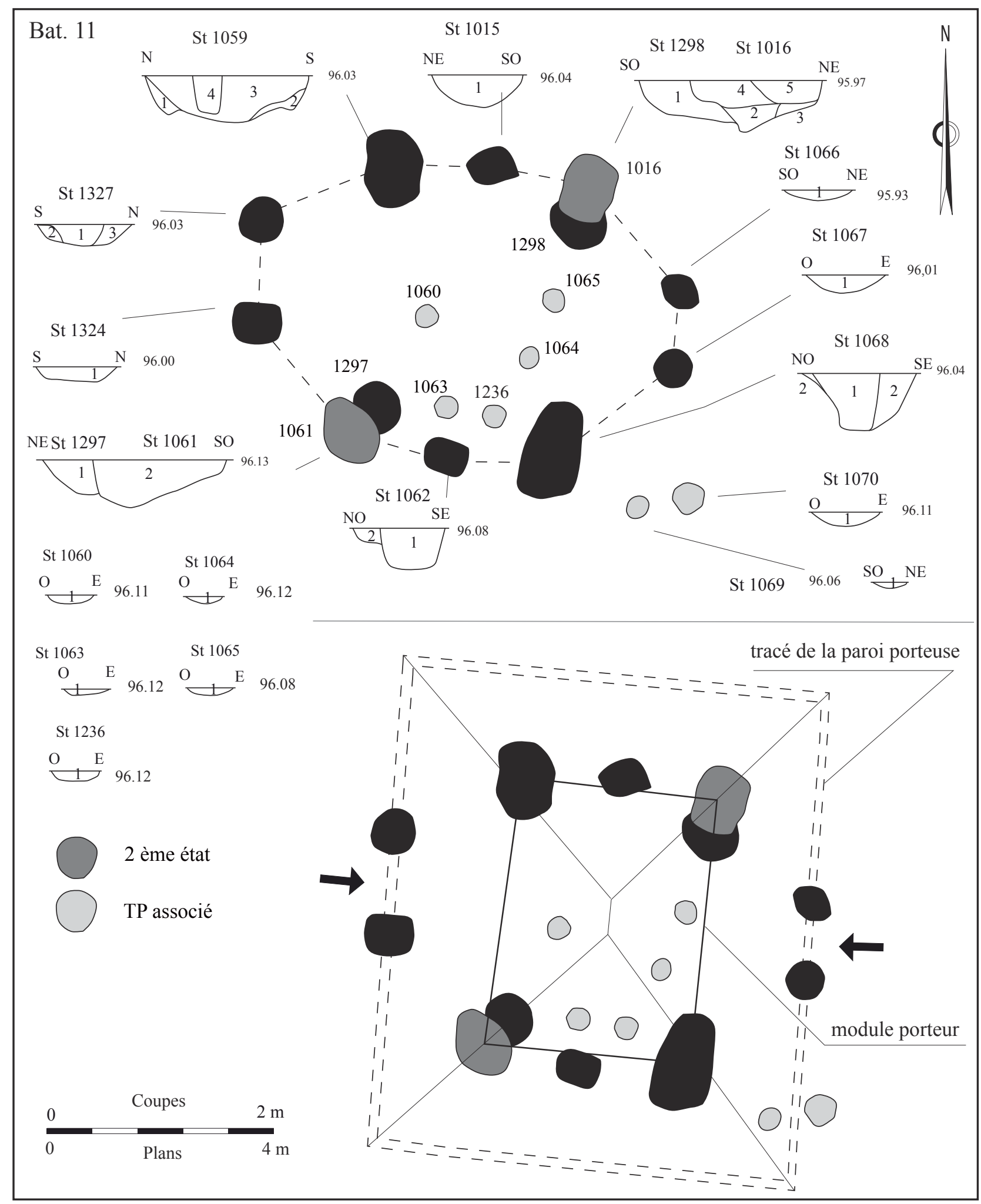

Figure 15 : Bonchamp-lès-Laval (53), plan détaillé du bâtiment B11, relevés des coupes des trous de poteau et proposition de restitution sur une hypothèse de bâtiment centré à paroi porteuse.

Figure 15: Detailed plan of building B11, sections of the post holes constituting it, suggested reconstruction employing a hypothesis of a centred building with load-bearing walls. 


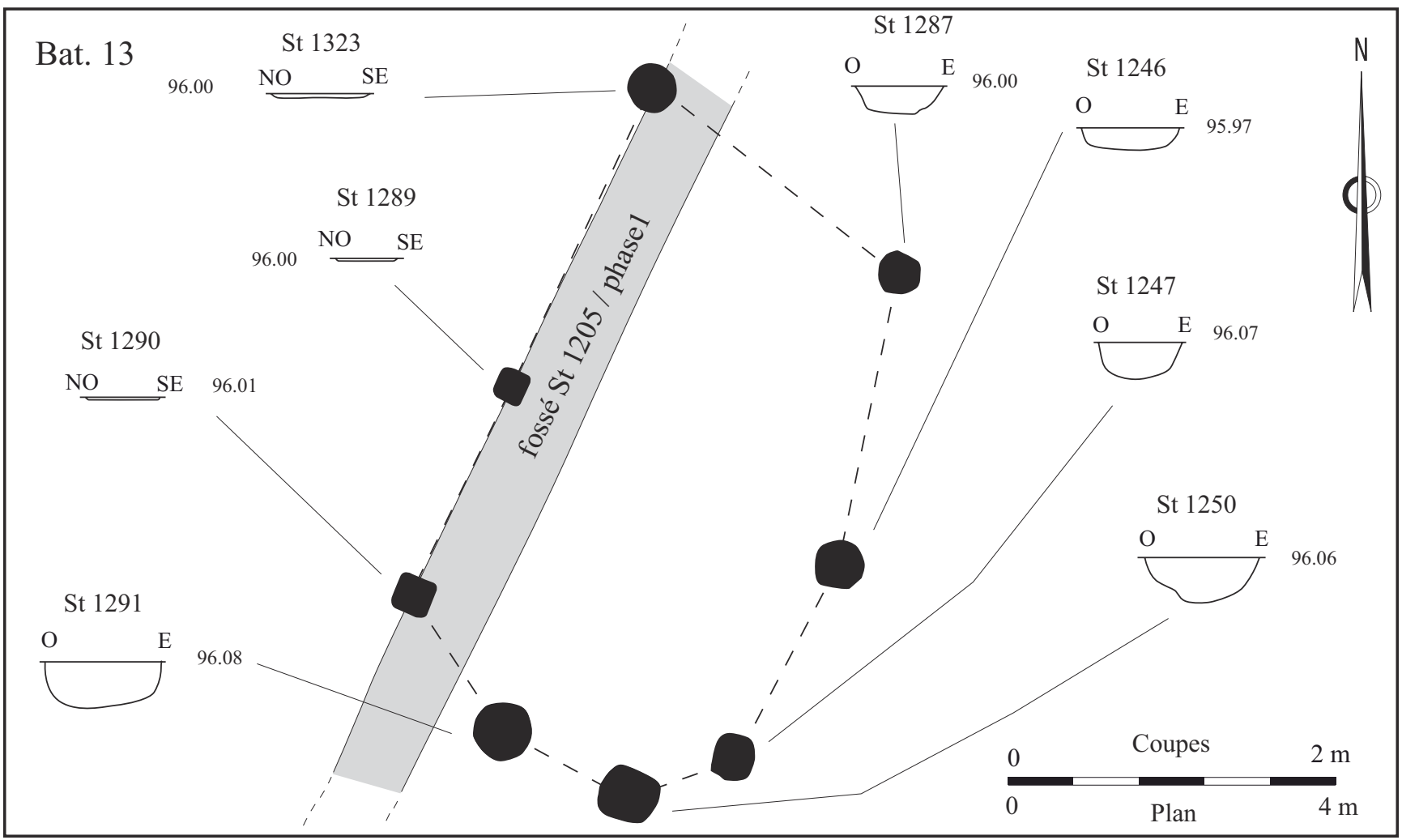

Figure 16 : Bonchamp-lès-Laval (53), plan détaillé du bâtiment B13 et relevés des coupes des trous de poteau le constituant. Figure 16: Detailed plan of building $B 13$ and sections of post holes constituting them.

\section{Les bâtiments B17/18/19}

Ces trois bâtiments sont appariés car, de plans comparables, ils se succèdent à un même endroit. Stratigraphiquement, B18 est antérieur à B17, tandis qu'il n'y a pas de relation avec B19 (fig. 19). Seraient-ils complets au nord? Le bâtiment B17 (postérieur à B18), de plan quadrangulaire est une structure à quatre forts poteaux ( 4 x 5,5 mètres; surface : 22 mètres carrés). Son plan est net car leurs comblements se caractérisaient par une remarquable abondance d'argile rubéfiée. Ont été découverts dans St 1121r six fragments d'un catillus en granite [12] et un tesson du milieu du $\mathrm{II}^{\mathrm{e}} \mathrm{ou}$ du début du I $\mathrm{I}^{\text {er }}$ siècle av. J.-C. Le bâtiment B18 (antérieur à B17), est une structure à quatre poteaux de plan quadrangulaire ( 4 x 5,5 mètres; surface : 22 mètres carrés). Nous ne savons si elle se poursuit plus au nord. Il y est noté une présence réduite d'argile rubéfiée. Le bâtiment B19 occupe un espace, une orientation et des dimensions similaires aux précédents ( $3,8 \times 5,5 \mathrm{~m}$; surface : 20,9 mètres carrés). Ses forts trous de poteau présentent des fantômes de poteaux (de 0,3 à 0,45 mètre de diamètre). Ces bâtiments offrent les caractéristiques d'un même ensemble reconstruit à l'identique plusieurs fois sur place. Bien qu'incomplets, nous excluons des structures à une ou deux nefs tels les bâtiments B4, B5 ou B6 déjà évoqués; à titre d'hypothèse, ce pourraient être des structures sur module porteur à quatre poteaux, tels les bâtiments B11 et B12.

\section{L'ensemble B20}

Cet ensemble B20 se rapporterait à un petit bâtiment sur deux poteaux porteurs d'une faittière (Maguer, 2005) (longueur : 2,1 m), dont l'espace situé entre les poteaux est occupé par la fosse quadrangulaire St 1309 (fig. 20). Cette fosse, à notre sens bien conservée $(1,04 \times 1,2 \mathrm{~m}$; profondeur : $0,62 \mathrm{~m}$ ), a des parois verticales et un fond plat et régulier, une excroissance au nord est moins marquée $(0,35$ x $0,7 \mathrm{~m}$; profondeur : $0,35 \mathrm{~m}$ ). Cet ensemble unique sur le site est bien conservé : il se rapporte aux petites fosses de plan carré découvertes à Levroux dans l'Indre (Buchsenschutz et al., 2000). Leur bon état de conservation signifie qu'elles " ont été relativement rapidement comblées quand la toiture qui les protégeait a disparu ", et que pour un nombre élevé de structures « leur remplissage ne nous apporte pas de clef d'interprétation parce qu'aucune couche n'est restée en place" (op. cit., p. 13). Cet ensemble B20 pouvait abriter une activité artisanale ou servir à stocker des denrées. 


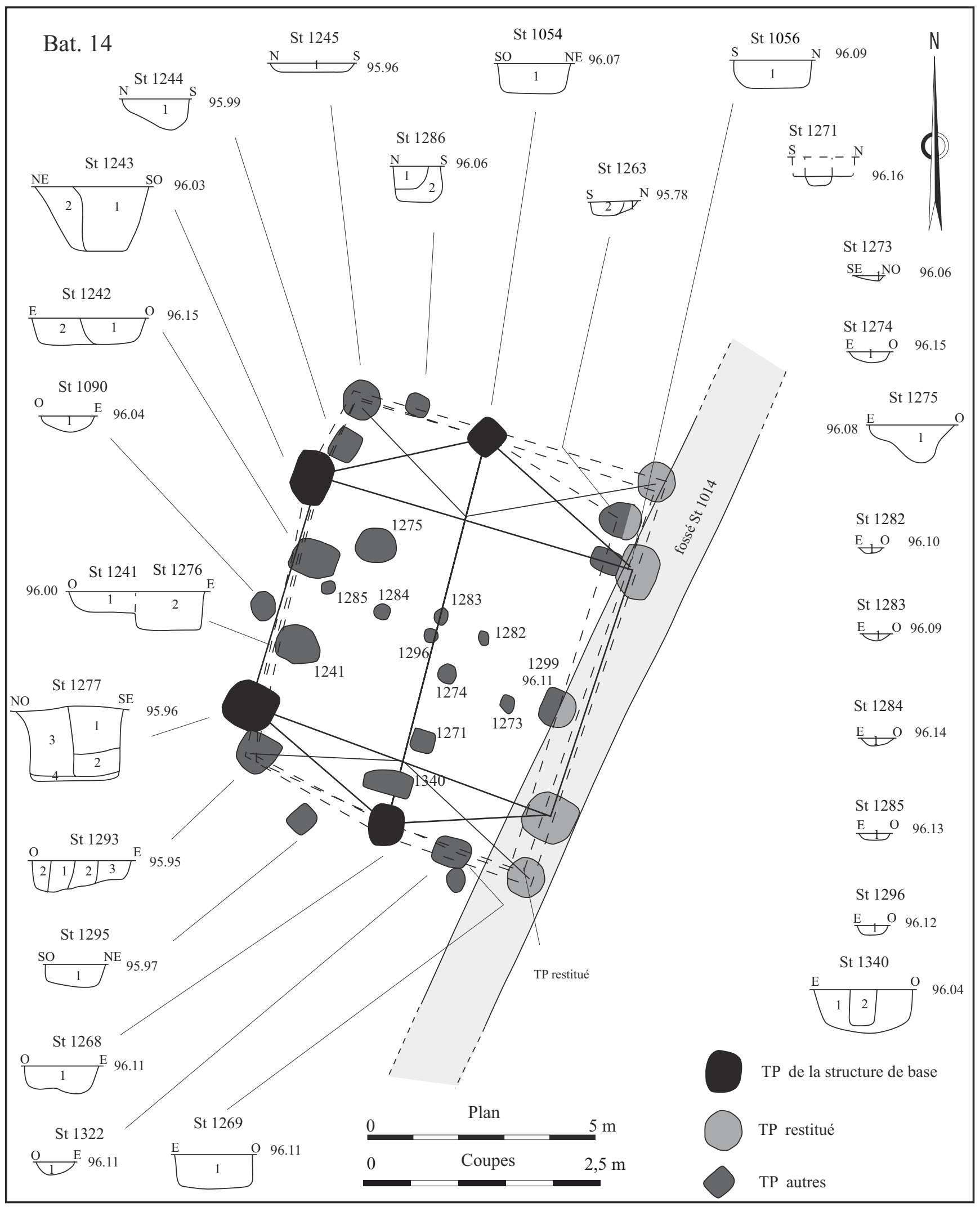

Figure 17 : Bonchamp-lès-Laval (53), plan détaillé du bâtiment B14 et relevés des coupes des trous de poteau le constituant. Figure 17: Detailed plan of building $B 14$ and sections of post holes constituting them. 


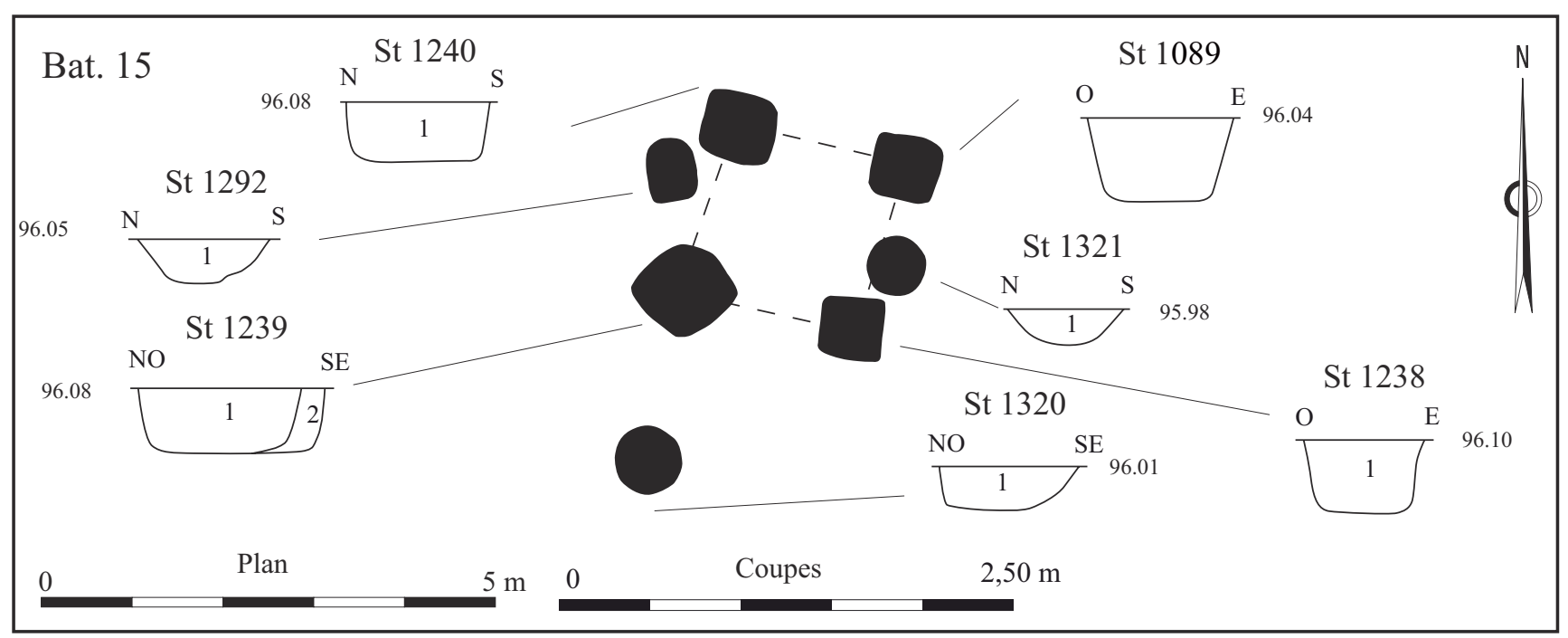

Figure 18 : Bonchamp-lès-Laval (53), plan détaillé du bâtiment B15 et relevés des coupes des trous de poteau le constituant. Figure 18: Detailed plan of building B15 and sections of post holes constituting them.

\section{Le bâtiment sur module porteur B21}

L'aire de ce bâtiment B21 se superpose ponctuellement à celle de B14 sans que nous sachions qui est antérieur à qui. B21 est matérialisé par quatre forts trous de poteau formant l'ossature d'un bâtiment sur plan centré $(3,5 \mathrm{x}$ 4,5 à 4,7 mètre de côté; fig. 21), auquel est adjoint à l'est le couple de poteaux St 1267 et 1272 qui matérialisent son porche d'entrée. Sa paroi périphérique passe sur son côté est, au-dessus du porche. Son tracé pour ses trois autres côtés est basé sur le même espace d'1,7 mètre de large (la surface de B21 serait d'approximativement 54 mètres carrés). Des négatifs de poteaux ont été identifiés dans St 1165 et 1294. Dans St 1272, du torchis rubéfié est relevé, ainsi que quatre fragments d'une lame de couteau en fer [3] (non représenté) et une plaque en tôle de fer [36] (non représentée).

\section{Le mobilier céramique de la phase 2: La Tène finale, $2^{e}$ moitié du II s. av. J.-C. (E. C.)}

La céramique de la phase 2 est difficile à quantifier, car elle est parfois redéposée dans les niveaux gallo-romains de l'enclos St 1037/1005. Elle est constituée d'un corpus de cent quarante-sept fragments et de vingt-trois individus en NMI. La céramique est présente dans les fossés de l'enclos St 1005, 1014 et 1037, dans le fossé bordier du chemin St 1229, et de manière annexe, dans quelques trous de poteau. Ces céramiques sont modelées, parfois régularisées à la tournette. Ces productions sont à pâte siliceuse et peuvent être regroupées en deux grandes catégories, la couleur de la première varie de l'orange au brun, souvent sur la même surface d'un récipient, indiquant soit une cuisson des vases dans un four sans sole, soit un contact direct avec le foyer. La seconde est à pâte micacée plus ou moins grossière, de teinte brune ou noire. Le taux de fragmentation des vases est très inégal d'une structure à l'autre, ce qui a pour conséquence de ne pas toujours permettre de distinguer les formes basses, représentées par les écuelles, des formes dites " mi-hautes ».

Le répertoire est comparable à celui issu des contextes d'habitat gaulois régionaux au second âge du Fer (fig. 22), citons par exemple les sites proches de La Carie 2 à Entrammes (Guillier et al., 2012), du Panveau à Aron (Valais, 2007), et enfin, les sites sarthois des Noirâs à Oisseau-le-Petit (Pétorin, 2007) et de La Gaudine à Vivoin (Guillier et al., 2006).

La datation des vases s'échelonne entre le milieu du $\mathrm{II}^{\mathrm{e}}$ et le milieu du $\mathrm{I}^{\mathrm{er}}$ siècle av. J.-C. Les écuelles prédominent et, en moindre quantité, les pots à cuire et les vases de stockage, ainsi que quelques amphores vinaires Dressel 1 (26 frag. ${ }^{4}$ ). Ces dernières correspondent à un bord (fig. 22, vase 1) et deux anses d'amphores de type Dressel $1 \mathrm{~A}$ à pâte orange ou rouge (vases 2 et 3 ).

Les écuelles sont les plus nombreuses (12 ex.). Outre leur utilisation à table, elles servent à la cuisson ou à réchauffer des aliments. Lissées ou décorées, leur diamètre à l'ouverture varie de 15 à $25 \mathrm{~cm}$. Le répertoire morphologique est constitué majoritairement d'écuelles à profil « en esse ». Elles sont à panse hémisphérique de type Gaudine 6A (Guillier et al., 2006) avec une lèvre déversée pourvue d'une incision labiale (6 ex. dont fig. 22, vases 4 à 8 ). Les autres sont plus galbées, avec un col droit développé (3 ex.) dont la base du col est décorée d'une incision (vases 9 et 10) ou d'un

4. Frag. = fragment, ex. = exemplaire. 


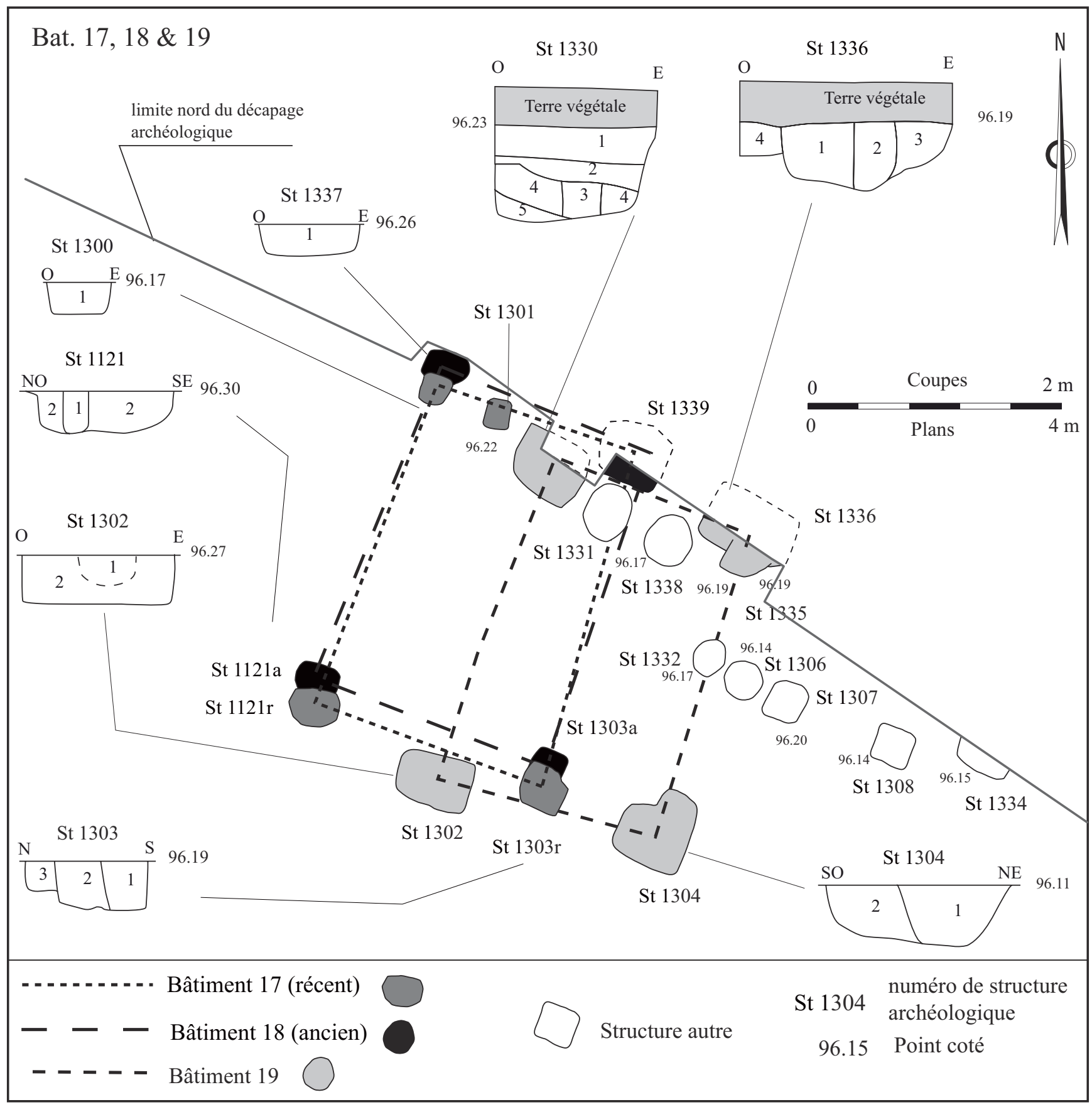

Figure 19 : Bonchamp-lès-Laval (53), plans détaillés des bâtiments B17, B18 et B19, et relevés des coupes des trous de poteau les constituant.

Figure 19: Detailed plans of buildings B17, B18 and B19 and sections of post holes constituting them.

cordon (vase 11), ou à col court avec la panse ornée d'incisions (vases 12 à 14). Trois bords d'écuelles tronconiques à lèvre aplatie de type 4 (Nillesse, 1997) et arrondie de type 6 (vases 15 et 16), redéposées dans les comblements antiques, viennent clore le corpus (vase 17).
Outre les incisions et cordons appliqués sur les écuelles, les panses sont parfois peignées de fines stries horizontales avec en surimpression un décor de bandes lissées formant des croisillons doubles (fig. 22, vase 18) ou des chevrons simples (vase 13). Cette association du peignage avec des bandes lissées est une technique décorative régulièrement appliquée 


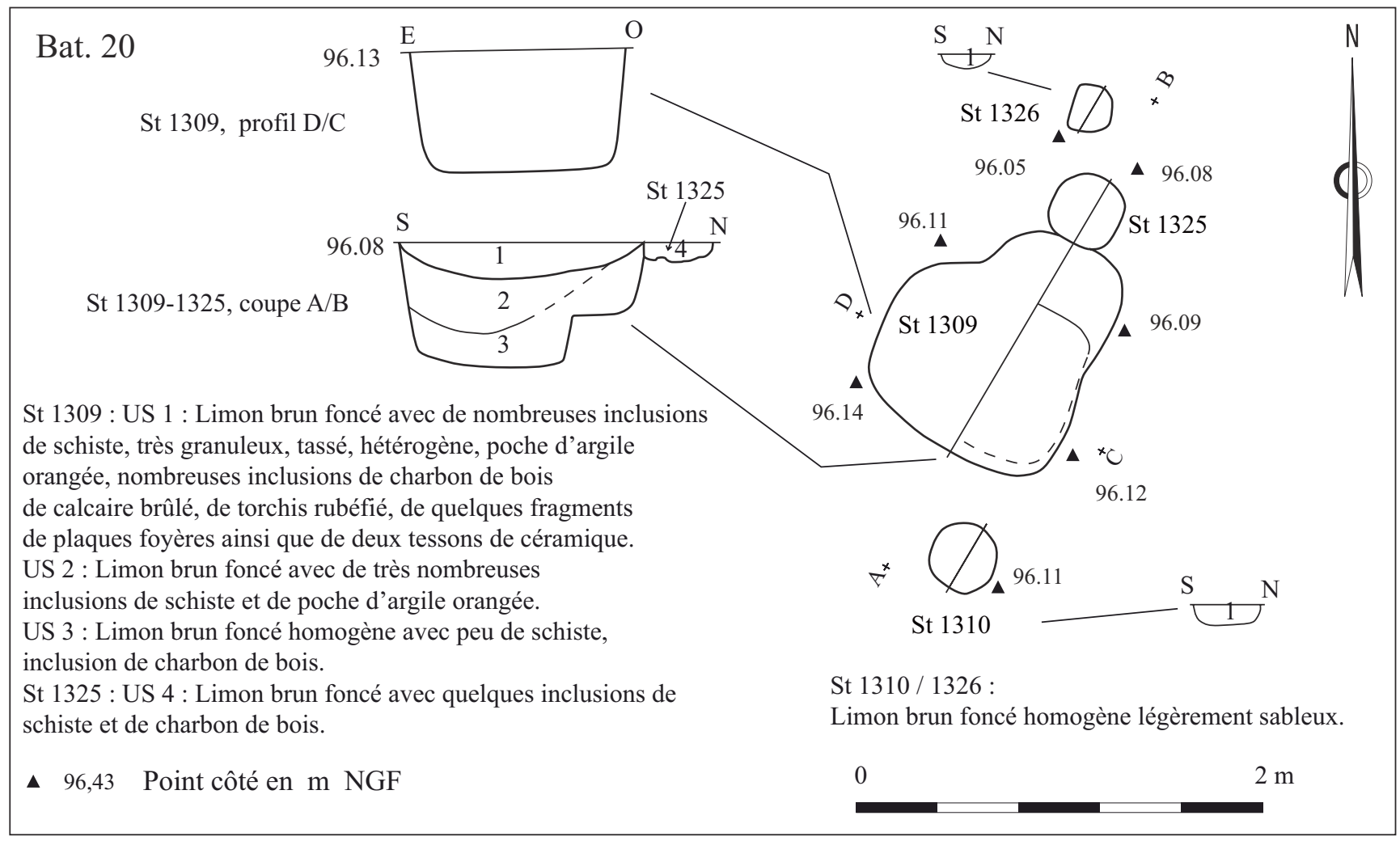

Figure 20 : Bonchamp-lès-Laval (53), plan détaillé de l'ensemble B20 et relevés des coupes des structures le constituant. Figure 20: Detailed plan of building B2O and sections of structures constituting them.

sur la céramique mayennaise, à Entrammes à La Carie 2 (Guillier et al., 2012) et en Pays de la Loire, en Sarthe par exemple (Maguer et al., 2003). Les pots ( 4 bords) ont des diamètres variant de 25 à $35 \mathrm{~cm}$. Ils ont une lèvre déversée arrondie dotée d'une incision labiale (vases 20 et 21 ). Enfin, trois lèvres de pots de stockage sont à mentionner, même s'ils sont en position résiduelle dans les comblements galloromains du fossé de l'enclos St 1037 (vases 20 à 22).

La répartition du mobilier archéologique de la phase 2

La répartition spatiale de ce mobilier archéologique se fait sur un nombre limité d'éléments et l'enclos St 1005/1037 en est le réceptacle privilégié. Les trous de poteau de l'habitat ont piégé une meule (B17, St 1121, [12]), quatre fragments d'une lame de couteau en fer et une plaque en tôle de fer (B21). L'enclos concentre l'essentiel de la céramique, accompagnée d'argile et de torchis rubéfié. Deux concentrations, localisées sur la partie centrale de St 1037, au sud de B17/18/19 et sur sa partie ouest, au sud de B11, B14 et B21, présentent des rejets culinaires ou domestiques : de la céramique, un couteau, ou des éléments liés au bâtiment, un ciseau à bois. Ce mobilier, rattaché à une dizaine de bâtiments est limité : la section fouillée aurait collecté une partie de leurs rejets, ces derniers pouvant s'effectuer ailleurs dans l'enclos (ou dans des fosses dépotoirs, dont aucun exemple n’a été mis au jour sur l'emprise fouillée).

\section{Linstrumentum des phases 1 et 2 :}

II s et I Ir s. av. J.-C. (S. R.) (fig. 23)

Parmi les objets les plus anciens illustrant cette période, on note un tesson de panse de récipient en lignite [29] ainsi qu'éventuellement un disque ou palet en schiste [28]. D'un diamètre maximum conservé de $18 \mathrm{~cm}$, cette portion de vase fortement évasée, offrant en surface un décor de fines cannelures réalisé au tour, pourrait se rattacher à une forme fermée dont un individu complet a été mis au jour dans une des tombes de la nécropole de Saint-Gatien-des-Bois dans le Calvados près de Deauville (Le Nagard, 2005), plutôt qu'à un vase baquet.

Les éléments de vaisselle en lignite, quels qu'ils soient, sont révélateurs du statut social élevé de leur propriétaire. Ils sont relativement rares en Europe, avec seulement vingttrois lieux de découverte, les attestations se regroupant dans le sud de l'Angleterre, en Normandie et dans la péninsule armoricaine (Baron, 2012). Les occurrences régionales ont été mises au jour sur les oppida d'Angers (Maine-et- 


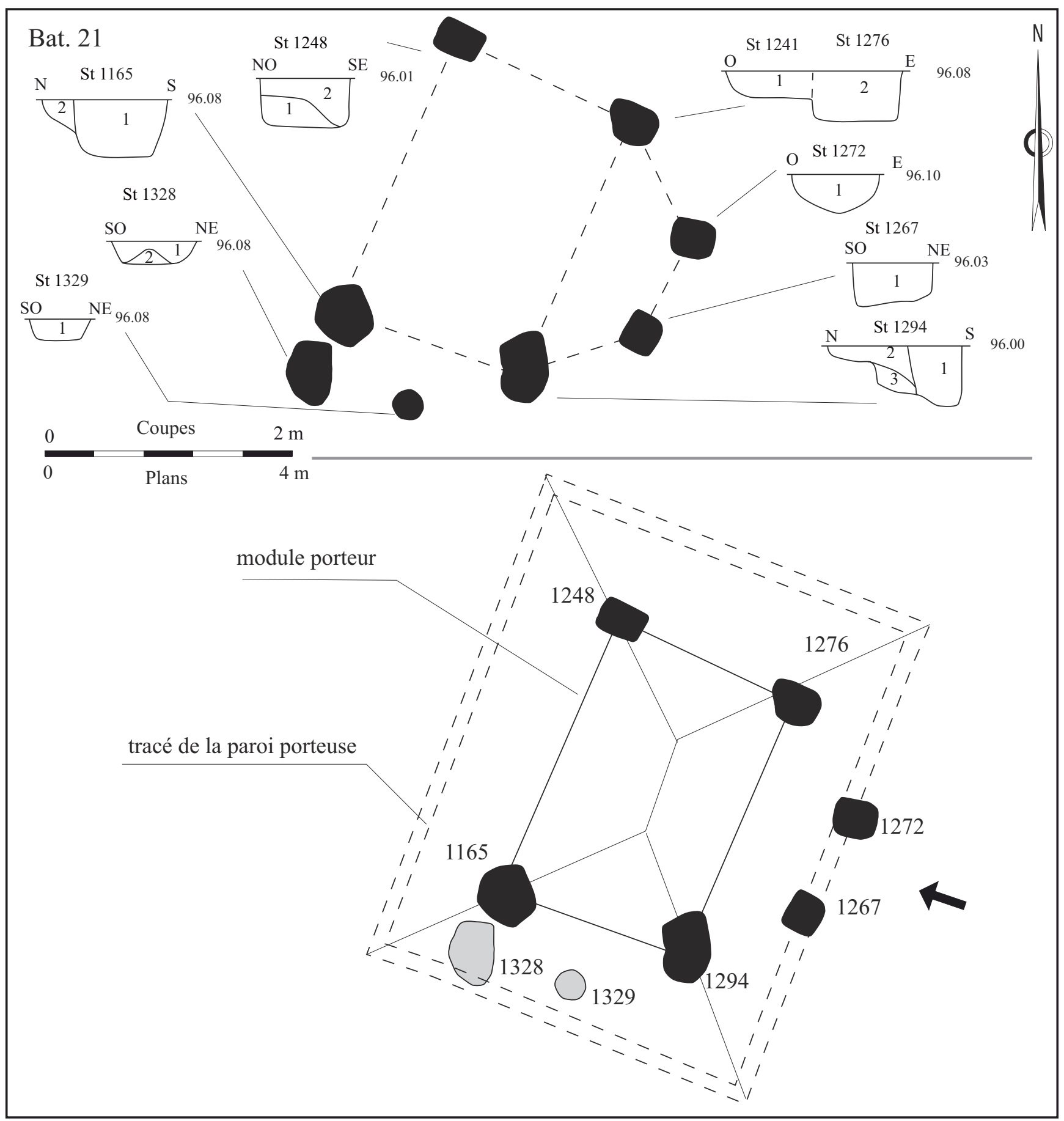

Figure 21 : Bonchamp-lès-Laval (53), plan détaillé du bâtiment B21, relevés des coupes des trous de poteau le constituant et proposition de restitution sur une hypothèse de bâtiment centré à paroi porteuse.

Figure 21: Detailed plan of building B21, sections of the post holes constituting it, suggested reconstruction employing a hypothesis of a centred building with load-bearing walls.

Loire, site du Château : Bouvet et al., 2003), d'Entrammes (Mayenne, site du Port-du-Salut) et de Moulay ainsi que sur le site de Jublains (information J.-P. Bouvet, SRA des Pays de la Loire). Un fragment de coupe ouverte à paroi oblique décorée d'une baguette a été mis au jour au sein de la ferme indigène du Panveau à Aron dans le nord de la Mayenne (Valais, 2007); on note également une mention de vase à Allonnes (Sarthe). L'exemplaire de Bonchamp- 


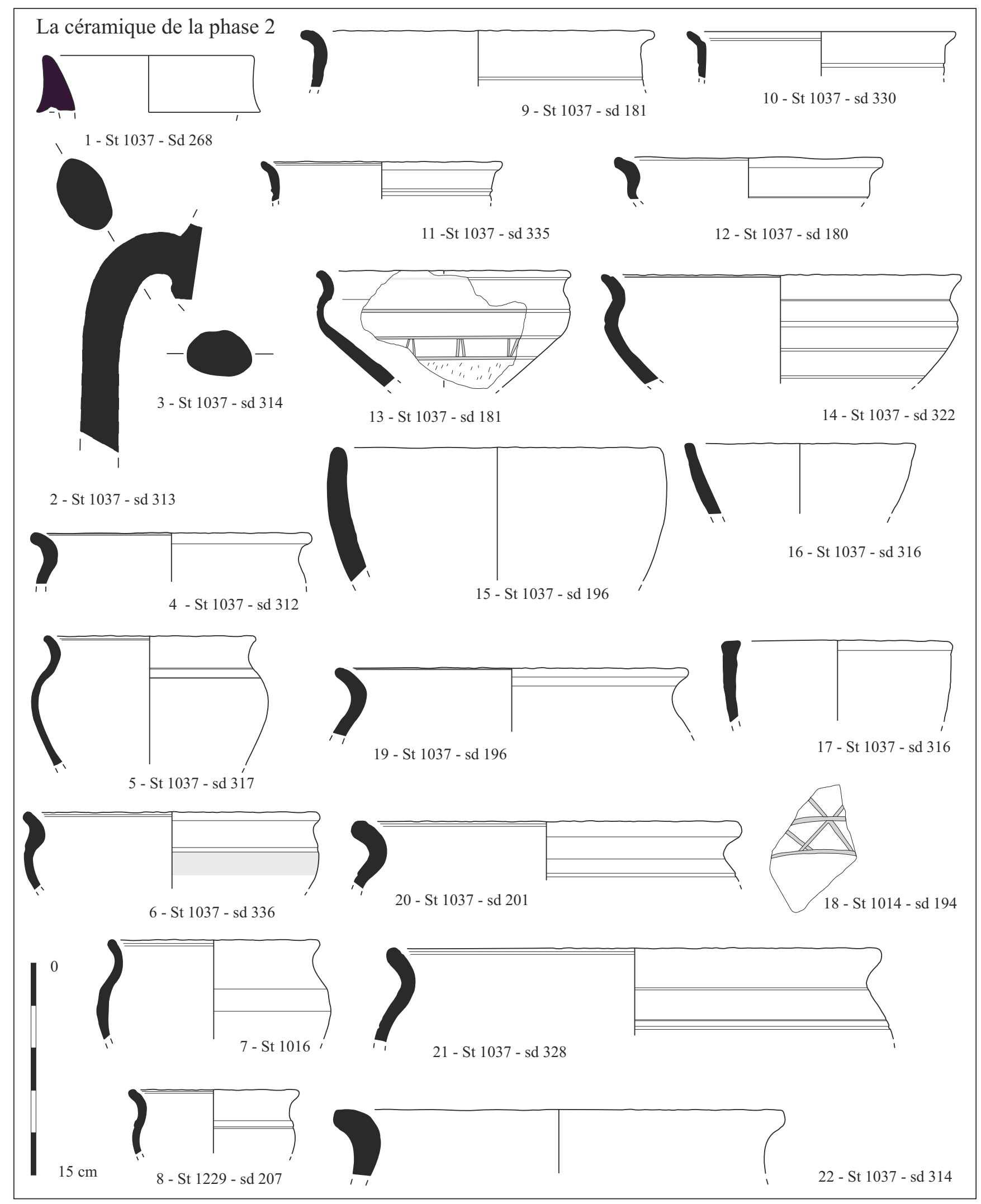

Figure 22 : Bonchamp-lès-Laval (53), la céramique de la phase 2.

Figure 22: The phase 2 pottery. 


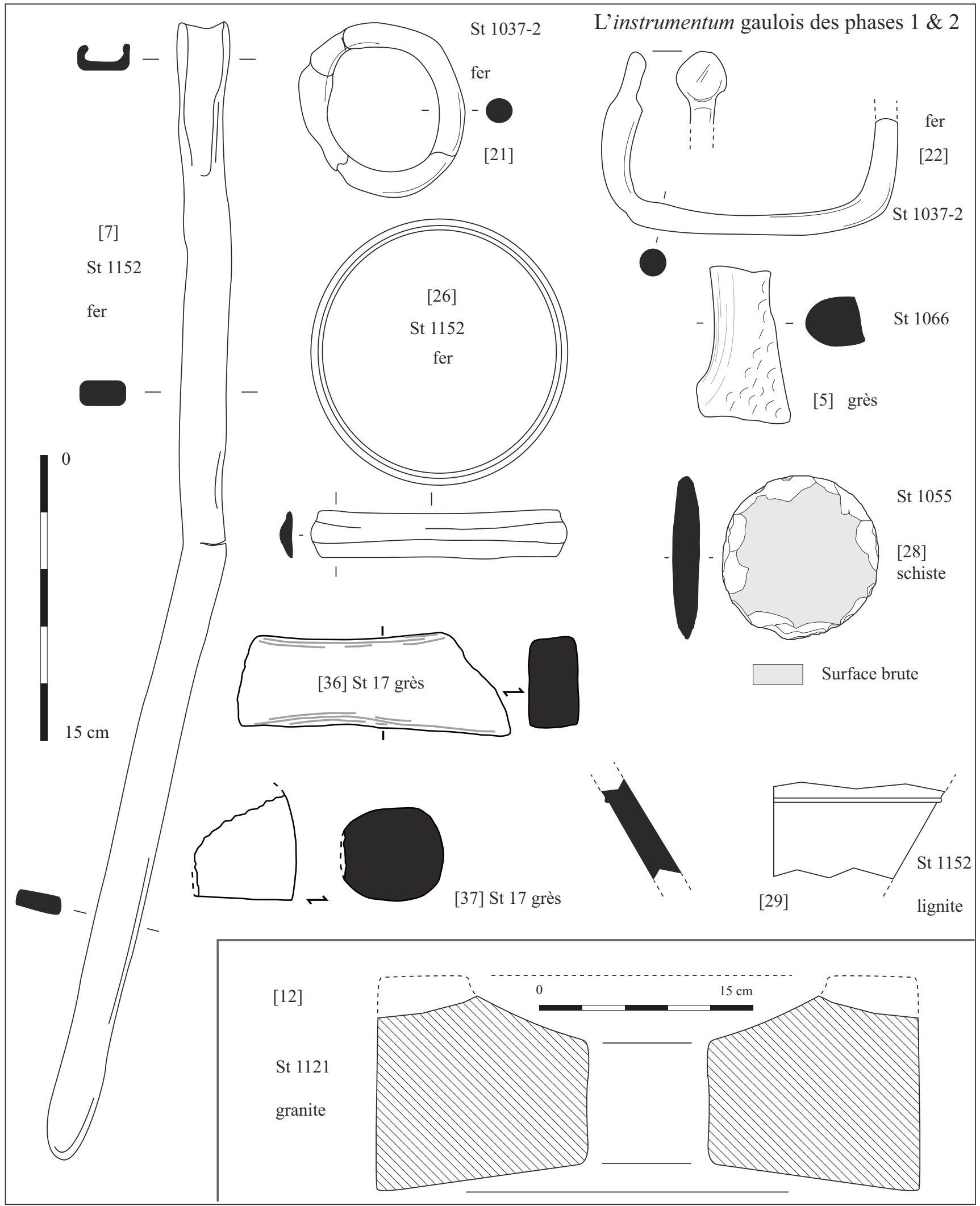

Figure 23 : Bonchamp-lès-Laval (53), l'instrumentum des phases $1 \& 2$.

Figure 23: The instrumentum of Phases 1 and 2. 
lès-Laval appartient à une série locale limitée et pose la question de la nature de l'occupation du site à la fin de l'âge du Fer. Les gisements de lignite les plus proches des Pays de la Loire, exploités au second âge du Fer, sont situés dans le Wessex et dans l'Allier (Baron, 2012). L'analyse du vase d'Allonnes (Thomas, 2003) a identifié une provenance anglaise du matériau, et il est vraisemblable d'attribuer à cette même origine, les récipients mis au jour au nord de la Loire. La matière première pouvait donc être importée, mais c'est plus vraisemblablement le produit fini qui était commercialisé. La rareté de diffusion de ces récipients va de pair avec le volume de matière première nécessaire à sa fabrication, les vases étant tournés et façonnés dans la masse. Cette production peut être un marqueur d'un type d'échanges spécifiques.

Les objets de la période laténienne en fer sont une soie de couteau à extrémité enroulée en anneau [2] (non figuré), un fragment de lame d'outil, peut-être de ciseau à bois [10] (non figuré), un anneau [21], rattachable au domaine immobilier, une tige en $U$ aux extrémités aménagées [22], correspondant à un élément d'huisserie, ou à un mors et un cerclage [26] qui a pu servir de renfort de crapaudine ou d'armature de moyeu de roue de charriot. Enfin, une barre de fer [7] ou currency bar correspond à un lingot de matière première de type CBL5 (Berranger, 2009). Ces demi-produits à extrémité roulée apparaissent au $\mathrm{III}^{\mathrm{e}}$ siècle. avant notre ère et dominent largement sur les autres formes de lingots commercialisés durant le siècle suivant (fin de LT C2 et LT D1), jusqu'au début de la période augustéenne. La répartition géographique de leurs occurrences, peu fréquentes en Gaule, montre une diffusion dans la partie occidentale du territoire, dans la péninsule armoricaine et sur un axe reliant Le Havre à Toulouse. La morphologie de l'exemplaire de Bonchamp-lès-Laval est à rapprocher de celle des demi-produits présents en Grande-Bretagne. L'association dans un même contexte de deux individus, vase en lignite et currency bar, pouvant provenir d'outre-manche est à signaler et marquerait les relations commerciales privilégiées entre le sud de l'Angleterre et le nord-ouest de la Gaule à la fin de l'âge du Fer. Ces lingots sont rares sur les établissements ruraux laténiens régionaux, citons un exemplaire, d'un type différent, aux Genâts (Vendée) (Nillesse, 2009).

Le domaine économique offre également, pour une part, une image des cultures vivrières tournées vers les céréales avec plusieurs fragments de meules rotatives [12 à 14], ces deux dernières sont issues du fossé d'époque gauloise St 1229 et du bâtiment B5. Quelques petits fragments de meules en grès roussard sont aussi issus du diagnostic (St 6 et 7). Deux lissoirs en grès fin [5 et 36] ainsi qu'un broyon [37] viennent clore ce modeste corpus. Enfin, les indices d'une métallurgie du fer, sont attestés par la présence de scories dès la phase 1 (St 1044 et 1253), ainsi que par une scorie de forge en calotte issue du bâtiment B11 (St 1016).

\section{LA PÉrIOdE ANTIQUE, D’Auguste Au DÉBut des ANTONINS}

\section{Un enclos dans la continuité de la période gauloise : la phase $3 a$}

La phase 3 ne présente pas de rupture nettement visible au sein du site (fig. 24). L'enclos St 1005/1037 en est un point fort, mais aucune structure d'habitat n'apparaissant sur son aire, elles peuvent être implantées plus au nord. Les autres structures fossoyées nouvellement creusées se superposent ou sont parallèles aux fossés antérieurs, ce sont au sud les fossés St 1194, 1195 et 1197 . Autre nouveauté, le bâtiment de plan rectangulaire B2, élevé également au sud du site.

\section{L'enclos St 1005/1037}

Cet enclos St 1005/1037, creusé à la phase 2 est encore en fonctionnement à la phase 3 (fig. 24). Le fossé tel qu'il devait y apparaitre est peu marqué au sol (profondeur : 0,5/0,7 m; fig. 11 : les couches marquées d'un point noir). D'après le mobilier, il est envisageable d'y restituer un profil d'équilibre avant son obturation finale qui marque la phase $3 \mathrm{~b}$.

\section{Les fossés St 1194, 1195 et 1197 : un axe de circulation au plan original au sud du site}

Les fossés St 1194 et 1195 sont situés parallèlement et immédiatement au sud de l'enclos précédent, à une distance qui varie de 16 à 18 mètre (fig. 24). Le troisième, St 1197 , placé plus au sud encore, est distant de 3 à 6 mètres des deux précédents.

Le fossé ouest, St 1195, long de 95 mètres, rectiligne, se superpose au fossé laténien St 1211/1229. Son extrémité Est s'incurve vers le nord à l'approche de B2, et s'y élargit en s'arrondissant. C'est un fossé au profil trapézoïdal, sauf sur son tiers est où les profils sont en forme de " $\mathrm{U}$ » ouvert (largeur : 1,4 à $2 \mathrm{~m}$; profondeur : 0,6 m; fig. 24). Les niveaux relevés déterminent une adaptation au terrain avec un sens d'écoulement des eaux d'est en ouest. Le mobilier archéologique, de rares tessons et fragments de tuiles, issus de la partie supérieure du comblement, se densifie à l'approche du bâtiment $B 2$, près duquel ont été mis au jour une fibule circulaire en bronze [17] et un crochet en fer [27].

Le fossé est, St 1194, rectiligne au profil en " $\mathrm{U}$ » (longueur : $55 \mathrm{~m}$; largeur : 1,02 à 1,1 m; profondeur : 0,28 à $0,40 \mathrm{~m}$; fig. 24), se superpose au fossé laténien St 1229/St 5. Son extrémité ouest, arrondie, s'infléchit vers le nord à l'approche du bâtiment B2, de la même manière que le fossé St 1195 . 


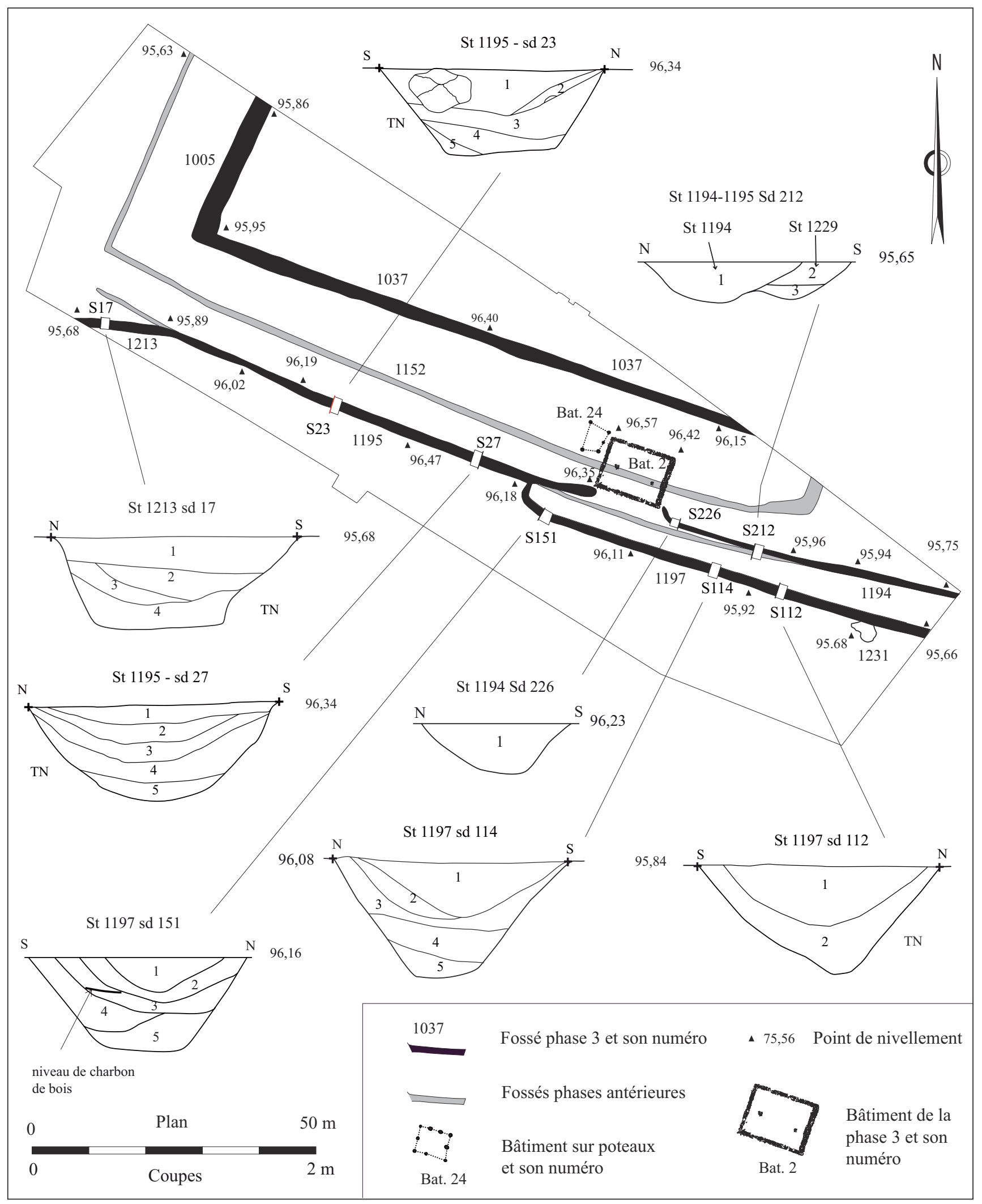

Figure 24 : Bonchamp-lès-Laval (53), plan général des structures constitutives de la phase 3; les fossés ouest, est et sud : présentation d'un choix de coupes.

Figure 24: General plan of the structures constituting Phase 3; the west, east and south ditches: presentation of a choice of sections. 
Le fossé sud, St 1197, au tracé rectiligne a été découvert sur 76 mètres de long lors de la fouille de 2012 (fig. 24), mais grâce aux résultats du diagnostic de 2014, il a pu être mis en évidence sur plus de 230 mètres (fig. 3). Son extrémité ouest s'infléchit vers le nord et s'accroche au fossé St 1195 après avoir dépassé le bâtiment B2 (fig. 24). Ce fossé présente un profil trapézoïdal, ponctuellement en " $\mathrm{V}$ " ouvert (largeur : 1,60 m; profondeur : de 1,45 à 1,68 m). Les niveaux relevés montrent une adaptation au terrain avec un sens d'écoulement des eaux d'ouest en est.

Ces trois fossés St 1195, 1194 et 1197, situés sur un même axe ONO/ESE, encadrent le bâtiment B2, à l'ouest, à l'est et au sud (fig. 24). À son approche, les extrémités des deux premiers s'incurvent vers le nord et se dirigent, sans les atteindre, vers les angles de B2. Le fossé sud St 1197 vient délimiter, avec les précédents, un axe de circulation qui débouche directement sur le bâtiment B2. Cet ensemble se trouve dans la directe filiation des axes de circulation antérieurs placés au sud des enclos des phases antérieures.

\section{Le bâtiment rectangulaire $B 2$}

Ce bâtiment B2 $(9,4 \times 12,2 \mathrm{~m})$ présente une surface interne de 83 mètres carrés (fig. 25). Les murs sont épais de 0,6 mètre sauf le mur est, sur la pente, qui est épais de 0,8 mètre. Ces murs sont implantés dans des tranchées (profondeur : 0,1 à 0,2 m) comblées d'un, parfois de deux, niveaux de blocs de calcaire de Laval. La mise en évidence de torchis rubéfié en surface de B2 lors du décapage archéologique, évoque un bâti élevé sur solin, en pans de bois et torchis. Les structures qui occupent l'aire interne de B2, St 1192 et 1193 (diamètres : de 1 et $0,9 \mathrm{~m}$; profondeurs : $0,10 \mathrm{~m}$ ), espacées de 6 mètres, se rapporteraient à des bases de piliers. L'emplacement de ce bâtiment, au sein d'un système de fossés, matérialisant un petit chemin, suggère la possibilité d'un bâtiment porche. Ce dernier serait largement ouvert au sud pour laisser un passage suffisant, d'où la présence des deux bases de piliers, de part et d'autre de ce passage. Cette hypothèse est confortée par la maçonnerie du mur sud B2 qui présente plusieurs blocs de calcaire de taille exceptionnelle, disposés à plat. Ils matérialiseraient les bases des pieds-droits d'une porte piétonnière de 1,5 mètres de large et d'un passage charretier large de $4 \mathrm{~m}$, centré sur le côté sud de B2.

Ce bâtiment B2 est accompagné du petit bâtiment sur poteaux B24 (fig. 25), localisé près de son angle nord-ouest, à moins d'1 mètre du mur pignon St 1189; il s'agit peut-être d'un appentis...

\section{Le mobilier céramique de la phase $3 a$ : la $1^{\text {re }}$ moitié du $\mathrm{I}^{\text {er }}$ siècle (E. C.)}

L'horizon gallo-romain précoce est présent, confirmant une occupation continue depuis La Tène finale. Les fossés de l'enclos gaulois St 1005 et St 1037 sont toujours en fonctionnement lors de la construction du bâtiment B2. Au total, ce sont 298 tessons qui ont été mis au jour pour un NMI de 65. Cependant, il est difficile de distinguer les assemblages de cette période en raison de leur présence dans les fossés de l'enclos St 1005 et St 1037 qui ont été utilisés postérieurement comme dépotoirs. La céramique est souvent fragmentée, brassée et en position de rejet secondaire.

L'assemblage précoce de la seconde moitié du $\mathrm{I}^{\mathrm{er}}$ siècle av. J.-C. se caractérise par des productions modelées de type "Besançon ", des importations fines de gobelets de type «Beuvray ». Elles sont associées à deux amphores vinaires : une Dressel $1 \mathrm{~b}$ à pâte orange micacée (fig. $26^{5}$, vase 1 ) et une Tarraconaise (vase 2). Les productions de type «Besançon » (6 frag. dont 4 bords), à la pâte siliceuse grossière, parfois très micacée, de teinte orange ou brune (vases 3 et 4), ont des diamètres à l'ouverture variant de 17 à $28 \mathrm{~cm}$. Ces vases, de tradition laténienne, subissent des modifications morphologiques qui se standardisent et deviennent prédominantes durant la période augustéenne (Lallemand $e t$ al., 2005). Les gobelets type "Beuvray" (2 frag., vase 5) sont à pâte fine orange et dotés d'un engobe interne rouge et externe brun. Leurs panses sont décorées de palmettes en chevrons et de guillochis. Ces gobelets augustéens ressemblent aux productions du Nivernais (Joly et al., 2003). Cet assemblage est complété par une écuelle modelée à panse hémisphérique (vase 6).

Les poteries datables de la première moitié du $\mathrm{I}^{\mathrm{er}}$ siècle apr. J.-C., sont typiques d'une occupation domestique (tabl. 2), allant des récipients destinés au transport et au stockage, à ceux habituellement utilisés pour la préparation et la cuisson des aliments et au service de table.

\section{Les récipients destinés au transport et au stockage}

Ce sont deux bords de dolia, tournés, à pâte siliceuse orange ou brune à lèvre déversée en méplat (fig. 26, vase 7). Ces productions des officines de Mougon (Indre-et-Loire) de type $E$ (Schweitz et al., 1986) sont diffusées dès l'époque tibérienne. Leurs diamètres varient de 37 à $52 \mathrm{~cm}$, ils sont poissés. Les autres gros contenants sont les amphores vinaires et à saumure. Elles sont, à l'époque tibérienne, d'origine hispanique comme l'amphore Pascual 1 à pâte claire. L'autre type d'amphore vinaire est une Dressel 2/4 tibérienne origi-

5. Nous nous sommes limités, pour la présentation du mobilier céramique gallo-romain (fig. 26 et 27), à ne figurer que les principales formes, toutefois en accentuant le trait sur la vaisselle modelée. 


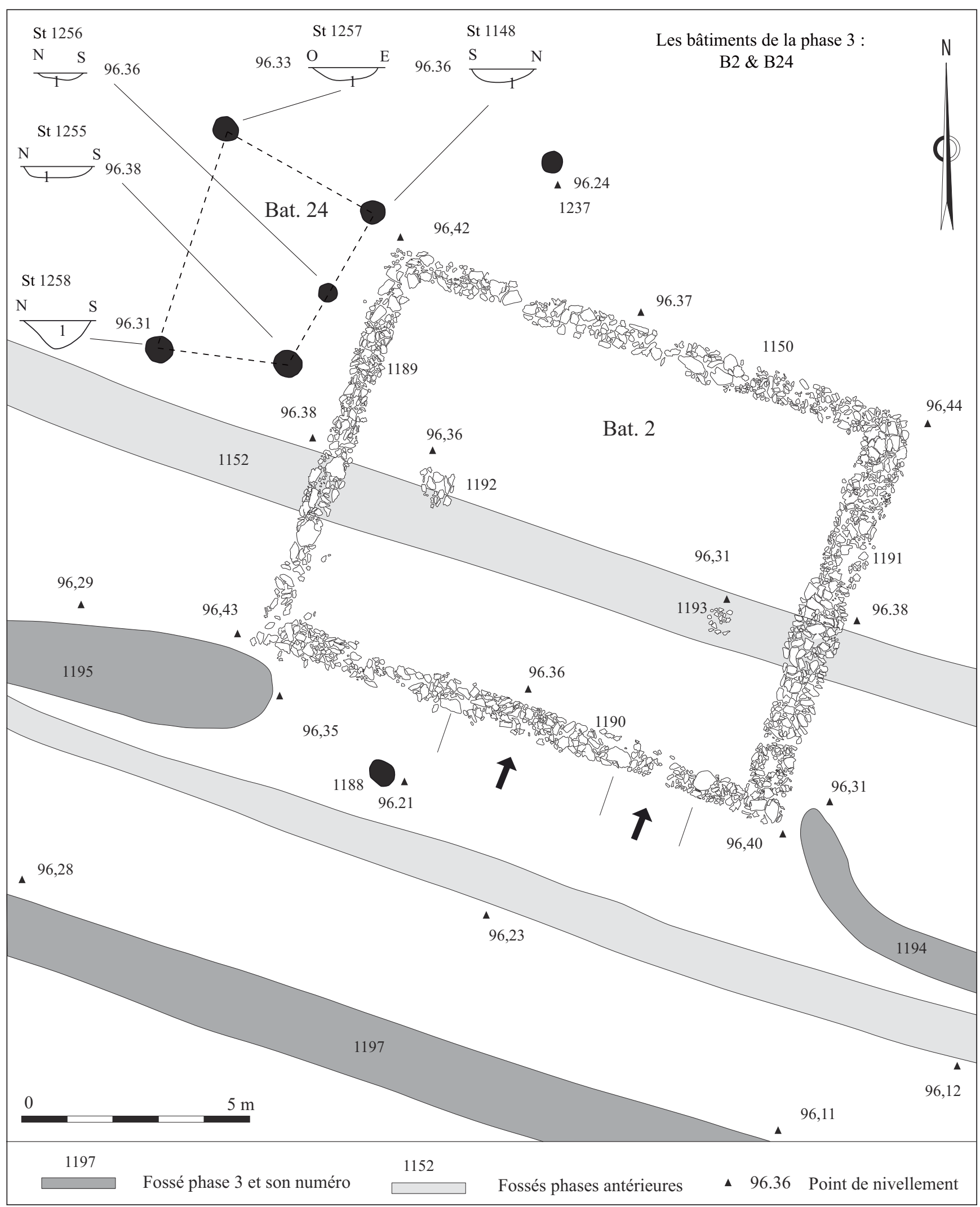

Figure 25 : Bonchamp-lès-Laval (53), phase 3 : plan de situation détaillée des bâtiments B2 et B24, et pour ce dernier, relevés des coupes des poteaux le composant.

Figure 25: Phase 3, detailed situation plan for buildings B2 and B24, and for the latter, the sections of the post holes constituting it. 


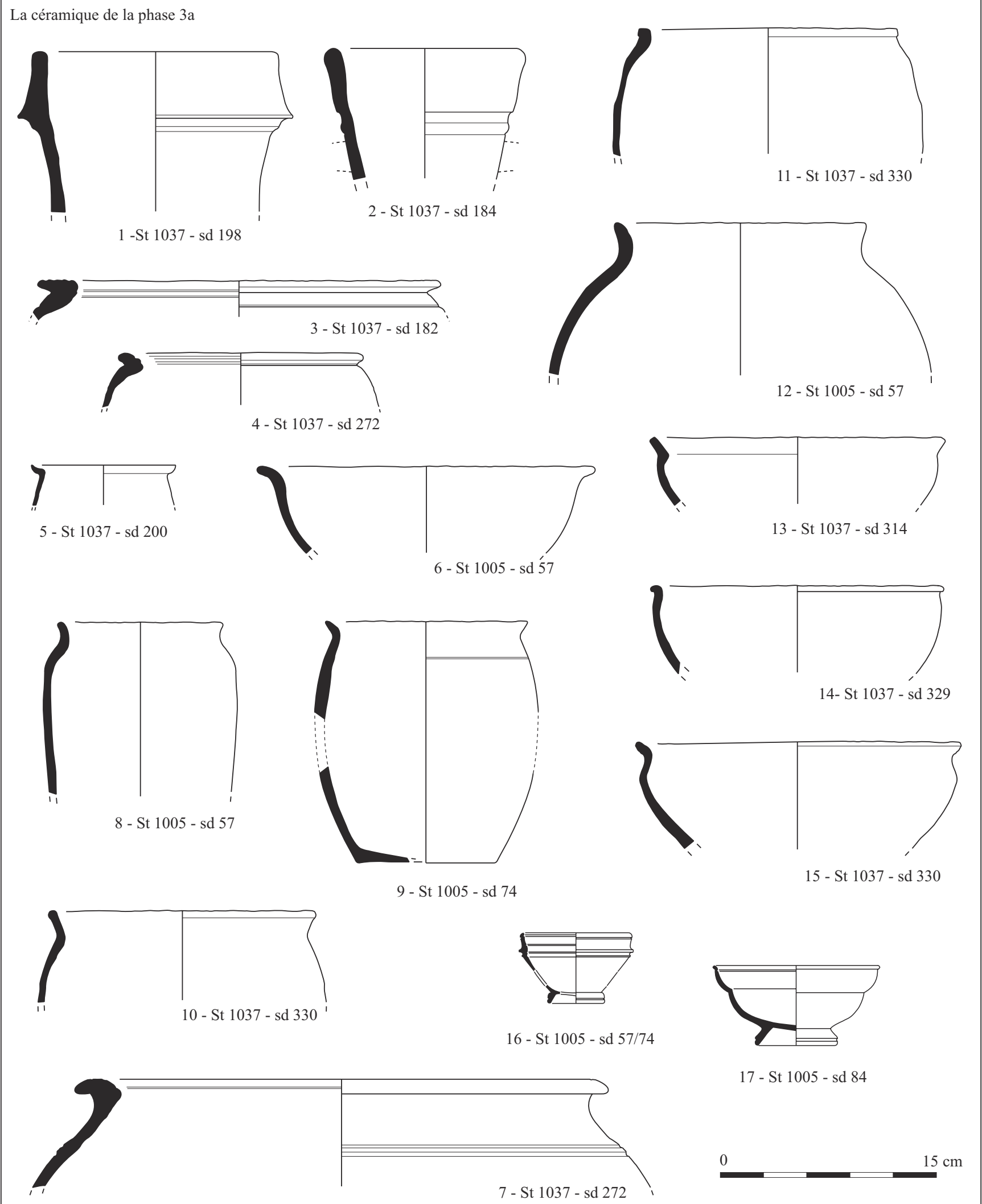

Figure 26 : Bonchamp-lès-Laval (53), la céramique de la phase 3 a.

Figure 26: The pottery from phase $3 a$. 


\begin{tabular}{|c|c|c|c|c|c|}
\hline Fonction & Catégorie céramique & $\mathrm{NR}^{*}$ & $\%$ & $\mathrm{NI}^{* *}$ & $\%$ \\
\hline \multirow{2}{*}{ Transport/stockage } & Amphore & 23 & 7,7 & 2 & 3,1 \\
\hline & Stockage (dolium) & 8 & 2,7 & 3 & 4,6 \\
\hline \multirow{2}{*}{ Préparation/conservation } & Commune & 64 & 21,5 & 7 & 10,8 \\
\hline & Modelée & 158 & 53 & 36 & 55,4 \\
\hline \multirow{2}{*}{ Préparation/présentation } & Terra nigra & 40 & 13,4 & 14 & 21,5 \\
\hline & Sigillée & 5 & 1,7 & 3 & 4,6 \\
\hline \multicolumn{2}{|l|}{ TOTAL } & 298 & 100 & 65 & 100 \\
\hline
\end{tabular}

Tableau 2 : Bonchamp-lès-Laval (53), phase 3a : répartition quantitative de la céramique triée sur des critères de fonction et de catégorie céramique (* : Nombre de restes; ${ }^{* *}$ : Nombre d'Individus, bords et fonds).

Table 2: Phase 3a: quantitative distribution of the pottery sorted by criteria for pottery function and category (*: Number of remains; **: Number of individuals, rims and bases).

naire de Kos (Grèce) (Siraudeau, 1988). À partir du milieu $\mathrm{du} \mathrm{I}^{\text {er }}$ siècle, les amphores sont majoritairement des productions régionales à pâte orange (Berthault, 1997). Quatre fragments d'amphores à huile de Bétique Dressel 20 ont été retrouvés.

\section{Les récipients pour la préparation et le stockage des denrées}

La céramique commune, à usage culinaire, est constituée de cruches et de pots. Certaines cruches issues de la vallée de l'Allier sont à pâte fine couleur crème et à engobe blanc. Les autres vases appartenant au vaisselier domestique sont les pots. La céramique modelée du Haut-Empire est régulièrement mise au jour dans le Maine (Chuniaud et al., 2002) et constitue de 10 à $20 \%$ du vaisselier. Les vases du Grand Coudray sont à usage culinaire. Deux types sont présents, les pots (17 ex.) et les coupes (14 ex.). Ces céramiques à pâte siliceuse de couleur brune ou noire peuvent comporter de nombreuses vacuoles. Les surfaces sont soigneusement lissées. Les pots sont de profil tronconique avec une lèvre déversée allongée légèrement effilée (fig. 26, vases 8 et 9), rectangulaire (vase 10) ou arrondie (vase 11). Trois exemplaires ont un profil plus globulaire (vase 12). Les coupes ont une panse hémisphérique, un col court et une lèvre plutôt rectangulaire (vase 13), à bord triangulaire (non représenté) ou à lèvre arrondie (vase 14). Une écuelle à profil « en esse " est aussi présente (vase 15). Des vases comparables sont régulièrement présents sur les sites mayennais de La Carie 2 à Entrammes (Guillier et al., 2012), de La Garde (Valais, 2005) et de La Davière (ibid.).

\section{Les récipients pour la préparation et la présentation des denrées}

Les productions de céramique fine en terra nigra (Ménez, 1985) sont des importations d'Aquitaine ou du Centre, les assiettes et les coupes prédominent. Les assiettes relèvent des formes Ménez 40, 46, 51 ou 55. Les coupes sont de type Ménez 96, 102 ou 103. La céramique sigillée (identification R. Delage/Inrap), une vaisselle destinée plus spécialement à la table, est issue des officines du sud de la Gaule : La Graufesenque (Aveyron) avec une coupelle Ve.A1 (non figurée) tandis que les deux coupelles Ritt.5 (fig. 26, vase 16) et Drag.27 (vase 17) sont issues du centre de la Gaule : Lezoux (Puy-de-Dôme).

\section{L'annonce d'un changement dans l'organisation du site : la phase $\mathbf{3 b}$}

Vers la fin du $\mathrm{I}^{\text {er }}$ siècle ou au début du siècle suivant, les fossés d'enclos St 1005 et St 1037 (fig. 24) sont obturés par l'apport d'un volume important de matériaux, piégeant un mobilier céramique conséquent. Cette phase de nivellement de l'enclos annonce clairement la phase 4, marquée par un changement dans les modes de construction et une mise à plat d'une partie des structures héritées de la période gauloise.

Le mobilier céramique de la phase $3 b$ : fin $t^{\text {er }} /$ début II siècle (E. C.)

Les fossés de l'enclos St 1005 et St 1037, ainsi que les fossés St 1186, St 1194, St 1195 et St 1197, sont comblés, et peuvent subsister sous la forme de haies. Au total, ce sont 1062 tessons qui ont été mis au jour pour un NMI de 111. Le répertoire des formes est celui habituellement retrouvé dans des contextes de consommation. L'éventail des poteries va du transport et au stockage, à la préparation et à la conservation des denrées alimentaires jusqu'à la vaisselle présentée à table (tabl. 3).

Les récipients destinés au transport et au stockage

Ces vases sont surtout les amphores vinaires à fond plat : Gauloise 2/4 de Narbonnaise (deux fonds et une anse); un 


\begin{tabular}{|l|l|c|c|c|c|}
\hline Fonction & Catégorie céramique & NR & $\%$ & NI** $^{* *}$ & $\%$ \\
\hline \multirow{2}{*}{ Transport/stockage } & Amphore & 121 & 11,4 & 6 & 5,4 \\
\hline \multirow{2}{*}{ Préparation/conservation } & Stockage (dolium) & 4 & 0,4 & 1 & 0,9 \\
\hline \multirow{3}{*}{ Préparation/présentation } & Commune & 87 & 8,2 & 11 & 9,9 \\
\cline { 2 - 6 } & Modelée & 770 & 72,4 & 71 & 64 \\
\hline TOTAL & Fine/terra nigra & 62 & 5,8 & 12 & 10,8 \\
\cline { 2 - 6 } & Paroi fine & 8 & 0,8 & 3 & 2,7 \\
\cline { 2 - 6 } & Sigillée & 1062 & 100 & 111 & 100 \\
\hline
\end{tabular}

Tableau 3 : Bonchamp-lès-Laval (53), phase 3b : répartition quantitative de la céramique triée sur des critères de fonction et de catégorie céramique (*: Nombre de restes; ${ }^{* *}$ : Nombre d'Individus, bords et fonds).

Table 3: Phase 3b: quantitative distribution of the pottery sorted by criteria for pottery function and category (*: Number of remains; **: Number of individuals, rims and bases).

fond et deux bords de Gauloise 4 des officines de ThéséePouillé (Loir-et-Cher; Barthélémy-Sylvand et al., 2005). Les autres amphores sont 18 tessons d'amphores Dressel 20. Les dolia sont représentés par un bord à lèvre arrondie (fig. 27, vase 1) de type 3 (Schweitz et al., 1986), semblable aux productions de Mougon (Indre-et-Loire).

Les récipients pour la préparation

et le stockage des denrées

La céramique commune est très fragmentée et représentée par cinq bords de cruches, deux pots, une marmite et un mortier. Les cruches sont à engobe micacé doré a une lèvre en corniche moulurée, deux autres sont à lèvre en poulie (fig. 27, vase 2). Les pots sont trop fragmentés pour en reconnaître la morphologie. La marmite, probablement tripode, a un bord rentrant (vase 3) et le mortier une lèvre débordante en collerette (vase 4). La céramique modelée constitue de 60 à $70 \%$ du vaisselier, pourcentage tout à fait exceptionnel. Les productions à pâte siliceuse brun-noir peuvent comporter de nombreuses vacuoles. Les surfaces sont soigneusement lissées et présentent des traces de carbone qui $y$ adhèrent. Ces productions sont semblables aux découvertes de Jublains (Mayenne), du Mans (Sarthe) et aux productions de l'atelier à Mazières-en-Mauges (Maine-etLoire). Les pots, prédominants (31 vases), sont majoritairement de profil tronconique avec une lèvre déversée allongée légèrement effilée (fig. 27, vases 5 et 6). Un exemplaire a une lèvre droite (vase 7) et quatre ont un profil globulaire (vase 8). Les rares formes ouvertes sont neuf coupes (vases 9 à 11) et deux plats (vase 12).

Les récipients pour la préparation et la présentation des denrées

La céramique fine est représentée par une coupe à collerette (fig. 27, vase 13) à pâte fine orange à engobe micacé rouge.
Cette forme est régulièrement trouvée dans des contextes de la seconde moitié au I $^{\text {er }}$ siècle dans les Pays de la Loire, par exemple à La Petite Coyère à La Cropte (Mayenne; Ledauphin, à paraître). Notons un gobelet (non représenté) à engobe noir Lezoux 331, identifié par R. Delage (Inrap). Les céramiques fines en terra nigra, à pâte fine brune, sont des coupes (10 ex.), des assiettes (3 lèvres) et des pots ( 2 bords). Les coupes ont une carène plus ou moins marquée de type Ménez 9, 106 et 110. Les assiettes en terra nigra sont des bords de type Ménez 42 et 55. Les formes fermées sont deux bords de pots de type Ménez 146. La céramique sigillée (fig. 27), complétant le service de table, provient de la Gaule du sud (La Graufesenque) et du Centre (Lezoux). Ce sont deux assiettes et une coupelle à lèvre débordante ornée d'un décor de feuille d'eau de type Ve. A2 (vase 14), Ve. B2 (vase 15), ainsi qu'une assiette Ve. E2 (vase 16) et une coupelle Ve. C1 (vase 17). Ces services sont complétés par un gobelet Déch. 64 en sigillée noire à décor guilloché (vase 18) et une coupe moulée Drag. 30 de Lezoux (vase 19) dont le décor est typique des styles anonymes de la fin du $\mathrm{I}^{\text {er }}$ siècle des ateliers du secteur de "Mon Repos " au sein du groupe d'ateliers de Saint-Taurin à Lezoux (R. Delage/ Inrap).

\section{L'extrémité sud d'une villa antique au début du II $^{\mathrm{e}}$ siècle : la phase 4}

Assez mal datée, elle est postérieure à la phase $3 \mathrm{~b}$, qui correspond au nivellement de l'enclos laténien puis antique vers la fin du $\mathrm{I}^{\text {er }}$ siècle ou au début du siècle suivant. Sont présents le mur St 1055/1124 qui marque l'angle sud-ouest du domaine, ainsi que les bâtiments B1 et B3 (fig. 28). Quelques tronçons de fossés et les talus les bordant, qui définissaient au sud l'accès à B2, St 1194, 1195 et St 1197 , seraient encore en activité (fig. 28, haut). 


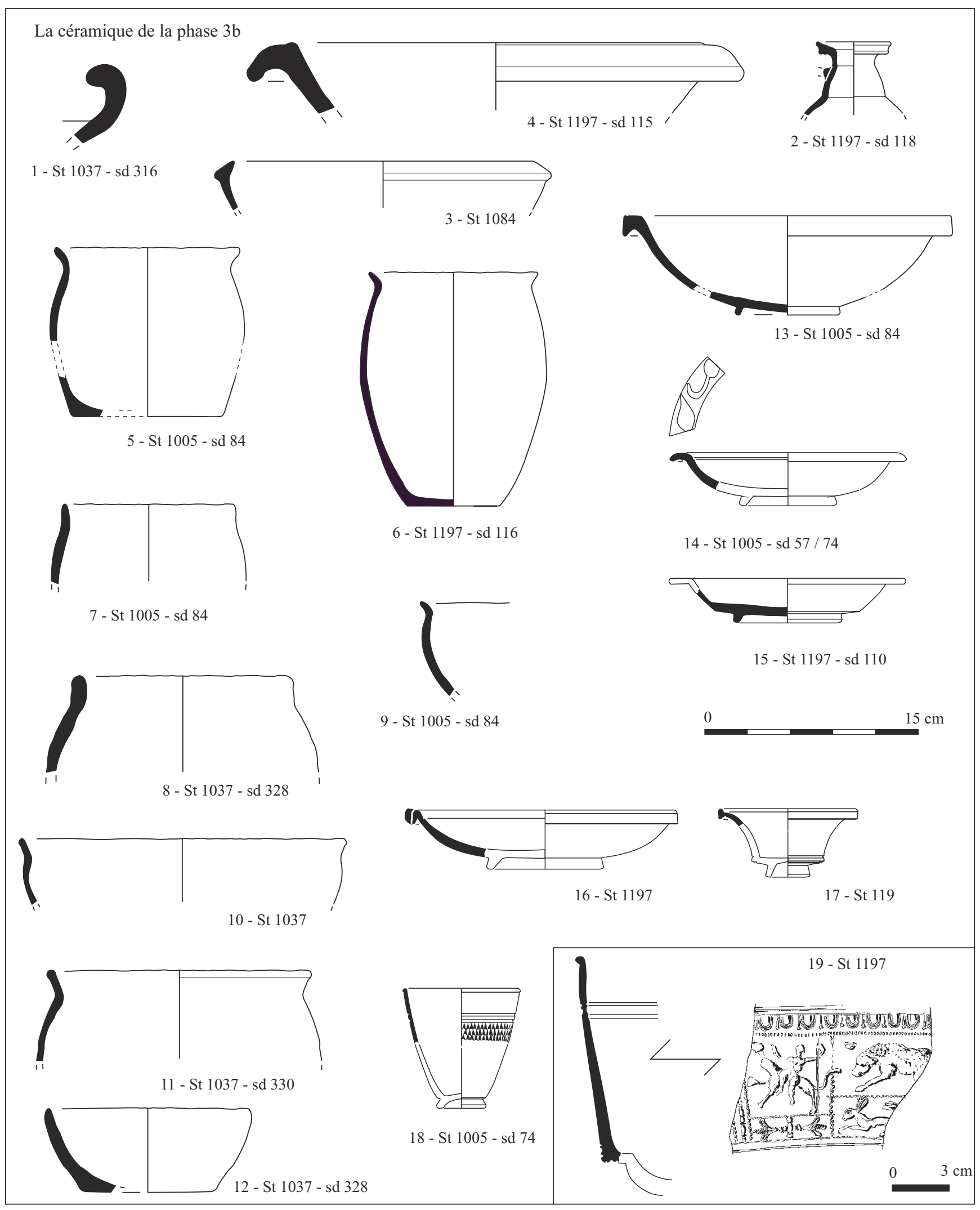

Figure 27 : Bonchamp-lès-Laval (53), la céramique de la phase $3 \mathrm{~b}$.

Figure 27: The pottery from phase 36. 


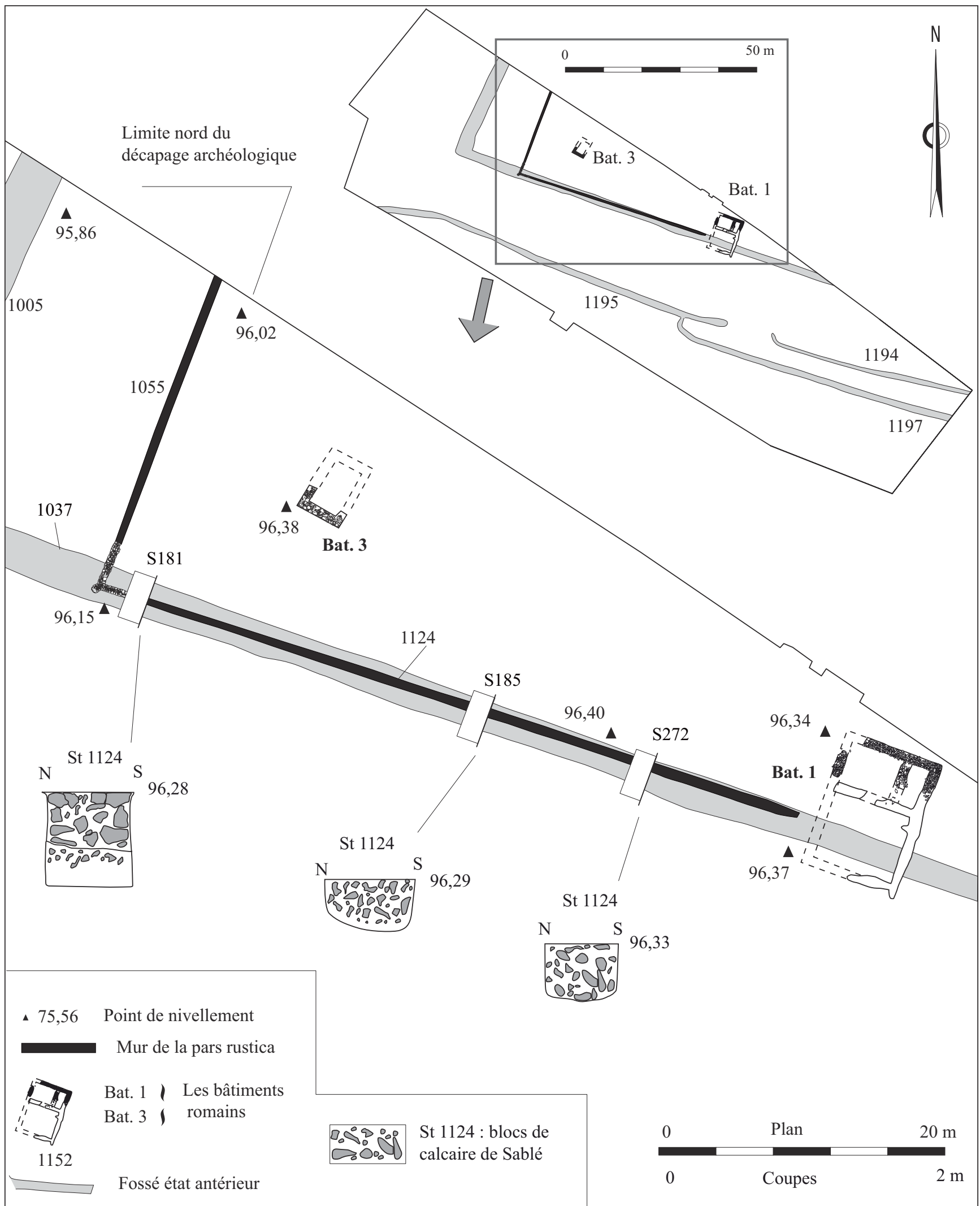

Figure 28 : Bonchamp-lès-Laval (53), plan des structures de la phase 4 et relevés de quelques coupes effectuées dans le mur sud, St 1124. Figure 28: Plan of structures in phase 4 and some of the sections carried out in the south wall, St 1124. 


\section{Le mur St 1055/1124: l'angle sud-ouest de la pars rustica}

Cet angle de la pars rustica est matérialisé par deux segments de murs perpendiculaires et jointifs : le premier, St 1055 (longueur : 23,5 m), est orienté NNE/SSO, tandis que le second, St 1124, (longueur : 51,7 m), est orienté ESE/ ONO (fig. 28). Le mur sud, St 1124 (largeur : 0,5/0,6 m; profondeur : 0,65/0,72 mètre à l'ouest, $0,36 / 0,45 \mathrm{~m}$, à l'est), creusé dans le comblement supérieur du fossé St 1037, s'arrête verticalement à 1 mètre du bâtiment $\mathrm{B} 1$, ménageant ainsi un passage piétonnier. Les fondations sont constituées de petits blocs de calcaire de Sablé. Dans son tiers ouest, elles sont surmontées d'un radier, constitué de blocs de calcaire de dimensions plus importantes et aux arêtes moins vives que dans les couches inférieures. Ce radier est lié par un mortier de chaux de teinte orangée. Le mur ouest, St 1055, est creusé pour partie dans le fossé St 1037 et pour partie dans le substrat schisteux, où il est à peine visible (profondeur : 1 ou $2 \mathrm{~cm}$ ). L'angle du mur, un peu plus fermé qu'un angle droit, est relativement bien conservé. Il se caractérise à son angle extérieur par un élément maçonné $(0,5 \times 0,5 \mathrm{~m})$, à la remarquable extrémité arrondie (fig. 29 et 30).

\section{Le bâtiment rectangulaire $B 1$}

Ce bâtiment $\mathrm{B} 1$ est déterminé par des murs et des tranchées de récupération (fig. 29). Les manques restitués, l'ensemble figure un bâtiment de plan rectangulaire $(7,1 \times 9,8 \mathrm{~m}$; surface : 69,6 mètres carrés). Sur son aire interne sont esquissés les espaces E1, E2 et E3 (d'une surface respective de 27,4, 10,7 et 3,6 mètres carrés). Les tranchées de fondation sont comblées de blocs de calcaire de Laval (profondeur : 0,06 à $0,12 \mathrm{~m}$; largeur : de 0,65 à $0,72 \mathrm{~m}$ ). Son interprétation peut être liée à son emplacement au sein de la villa. Ce bâtiment B1, placé à l'extrémité sud de la pars rustica, non loin de l'entrée de la phase précédente, au débouché du cheminement St 1194/1195/1197 (fig. 28, haut), et proche de l'hypothétique axe de symétrie nord-sud de la villa, pourrait être le logement du gardien. Les espaces E1 et E2 définissent des espaces de vie, le dernier, E3, au plan rectangulaire allongé, signalant éventuellement une cage d'escalier.

\section{Un bâtiment au plan incomplet : B3}

Le bâtiment B3 est matérialisé par l'extrémité sud d'une petite construction (largeur : 3,25 m), détruite en partie au nord (fig. 29). Le matériau mis en œuvre est le calcaire de Sablé, le seul autre utilisé est représenté par un bloc de quartz filonien, d'origine locale. Son emplacement au sein de la pars rustica le place au sein des bâtiments de l'exploitation agricole.

\section{Lìnstrumentum antique (fig. 31) (S. R.)}

Pour la période romaine, les domaines domestique et personnel sont les moins représentés. On note pour le premier, un couteau en fer de type Manning Q22 [1] à emmanchement à douille (Manning, 1985), une lame fragmentée [3] (non représentée) et un tesson d'un récipient en verre [4] (ni identifié ni représenté). L'emmanchement à douille pour le couteau [1] est moins courant que celui à soie; il équipe cependant des exemplaires couvrant tout le Haut Empire. Le second domaine comprend trois fibules en alliage cuivreux. Un exemplaire de type Feugère 14b1b [15] (Feugère, 1985), dit de "Langton-Down ", illustre une production courante, diffusée sur l'ensemble du territoire romain entre 15 av. et 70 apr. J.-C. Elle est associée à la fibule [16], proche du type Feugère 14a, datée de la période augusto-tibérienne. La fibule [17], de type Feugère 27a, peu fréquente, caractérise la période autour du changement d'ère. Ces fibules constituent un ensemble chronologique cohérent et homogène. Le domaine de la construction (immobilier) est mis en évidence par des éléments d'huisserie, agrafes, crochet avec plaque de fixation [27] et fragments de ferrures. Les clous en fer se rapportent à la menuiserie et à l'huisserie plutôt qu'à la charpenterie. Le domaine économique offre pour une part une image de cultures vivrières tournées vers les céréales avec une extrémité de volant (faucille) [6] et un fragment informe de meule rotative en grès roussard [11] (non représenté); pour une autre part, le travail du bois avec un fragment de lame de scie [8] et un petit ciseau droit [9]. Les indices d'une métallurgie du fer sont matérialisés par des scories essentiellement présentes dans le comblement supérieur du fossé St 1005/1037, ainsi que par deux scories de forge en calotte issues du même fossé.

\section{LES MATÉRIAUX GÉOLOGIQUES DU SITE GAULOIS ET ANTIQUE : IDENTIFICATION ET PROVENANCE (V. D.)}

\section{Méthodologie}

Cent seize échantillons ont été prélevés sur le terrain et dans trois carrières proches du site. Ils ont été inventoriés et identifiés pétrographiquement par observation macroscopique à l'œil nu et à l'aide d'une loupe à fort grossissement. Cette étude s'est accompagnée d'une recherche des affleurements et carrières environnants et d'un dépouillement des données cartographiques. 


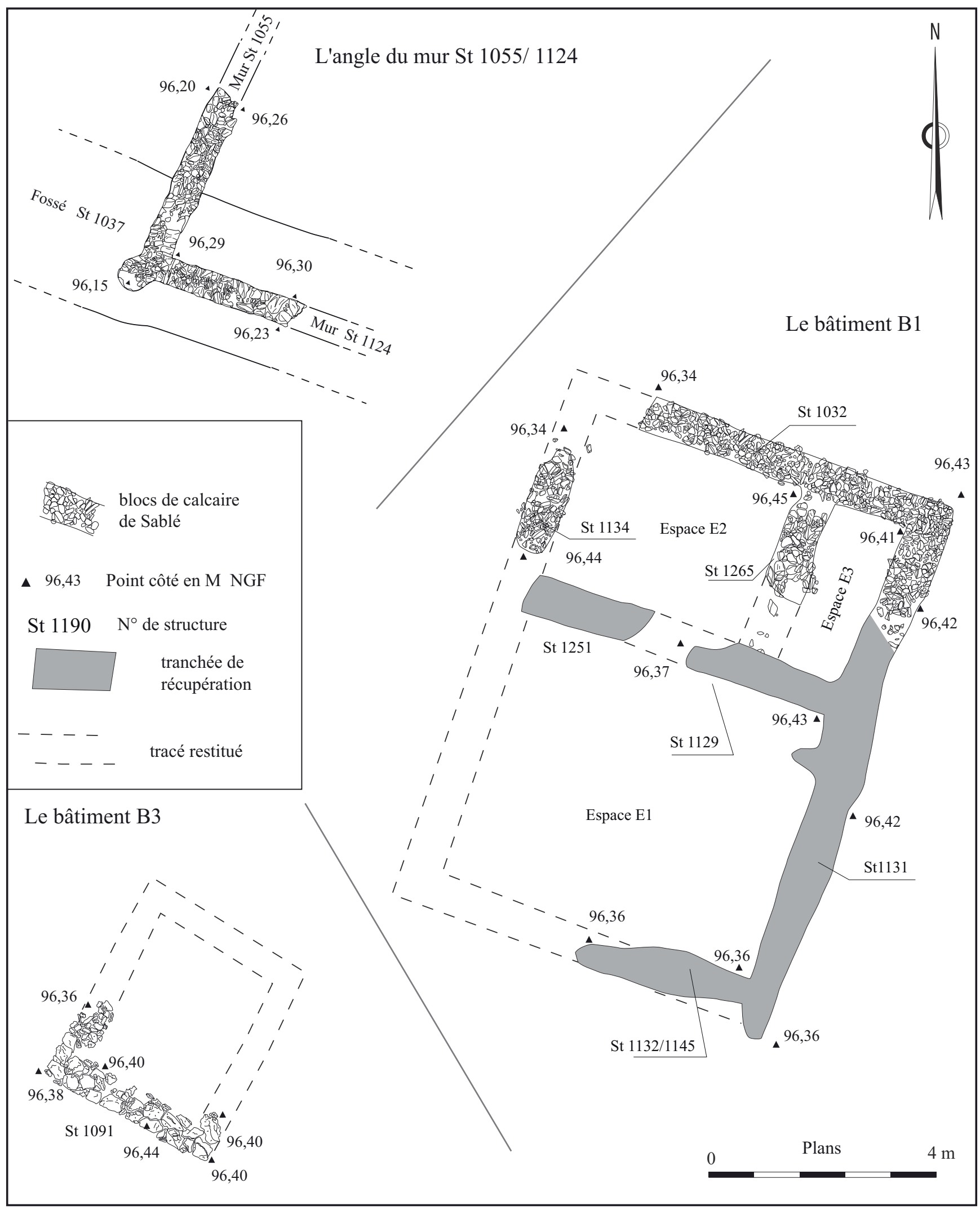

Figure 29 : Bonchamp-lès-Laval (53), phase 4, relevés de détail de l'angle sud-ouest de la pars rustica, du bâtiment B1 et du bâtiment B3. Figure 29: Phase 4, detail plan of the south west angle of the pars rustica, building B1 and building B3. 


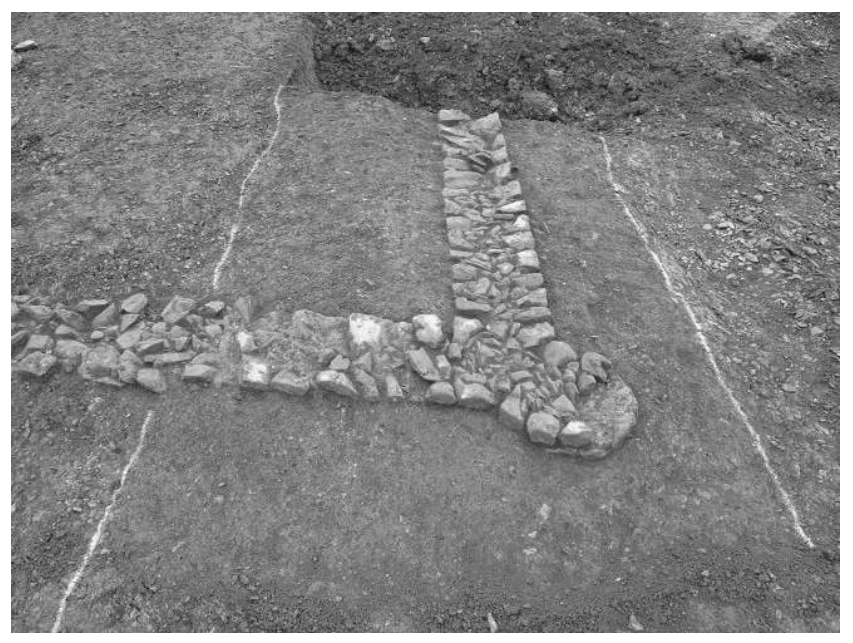

Figure 30 : Bonchamp-lès-Laval (53), phase 4, l'angle sud-ouest de la pars rustica de la villa St 1055/1124 (les côtés nord et sud du fossé St 1037 sont surlignés) (vue prise vers l'est, cliché Benoît Bazoge - INRAP).

Figure 30: Phase 4, the south-west corner of the pars rustica, St 1055/1124, (view taken looking to the east; photograph Benoit Bazoge, INRAP).

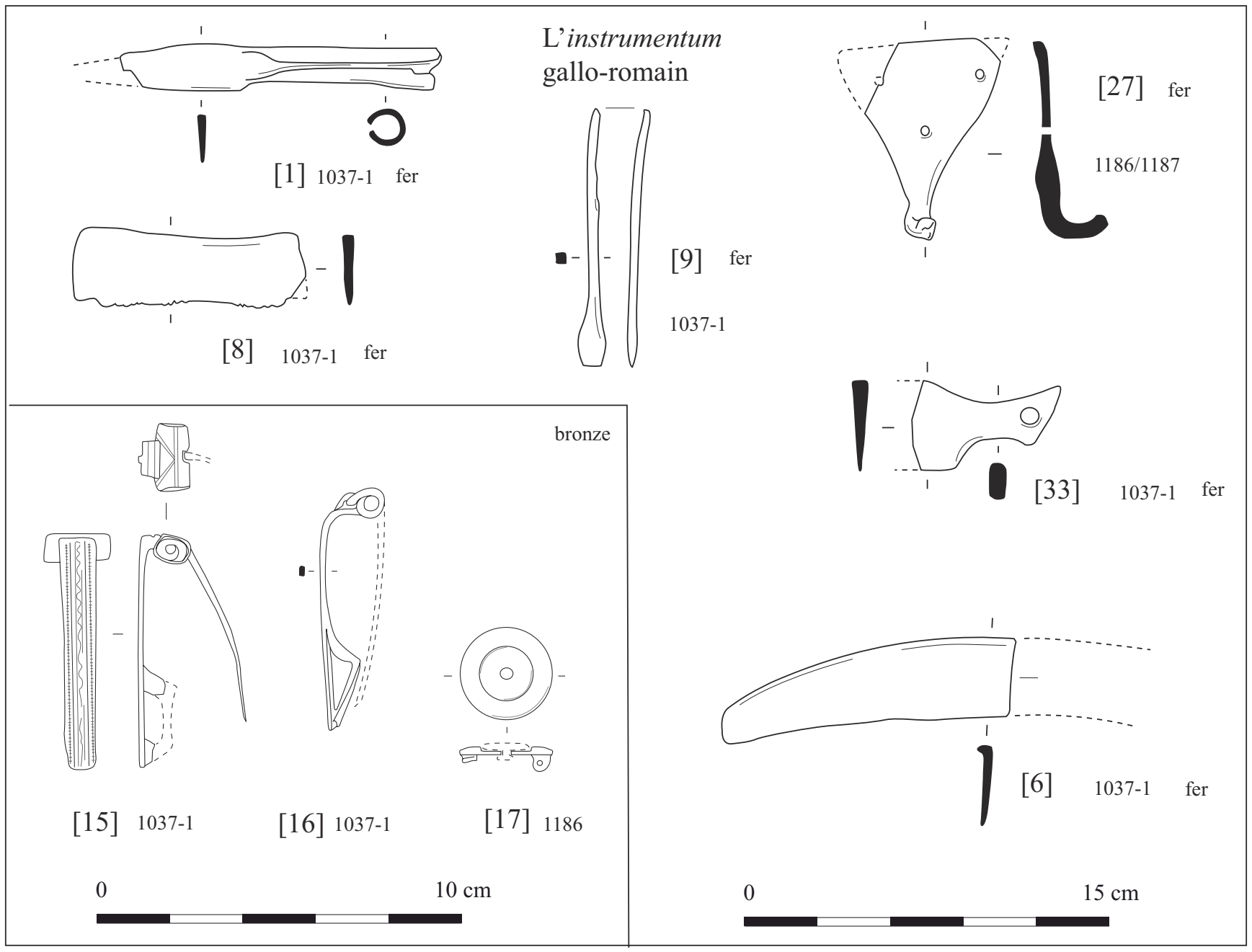

Figure 31 : Bonchamp-lès-Laval (53), l'instrumentum gallo-romain. Figure 31: The Gallo-Roman instrumentum. 


\section{Les matériaux disponibles à l'affleurement sur le site archéologique}

Le substrat est rapporté à la Formation des Schistes de Laval (h2c-3) (Carbonifère). Au niveau du décapage, le faciès le plus abondant correspond aux schistes ardoisiers à débit en fines plaquettes, assez altérés et redressés quasi à la verticale. Ces schistes, où des filons de quartz ont été identifiés, alternent parfois avec un faciès massif, presque gréseux ou très oxydé et ferrugineux.

\section{Identification des matériaux découverts dans les structures}

L'unique échantillon de quartz filonien blanc-brunâtre, d'aspect laiteux, est issu du bâtiment antique B3 (fig. 29). Ainsi, malgré sa relative disponibilité au niveau de quelques filons repérés sur le site, ce matériau n'a pas fait l'objet d'extraction. L'échantillon correspondrait à un prélèvement ponctuel, d'un matériau immédiatement disponible.

Le substrat schisteux du site n'a pas été utilisé pour la construction. Seul un disque de schiste ardoisier [28] (fig. 23), mal daté (gaulois?), a été découvert dans le mur ouest de la pars rustica (St. 1055).

Les échantillons de granite sont des fragments de meules, issus du fossé gaulois St 1229 [13], de la structure St 1121 [12] et du bâtiment gaulois B17. Ces granites sont assez grossiers avec des grains de trois à quatre millimètres, de teinte claire, brun-rosé, avec du mica blanc dominant, mais aussi du mica noir, avec présence d'oxydations et de plagioclases. Ils seraient de même type, à l'exception des fragments altérés par la chauffe de B17. Par comparaison, sur le site de La Carie 2 à Entrammes (Deloze, 2012), l'étude des meules gauloises et antiques a révélé trois types de granite, un granite clair à deux micas, un granite clair à mica blanc et un granite grossier à mica noir. Ainsi, seul le premier granite clair à deux micas d'Entrammes apparaît semblable au granite grossier à deux micas, à muscovite dominante, de Bonchamp-lès-Laval.

Les quatre-vingts échantillons de calcaire constituent l'essentiel du corpus prélevé. Ils offrent des teintes allant du gris, gris clair, gris foncé, gris-brun, au gris-bleuté, bleu-gris, ou une teinte marbrée gris-blanc-violacé à gris-bleu-blancorangé. À l'extérieur, l'aspect est crayeux, alors qu'à l'intérieur, il est plus foncé. On remarque des coquilles fossiles et de nombreux lits millimétriques de calcite blanchâtre. Au niveau des matériaux calcaires retrouvés dans les murs de la pars rustica (St 1124), se distinguent dans les fondations un premier faciès aux arêtes vives (blocs débités), le second aux angles arrondis (blocs bruts), est utilisé dans leur partie supérieure. Les dix-huit échantillons des grès relèvent de cinq types différents :
- Le type 1 est un grès grossier à ciment ferrugineux. $S^{\prime} y$ rattachent les fragments de meules [11] de St 1037, [14] de St 1229, et les échantillons de la structure St 1309 (B 20);

- Le type 2 est un grès assez fin, très oxydé et un peu ferrugineux, de teinte rouille à noirâtre-gris, friable. Il est issu du fossé St 1152 de la phase 1;

- Le type 3 est un grès à grain moyen de teinte rouilleorangé, à grains de quartz gris assez bien visibles à l'œil nu et contenus dans un ciment orangé-rouille non ferrugineux. Ils ont été découverts dans le fossé gaulois puis antique St 1037, la fosse artisanale St 1309, le poteau St 1297 du bâtiment gaulois $\mathrm{B} 11$;

- Le type 4 est un grès caractéristique aux teintes assez bariolées, souvent violacées, et à grain assez fin qui a été découvert dans la structure gauloise St 1297 (B11 : fig. 15);

- Le type 5 : ce grès très fin de teinte brun clair à quelques paillettes de muscovite et des minéraux noirâtres correspond à un lissoir retrouvé dans la structure gauloise St 1066 (B 11) [5] (fig. 23).

La première constatation concernant ces grès est qu'ils ont été découverts dans des structures de la période gauloise, exception faite pour la structure St 1037, la seule structure antique a avoir révélé un matériau gréseux [14], dont nous ne savons pas s'il est en position secondaire ou non. Un seul silex, de teinte brun-gris aux bords rougeâtres, sans cortex visible, mais à quelques points d'oxydation rouille, de datation préhistorique, se retrouverait en position secondaire dans le fossé gaulois St 1152.

\section{Provenance des différents matériaux exogènes au site}

Les trois massifs de granodiorites signalés à $8 \mathrm{~km}$ au nord du site appartiennent au batholite mancellien fini-cadomien (Ménillet et al, 1988). Le plus important est celui d'AlexainDeux-Evailles, aux affleurements arénisés. Le caractère porphyroïde du granite, la présence de muscovite plus abondante que la biotite, ainsi que de plagioclases, privilégierait l'hypothèse d'une origine depuis la partie sud-orientale du massif d'Alexain-Deux-Évailles, pour les granites des meules gauloises de Bonchamp-lès-Laval.

Les affleurements de calcaires les plus proches constituent une bande d'orientation nord-ouest/sud-est depuis Louverné jusqu’à Soulgé-sur-Ouette (Mary et al., 1989) : il s'agit du calcaire de Sablé (h1b-2b) rattaché au Tournaisien supérieur-Viséen supérieur (Carbonifère). Les points d'extraction pour les périodes récentes se situent sur les communes de Louvigné et d'Argentré. Ils sont localisés aux alentours des fours à chaux de La Gare à Louverné (à $1,5 \mathrm{~km}$ au NO du site), et des anciens fours à chaux du Bas Mont Roux (à 4 km à l'ESE du site) et des Rochers (à $4 \mathrm{~km}$ au SE du site) à Argentré. Ces affleurements ont pu être exploités dès l'époque antique. 
La présence proche de plusieurs types de grès est révélée par les cartes géologiques d'Evron (Mary et al., 1989) et de Meslay-du-Maine (Ménillet et al., 1988). Il apparaît que les cinq types mis en évidence se rattacheraient aux formations ci-dessous :

- Les types 1 et 2 appartiennent aux grès ferrugineux et roussards qui s'observent à la surface du socle ou dans les sables attribués au Pliocène (Ménillet et al., 1988). Les plus proches affleurements de ces grès ferrugineux et roussards plio-quaternaires sont situés à $17 \mathrm{~km}$ au sud-est du site;

- Le type 3, se rattacherait aux grès tertiaires. Il s'agit de grès lustrés résiduels souvent éolisés (Ménillet et al., 1988), retrouvés en blocs isolés ou inclus dans une formation superficielle sablo-limono-argileuse. Ils sont connus autour d'Entrammes, à $12 \mathrm{~km}$ au sud, puis ensuite un peu plus loin vers Meslay-du-Maine, à $17 \mathrm{~km}$ au sud-est;

- Le type 4 se rattacherait à l'un des niveaux fins du grès de Sainte-Suzanne de teinte gris-violacé (Cambrien moyen), qui affleure à partir de Montsûrs, à $14 \mathrm{~km}$ à l'est du site;

- Le type 5 apparaît proche du grès du Gahard (Dévonien) : celui-ci présente des alternances de grès ferrugineux et de quartz-wackes, d'où aurait pu être extrait le matériau ayant servi à fabriquer ce lissoir. La cartographie signale quelques affleurements, entre Louverné et Soulgésur-Ouette, soit de 2 à $12 \mathrm{~km}$ de Bonchamp.

Les premiers affleurements jurassiques de silex se placent plus à l'est et au sud-est, entre Loué et Sablé et au niveau de la vallée de la Sarthe. L'artefact siliceux correspondrait au silex gris des calcaires du Bajocien (J1), qui apparaissent à une quarantaine de kilomètres de Bonchamp-lès-Laval (Clément et al., 1987).

\section{Conclusion sur les matériaux utilisés} sur le site du Grand-Coudray

Parmi les matériaux immédiatement disponibles au niveau du substrat du site, seul un échantillon de quartz filonien a été reconnu dans un des murs du site antique, correspondant à un acte ponctuel et opportuniste. Les schistes n'ont pas été utilisés à l'époque antique pour la construction. Si l'on compare les matériaux provenant des structures antiques et gauloises, on constate que sur les premières ont été mis en œuvre en grande majorité des matériaux calcaires pour la construction de leurs murs, (tabl. 4), alors que les deuxièmes ont révélé plus de variété avec des éléments en grès et en granite surtout pour des activités artisanales (meules, lissoirs...), et de manière plus anecdotique, du lignite. Pour la période gauloise, deux structures seulement ont livré du calcaire de Sablé : ponctuellement dans le comblement de l'ensemble B20 (fig. 20, St 1309) et de manière importante pour la construction du cheminement SD17/St17 (fig. 7).

\section{5. ÉLEMENTS DE DISCUSSION ${ }^{6}$}

Le site archéologique du Grand-Coudray à Bonchamplès-Laval (Mayenne) s'il est incomplet au nord, présente les points forts que sont des enclos et des axes de circulation remarquablement pérennes du $\mathrm{II}^{\mathrm{e}}$ siècle av. J.-C. au $\mathrm{II}^{\mathrm{e}}$ siècle apr. J.-C. Les vestiges laténiens sont exceptionnellement accompagnés de dix-neuf bâtiments et structures à poteaux. Le peu de céramique laténienne est compensé par un instrumentum diversifié. Les surfaces fouillées en 2012, mesurant 2990 et 1188 mètres carrés pour les phases 1 et 2 ,

\begin{tabular}{|l|c|c|}
\hline Type de matériau & Nombre d'échantillons dans les structures gauloises & Nombre d'échantillons dans les structures antiques \\
\hline Calcaire de Sablé & 6 & 62 \\
\hline Granite d'Alexain & 4 & 2 \\
\hline Grès roussard (type 1) & 5 & \\
\hline Grès ferrugineux (type 2) & 1 (phase 1) & \\
\hline Grès résiduels tertiaires (type 3) & 6 & \\
\hline Grès de Ste-Suzanne (type 4) & 3 & 1 \\
\hline Grès du Gahard (type 5) & 1 & 1 (remanié) \\
\hline Quartz filonien & 1 (phase 1) & \\
\hline Schiste ardoisier & 1 (remanié) & \\
\hline Lignite & & \\
\hline Silex du Bajocien & & \\
\hline
\end{tabular}

Tableau 4 : Bonchamp-lès-Laval (53), répartition des différents types de matériaux dans les structures gauloises et antiques. Table 4: Distribution of the different types of materials in Gallic and Gallo-Roman structures.
6. Pour les éléments de comparaison bibliographiques, nous nous sommes dans la mesure du possible limités à une approche locale ou régionale. 
correspondent à plus ou moins $20 \%$ des surfaces encloses d'origine, Il en est de même pour la phase 3 , tandis que pour la phase 4 , un chiffre de l'ordre de $10 \%$ est envisagé. Ces données sont utilement complétées, essentiellement pour la phase 1, et plus ponctuellement pour la phase 3, par les résultats du diagnostic de mars 2014 (Guillier, 2014a).

\section{Des enclos et un axe de circulation remarquablement pérennes}

De la phase 1 à la phase 4, les enclos se superposent, sont concentriques ou adoptent les mêmes orientations, tandis que sur la partie sud du site leurs systèmes d'accès sont pérennes ou se superposent (fig. 5, 11, 24 et 28). Comme point de comparaison privilégié, relevons le site des Natteries à Cholet (Maine-et-Loire) où l'enclos de la phase 2, aux fossés peu larges, est remplacé lors de la phase 3 par un enclos resserré aux fossés défensifs (Maguer et al., 2009). Régionalement, les évolutions morphologiques répondent à plusieurs modèles. L'enclos même ne bouge pas ou peu, mais des partitions internes sont notées; il est aussi reconnu l'adjonction d'un nouvel enclos aux Genâts à Fontenay-leComte (Vendée). Autre type d'évolution, au premier enclos s'ajoute un second, concentrique, par exemple aux Nouis à Coulans-sur-Gée (Sarthe; Chevet et al., 2013). Le modèle défini aux Natteries et peut-être à Bonchamp-lès-Laval, avec une réduction de la taille des enclos, semble peu commun (Maguer et al., 2009).

Les résultats du diagnostic de 2014 confirment que l'enclos de la phase 2 du Grand-Coudray voit sa surface nettement réduite par rapport à la phase 1 et ce par l'abandon des fossés St 5, 6 et 7.

À Bonchamp-lès-Laval, les différences de largeur et de profondeur des fossés entre les phases 1 et 2 (fig. 5, 6 et 11), à l'image des Natteries, soulignent un caractère particulier. La profondeur des fossés au sud atteint à la phase 1 à peine 0,50 mètre, alors qu'une synthèse récente fait état d'une profondeur moyenne de 1,47 mètre (Maguer et al., 2009), seul le côté Est présente une profondeur ponctuellement plus marquée (de 1,70 à $2 \mathrm{~m}$ : fig. 6), mettant en valeur une entrée monumentalisée par un portail, le caractère ostentatoire n'est donc établi que sur la façade orientale de l'établissement. Cette relation entre des fossés présentant des dimensions plus importantes qu'ailleurs sur le site et des porches ou portails a déjà été relevée : au Chemin-Chevaleret à Échiré (Deux-Sèvres) et à La Tesserie à Couesmes (Indre-et-Loire; Quilliec et al., 2011, p. 282). Les matériaux extraits des fossés peuvent être placés en talus à l'intérieur de l'enclos, à l'extérieur ou bien encore régalés : pour la phase 1 les indices sont peu concluants, sauf pour le fossé Est, celui marqué par un portail d'entrée dont l'emplacement, à l'extérieur de l'enclos, précise l'implantation du talus à cet endroit. L'emplacement du bâtiment B12 auprès du fossé interne St 1152 irait dans ce sens également (fig. 5 et 12). Ce fossé interne St 1003/1152 de la phase 1 est agrandi à l'est (fig. 5, étape 1/b : St 1044), annonçant la phase 2 , où les fossés sont profonds de 1 mètre au sud et de 1,80 mètre à l'ouest. Les volumes de matériaux extraits des fossés sont maintenant multipliés par quatre au sud et douze à l'ouest. Les zones vides de structures le long du côté interne de l'enclos de la phase 2 marquent, de manière classique, l'emplacement en négatif d'un talus (fig. 12). Sa largeur devait varier de 2 à 4 mètres pour une hauteur de 1,5 à 2,3 mètres environ. Nous relevons le caractère ostentatoire de ce fossé, qui n'offre toutefois pas le caractère défensif de celui des Natteries.

Une partition interne sur le côté occidental des deux enclos (fig. 5 et 11), isole des espaces de 20 et 18 mètres de large pour les phases 1 puis 2. Cette partition s'observe par exemple sur le site du Panveau à Aron dans le nord de la Mayenne (Valais, 2007).

L'enclos de la phase 2 est encore en usage à la phase 3 au début du $\mathrm{I}^{\mathrm{er}}$ siècle apr. J.-C. (fig. 24) et son comblement final (phase 3b), est recoupé sur une bonne partie de sa longueur à la phase 4 par le mur sud de la pars rustica de la villa, St 1124 (fig. 28), pérennisant les axes anciens jusqu'au $\mathrm{II}^{\mathrm{e}}$ siècle. Régionalement mentionnons à Beaucouzé, dans le Maine-et-Loire (Maguer et al., 2009), le site de La Corbinière, dont des fossés laténiens sont encore en usage jusqu'à la fin des julio claudiens : le site de Bonchamp-lèsLaval fait régionalement exception avec ces superpositions, et ce en opposition avec la Picardie, où les réoccupations antiques de sites gaulois sont nombreuses (Gaudefroy, 2011 : $20 \%$ de superpositions exactes y sont relevées).

L'axe de circulation au sud de l'enclos de la phase 1 (fig. 5), mis en évidence sur 170 mètres, perdure à la phase 2 (fig. 11). Un parallèle régional à cet axe de circulation est présent sur la ferme indigène des Grandes Versennes à Sainte-Hermine dans le sud de la Vendée (Nillesse, 1994).

L'époque antique voit une réorganisation de l'accès sud (fig. 24) avec le creusement d'un ensemble complexe de fossés et la construction du bâtiment porche B2. Pour la villa de la phase 4, l'accès sud à la pars rustica serait contrôlé par le bâtiment B1 (fig. 28) et par les fossés de la phase 3, encore en activité. Ces cheminements, voiries ou accès sont courants en Picardie (Gaudefroy, 2011). Régionalement, un axe de circulation a été déterminé aux Natteries (Maguer $e t$ al., 2009), au sud de l'enclos monumental. Un chemin de 10 mètres de large daté du $\mathrm{II}^{\mathrm{e}}$ siècle av. J.-C. a été fouillé à 100 mètres du site de La Chapellière à La Chaize-le-Vicomte en Vendée (Guérin, 2003). Leurs largeurs varient de 3 à 8 mètres, mais celle la plus communément mesurée varie de 
5 à 6 mètres (Gaudefroy, 2011), à l'image de Bonchamp-lèsLaval (phase 1) où le fossé sud est distant de l'enclos de 6 à 6,5 mètres (fig. 5). Enfin, un tel empilement stratigraphique sur un établissement rural laténien puis antique est peu mis en évidence régionalement.

\section{Inventaire, typologie et analyse fonctionnelle des bâtiments et constructions à poteaux}

Sur vingt-trois constructions à poteaux mises au jour, dix-neuf sont laténiennes et quatre sont antiques. Pour la période laténienne, les structures découvertes peuvent être scindées en deux ensembles, en fonction de leur taille et de la complexité de leurs plans. Dans un premier temps nous relevons les structures matérialisées par les cinq groupes suivants :

Le Groupe 1 est représenté par les deux états du portail de la phase 1 : les structures B22 et B23 (tabl. 5; fig. 7), mais sans que nous puissions déterminer une chronologie entre eux (tabl. 1). Ces portails sont associés à une interruption du tracé du fossé Est de l'enclos externe. Cet ensemble est assez peu commun régionalement. Dans le département de la Mayenne citons un point de comparaison sur le site de La Chesnaie à La Selle-Craonnaise (Tourneur, 2006). Régionalement, mentionnons les sites de Beauséjour à Angers dans le Maine-et-Loire (Pétorin, 2010, p. 14-15), de La Métairie de La Lande à Guérande en Loire-Atlantique (Bellanger, 2011) ou bien encore des Grandes Versennes à Sainte-Hermine en Vendée (Nillesse, 1994). Plus éloignés, citons les deux portails d'accès successifs du site antique de Saint-Marcel dans le Morbihan (Le Boulanger et al., p. 177-180) et le portail de La Tène finale de La Tesserie à Couesmes en Indre-et-Loire (Quilliec et al., 2011, p. 195 et 206/207). Mentionnons également des portails sur les sites gaulois du Corps de Garde à La-CelleSaint-Avant (Indre-et-Loire), de La Pièce de Chameul à Chevilly (Loiret), du Chemin-Chevaleret à Échiré (DeuxSèvres), des Limandes à Cergy ou de La Ferme des Fontaines à Herblay (Val-d'Oise; Quilliec et al., 2011, p. 281-283). Généralement, les entrées des enclos sont constituées d'une simple interruption dans les fossés les limitant (Maguer et al., 2009, p. 431-432), les exemples en sont relativement nombreux régionalement. Des entrées en chicane peuvent aussi avoir été aménagées, mais il s'agirait d'éléments liés à la gestion du cheptel. Parfois ces portails peuvent être liés à une passerelle, à l'image du site du Grand Paisilier à Pouillé en Vendée (Nillesse, 1994, p. 282-283). Les portails d'entrée sont matérialisés par des fosses d'implantation de poteaux le plus souvent positionnés à l'intérieur des enclos, au niveau des talus les bordant à cet endroit (Maguer et al., 2009, p. 432; Bellanger, 2011; Quilliec et al., 2011...). C'est en cela que nos exemples mayennais diffèrent puisque situés à l'extérieur de l'enclos, éléments indiquant que les talus étaient externes. En Picardie, la présence d'entrées de ce type serait liée à des sites de rang hiérarchique élevé (Gaudedroy, 2011, p. 237). Autre élément particulièrement intéressant à noter, la présence de l'empierrement St 17, en calcaire de Sablé (fig. 7), matérialisant un cheminement de 2 mètres de largeur environ, passant dans l'interruption entre les fossés St 6 et 7 et desservant l'aire interne du premier établissement gaulois. Ce chemin est là aussi un type de vestige peu reconnu régionalement.

Le Groupe 2 est représenté par la seule structure B20 (tabl. 5), apparentée aux bâtiments élevés sur deux poteaux porteurs de faittière (Maguer, 2005), présentant parfois sur leur aire, de petites fosses.

Le Groupe 3 est matérialisé par le seul bâtiment B6 (tabl. 5) : deux rangées de poteaux parallèles, appariés deux à deux, déterminent un plan à nef unique, régionalement bien reconnu. Notre exemplaire mayennais, d'une surface restreinte, s'apparente aux structures annexes : remise, stockage, artisanat...

Le Groupe 4 est mis en évidence par les deux bâtiments à deux nefs que sont B4 et B5 (tabl. 5). Ce type de structure se retrouve communément dans l'ouest de la Gaule.

Le Groupe 5 regroupe les greniers surélevés à quatre poteaux bien reconnus régionalement : les bâtiments $\mathrm{B} 7$, B8/9, B10 et B15 (tabl. 5). Citons pour la Mayenne, Le Clos-Henry à Château-Gontier (Valais et al., 2008) avec trois greniers, Le Panveau à Aron (Valais, 2007) avec sept greniers, La Chesnaie à La Selle-Craonnaise (Tourneur, 2006) avec une occurrence. Enfin, le vicus laténien d'Entrammes de La Tène C2/D1 en a livré quatre-vingt-deux (Guillier, 2009).

Dans un second temps nous présentons les trois groupes suivants qui relèvent de structures aux dimensions plus importantes et aux plans plus complexes (tabl. 6).

Le Groupe 6 est mis en évidence par les bâtiments B17, B18 et B19 (tabl. 6), aux plans quadrangulaires sans poteau intermédiaire ni trace visible d'accès. Difficiles à restituer et éventuellement incomplets au nord (fig. 19), s'agit-il de structures simples ou porteuses à l'image du groupe 7 (Quilliec et al., 2011) ? Régionalement, de telles structures sont au nombre de huit à La Bleure à Cholet (Maine-etLoire; Sandoz, 1999), où leur répartition inciterait à y déceler des habitats.

Le Groupe 7 englobe les constructions élevées sur module porteur : ce sont les bâtiments B11; B12 et B217 (tabl. 6). Ce type de bâtiment à porche (Laurelut et al., 2004) est identifié de la Bretagne continentale à la Bohème (Laurelut

7. Et éventuellement B13. 


\begin{tabular}{|c|c|c|c|c|}
\hline Bâtiment & $\begin{array}{l}\text { Chronologie, } \\
\text { groupe typologique }\end{array}$ & Dimensions, surface & Plan & Remarques \\
\hline $\begin{array}{l}\text { B4 } \\
\text { (fig. 8) }\end{array}$ & $\begin{array}{l}\text { laténien, phase } 1 \\
\text { GR4 }\end{array}$ & $\begin{array}{l}4,5 \times 5,5 \mathrm{~m} \\
\text { surface } 25 \mathrm{~m}^{2}\end{array}$ & & Bâtiment à deux nefs \\
\hline $\begin{array}{l}\text { B5* } \\
\text { (fig. 8) }\end{array}$ & $\begin{array}{l}\text { laténien, phase } 1 \\
\text { GR4 }\end{array}$ & $3,5^{*} \times 4,2 \mathrm{~m}$ & & $\begin{array}{l}\text { Structure incomplète au } \\
\text { nord }\end{array}$ \\
\hline $\begin{array}{l}\text { B6* } \\
\text { (fig. 13) }\end{array}$ & $\begin{array}{l}\text { Laténien, phase } 2 \\
\text { GR3 }\end{array}$ & $\begin{array}{l}2,6 \times 4 \mathrm{~m} \\
\text { surface } 10,5 \mathrm{~m}^{2}\end{array}$ & & $\begin{array}{l}\text { Un poteau restitué au } \\
\text { nord-est }\end{array}$ \\
\hline $\begin{array}{l}\text { B7 } \\
\text { (fig. 13) }\end{array}$ & $\begin{array}{l}\text { laténien, phase } 2 \\
\text { GR5 }\end{array}$ & $\begin{array}{l}2,5 \times 2,5 \mathrm{~m} \\
\text { surface } 6,25 \mathrm{~m}^{2}\end{array}$ & & $\begin{array}{l}\text { Structure de type grenier à } \\
\text { quatre poteaux }\end{array}$ \\
\hline $\begin{array}{l}\text { B8 } \\
\text { (fig. 14) }\end{array}$ & $\begin{array}{l}\text { laténien, phase } 2 \\
\text { GR5 }\end{array}$ & $\begin{array}{l}2,4 \times 2,5 \mathrm{~m} \\
\text { surface } 6 \mathrm{~m}^{2}\end{array}$ & & $\begin{array}{l}\text { Structure de type grenier à } \\
\text { quatre poteaux } \\
\text { (recoupé par B9) }\end{array}$ \\
\hline $\begin{array}{l}\text { B9 } \\
\text { (fig. 14) }\end{array}$ & $\begin{array}{l}\text { laténien, phase } 2 \\
\text { GR5 }\end{array}$ & $\begin{array}{l}2 \times 2,5 \mathrm{~m} \\
\text { surface } 5 \mathrm{~m}^{2}\end{array}$ & & $\begin{array}{l}\text { Structure de type grenier à } \\
\text { quatre poteaux } \\
\text { (recoupe B8) }\end{array}$ \\
\hline $\begin{array}{l}\text { B10 } \\
\text { (fig. 14) }\end{array}$ & $\begin{array}{l}\text { laténien, phase } 2 \\
\text { GR5 }\end{array}$ & $\begin{array}{l}1,5 \times 2 \mathrm{~m} \\
\text { surface } 3 \mathrm{~m}^{2}\end{array}$ & & $\begin{array}{l}\text { Structure de type grenier à } \\
\text { quatre poteaux }\end{array}$ \\
\hline $\begin{array}{l}\text { B15 } \\
\text { (fig. 18) }\end{array}$ & $\begin{array}{l}\text { laténien, phase } 2 \\
\text { GR5 }\end{array}$ & $\begin{array}{l}2 \times 2 \mathrm{~m} \\
\text { surface } 4 \mathrm{~m}^{2}\end{array}$ & & $\begin{array}{l}\text { Structure de type grenier à } \\
\text { quatre poteaux }\end{array}$ \\
\hline $\begin{array}{l}\text { B20 } \\
\text { (fig. 20) }\end{array}$ & $\begin{array}{l}\text { laténien, phase } 2 \\
\text { GR2 }\end{array}$ & $\begin{array}{l}2 \times 1 \mathrm{~m} \\
\text { surface } 2 \mathrm{~m}^{2}\end{array}$ & & 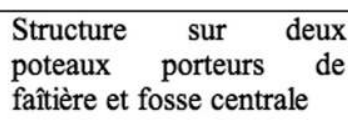 \\
\hline $\begin{array}{l}\text { B22 } \\
\text { (fig. 7, } \\
\text { tabl. 1) }\end{array}$ & $\begin{array}{l}\text { laténien, phase } 1 \\
\text { GR1 }\end{array}$ & Longueur : $6,20 \mathrm{~m}$ & & Portail, état 1 \\
\hline $\begin{array}{l}\text { B23 } \\
\text { (fig. 7, } \\
\text { tabl. 1) }\end{array}$ & $\begin{array}{l}\text { laténien, phase } 1 \\
\text { GR1 }\end{array}$ & Longueur: $5,6 \mathrm{~m}$ & & Portail, état 2 \\
\hline
\end{tabular}

Tableau 5 : Bonchamp-lès-Laval (53), les principales données relatives aux bâtiments et constructions sur poteaux gaulois du site, les groupes 1 à 5 (dimensions exprimées en mètres, Longueur x largeur; surfaces en mètre carré; * : données incomplètes). Les plans sont orientés au nord.

Table 5: The main data relating to the Gallic buildings on the site, the groups 1 to 5 (dimensions expressed in metres, Length $x$ width; surfaces in $m 2$; *: approximate or incomplete data).

et al., 2004) et bien renseigné régionalement (tabl. 7), où des sous-types s'y distinguent en fonction de l'absence d'accès visible (7/A), du nombre d'accès, un (7/B) ou deux (7/C). Une éventuelle variante (7/D) présenterait un plan allongé, avec un module porteur à six poteaux (B13). Il est noté que le type $7 / \mathrm{C}$, à deux entrées opposées, est assez peu commun (Maguer, 2005, p. 336).

Cet inventaire reflète la présence de modules (tabl. 7). Le plus petit d'environ 5 mètres de côté, est présent à Vivoin; le module moyen, de 6 à 8 mètres de côté, le plus courant, est bien représenté à Bonchamp-lès-Laval, tandis que le grand module, supérieur à 8 mètres, est référencé aux Natteries. Il serait possible de corréler ces modules au rang hiérarchique des sites. En revanche, certains sites n'en présentent pas, parfois malgré un grand nombre de bâtiments, comme à La Bleure, qui offre en revanche des bâtiments du groupe 6 (faut-il en ce sens rapprocher les groupes 6 et 7 ?). Qu'abritaient-ils? Les avis sont partagés. Certains auteurs n'écartent aucune possibilité "Usage domestique et/ou artisanal, résidence aristocratique, lieu de stockage, hangar, remise, lieu de culte, lieu de réunion " (Deffresigne-Tikonoff, 2005, p. 145); est aussi avancée la possibilité d'étables ou d'écuries (Quilliec et al., 2011, p. 286). Certains points sont variables, les largeurs des accès signalées comme constantes, autour de 1,80 à 2,50 mètres (Laurelut et al., 2004), varient autour de 1 mètre à Bonchamp-lès-Laval. Une importante largeur peut se conjuguer avec des fonctions de stockage, d'étable ou d'écurie. La présence de deux accès marquerait des fonctions différenciées (type 7/C). Régionalement, il s'agit de bâtiments en situation privilégiée au sein des enclos, 


\begin{tabular}{|c|c|c|c|c|}
\hline Bâtiment & $\begin{array}{l}\text { Chronologie, } \\
\text { groupe typologique }\end{array}$ & Dimensions, surface & Plan & Remarques \\
\hline $\begin{array}{l}\text { B11 } \\
\text { (fig. 15) }\end{array}$ & $\begin{array}{l}\text { laténien, phase } 2 \\
\text { GR7 }\end{array}$ & $\begin{array}{l}5 \times 7,5 \mathrm{~m} \\
\text { surface } 33 \mathrm{~m}^{2} \text { env. }\end{array}$ & & $\begin{array}{l}\text { Structure sur module } \\
\text { porteur. Surface estimée } \\
64 \mathrm{~m}^{2} \text { env. }\end{array}$ \\
\hline $\begin{array}{l}\text { B12 } \\
\text { (fig. 9) }\end{array}$ & $\begin{array}{l}\text { laténien, phase } 1 \\
\text { GR7 }\end{array}$ & $\begin{array}{l}6,3 \times 7 \mathrm{~m} \\
\text { surface } 30 \mathrm{~m}^{2} \text { env. }\end{array}$ & & $\begin{array}{l}\text { Structure sur module } \\
\text { porteur. Surface estimée } \\
70 \mathrm{~m}^{2} \text { env. }\end{array}$ \\
\hline $\begin{array}{l}\text { B13 } \\
\text { (fig. 16) }\end{array}$ & $\begin{array}{l}\text { laténien, phase } 2 \\
\text { GR7 (?) }\end{array}$ & $\begin{array}{l}4 / 4,5 \times 7,5 \mathrm{~m} \\
\text { surface } 31 \mathrm{~m}^{2} \text { env. }\end{array}$ & & $\begin{array}{l}\text { Bâtiment à pans coupés } \\
\text { ou sur module porteur }\end{array}$ \\
\hline $\begin{array}{l}\text { B14* } \\
\text { (fig. 17) }\end{array}$ & $\begin{array}{l}\text { laténien, phase 1 ? et } \\
\text { phase 2 } \\
\text { GR8 }\end{array}$ & $\begin{array}{l}7 \times 8,8 \mathrm{~m} \\
\text { surface } 61,6 \mathrm{~m}^{2} \\
\text { env.* }\end{array}$ & & $\begin{array}{l}\text { Structure sur module } \\
\text { porteur }\end{array}$ \\
\hline $\begin{array}{l}\text { B17* } \\
\text { (fig. 19) }\end{array}$ & $\begin{array}{l}\text { laténien, phase } 2 \\
\text { GR6 }\end{array}$ & $\begin{array}{l}4 \times 5,5 \mathrm{~m} \\
\text { surface } 22 \mathrm{~m}^{2}\end{array}$ & & $\begin{array}{l}\text { Structure sur module } \\
\text { porteur? recoupe B18 }\end{array}$ \\
\hline $\begin{array}{l}\text { B18* } \\
\text { (fig. 19) }\end{array}$ & $\begin{array}{l}\text { laténien, phase } 2 \\
\text { GR6 }\end{array}$ & $\begin{array}{l}4 \times 5,5 \mathrm{~m} \\
\text { surface } 22 \mathrm{~m}^{2}\end{array}$ & & $\begin{array}{l}\text { Structure sur module } \\
\text { porteur? recoupé par } \\
\text { B17 }\end{array}$ \\
\hline $\begin{array}{l}\text { B19* } \\
\text { (fig. 19) }\end{array}$ & $\begin{array}{l}\text { laténien, phase } 2 \\
\text { GR6 }\end{array}$ & $\begin{array}{l}3,8 \times 5,5 \mathrm{~m} \\
\text { surface } 20,9 \mathrm{~m}^{2}\end{array}$ & & $\begin{array}{l}\text { Structure sur module } \\
\text { porteur? }\end{array}$ \\
\hline $\begin{array}{l}\text { B21 } \\
\text { (fig. 21) }\end{array}$ & $\begin{array}{l}\text { laténien, phase } 2 \\
\text { GR7 }\end{array}$ & $\begin{array}{l}3,5 \times 5,7 \mathrm{~m} \\
\text { surface } 21 \mathrm{~m}^{2} \text { env. }\end{array}$ & & $\begin{array}{l}\text { Structure sur module } \\
\text { porteur. Surface estimée } \\
54 \mathrm{~m}^{2} \text { env. }\end{array}$ \\
\hline
\end{tabular}

Tableau 6 : Bonchamp-lès-Laval (53), les principales données relatives aux bâtiments gaulois du site, les groupes 6 à 8 (dimensions exprimées en mètres, Longueur x largeur; surfaces en mètre carré; ${ }^{*}$ : données incomplètes). Les plans sont orientés au nord.

Table 6: The main data relating to the Gallic buildings on the site, the groups 6 to 8 (dimensions expressed in metres, Length $x$ width; surfaces in $m 2$; *: approximate or incomplete data).

quand il ne s'agit pas des plus importants : c'est l'argument principal développé pour un habitat (Laurelut et al., 2004; Maguer et al., 2013). Ce groupe 7 présente des configurations variées, mais toujours un plan centré avec quatre gros poteaux formant module porteur et des parois rejetées, ces dernières se distinguent par la présence de quelques poteaux et de porches d'accès qui en témoignent (fig. 9, 15 et 21), ou bien par la présence d'une sablière basse périphérique, à l'image des sites d'Aron, Carquefou, Chemillé, Cholet, Saint-Fulgent et Yvré-l'Évêque (tabl. 7) (Maguer, 2005, p. 334, 335 et 338). Ces caractéristiques techniques définissent un type architectural homogène, caractéristique de la fin de l'indépendance gauloise (Quilliec et al., 2011, p. 285). L'ensemble de ces éléments permet essentiellement deux propositions de restitution, "L'une, minimaliste, correspond à un bâtiment avec un toit en pavillon ", tandis que la seconde présente un étage, élevé sur les poteaux porteurs (Maguer, 2005, p. 339), hypothèses reprises récemment pour des bâtiments comparables découverts aux confins des territoires des Andes, des Cénomans et des Turons (Quilliec et al., 2011, p. 288). La seconde hypothèse est dans plusieurs cas mise en cause par la trop longue portée des sablières hautes (Quilliec et al., 2011, p. 286). À notre sens, cette seconde hypothèse ne pourrait être également valable qu'à la condition que les couvertures soient dans des matériaux non périssables de type tuile, lauze... Ce qui n'est démontré 


\begin{tabular}{|c|c|c|c|c|c|c|}
\hline Commune & Site & $\begin{array}{l}\text { Dépar- } \\
\text { tement }\end{array}$ & $\begin{array}{c}\text { Dimensions } \\
\text { du module } \\
\text { porteur }\end{array}$ & $\begin{array}{c}\text { Dimensions } \\
\text { en plan de la } \\
\text { sablière }\end{array}$ & $\begin{array}{l}\text { Dimensions } \\
\text { restituées }\end{array}$ & $\begin{array}{c}\text { Références, remarques, } \\
\text { [sous-type] }\end{array}$ \\
\hline Aron & Le Panveau & 53 & $4,5 \times 5$ & $7 \times 9,50$ & sans objet & Valais, 2007 [7/A] \\
\hline Aubigny & La Pâquerie & 85 & $4 \times 5$ & sans objet & $\begin{array}{l}7,10 \times 9,40 \\
\text { env. }\end{array}$ & Pétorin, 2013, bat. I.a [7/C] \\
\hline Aubigny & La Pâquerie & 85 & $5,50 \times 7,50$ & sans objet & $9,80 \times 13$ env. & $\begin{array}{l}\text { Pétorin, 2013, bat. I.b } \\
\text { [7/C (augustéen)] }\end{array}$ \\
\hline Bonchamp-lès-Laval & Le Grand Coudray & 53 & $3,5 \times 5$ & sans objet & $5 \times 7,5$ env. & $\mathrm{n}^{\circ} \mathrm{B} 11[7 / \mathrm{C}]$ \\
\hline Bonchamp-lès-Laval & Le Grand Coudray & 53 & $4 \times 6,5$ & sans objet & $6,3 \times 7$ env. & $\mathrm{n}^{\circ} \mathrm{B} 12[7 / \mathrm{B}]$ \\
\hline Bonchamp-lès-Laval & Le Grand Coudray & 53 & $4,5 \times 7,5$ & sans objet & $7 \times 9$ env. & $\mathrm{n}^{\circ} \mathrm{B} 13[7 / \mathrm{D}(?)]$ \\
\hline Bonchamp-lès-Laval & Le Grand Coudray & 53 & $3,5 \times 4,5$ & sans objet & $6,5 \times 8,3$ env. & $\mathrm{n}^{\circ} \mathrm{B} 21[7 / \mathrm{B}]$ \\
\hline Carquefou & Le Clouet & 44 & $4 \times 5$ & $\begin{array}{l}10 \times 11 \text { en- } \\
\text { viron }\end{array}$ & sans objet & $\begin{array}{c}\text { Le Goff, 1998, } \\
\text { Maguer et al., 2013, [7/B ?] }\end{array}$ \\
\hline Chemillé & La Boirie & 49 & $5 \times 7$ & $9 \times 13$ & sans objet & Maguer, $2005[7 / \mathrm{B}]$ \\
\hline Cholet & $\begin{array}{l}\text { La Chauvelière- } \\
\text { Neuve }\end{array}$ & 49 & $4,5 \times 6,8$ & $9,5 \times 13$ & sans objet & $\begin{array}{c}\text { Maguer, } 2005 \\
\text { [7/B (La Tène - augustéen) }\end{array}$ \\
\hline Cholet & Les Natteries & 49 & $5,50 \times 6,10$ & sans objet & $\begin{array}{l}11,5 \times 11,5 \\
\text { env. }\end{array}$ & Maguer, 2005, no E46 [7/C] \\
\hline Cholet & Les Natteries & 49 & $4 \times 5,5$ & $10 \times 12,5$ & sans objet & $\begin{array}{c}\text { Maguer, 2005, } \mathrm{n}^{\circ} \mathrm{E} 49 \\
\text { foyer central, }[7 / \mathrm{B}]\end{array}$ \\
\hline Fontenay-Le-Comte & Le Coq Hardy & 85 & $3,5 \times 5,5$ & sans objet & $6,5 \times 8,6$ env. & Nillesse, 2006, $n^{\circ}$ E13 [7/C] \\
\hline Fontenay-Le-Comte & Les Genâts & 85 & $4,2 \times 6$ & sans objet & $7,2 \times 9,5$ env. & Nillesse, 1997, nº E6 [7/B] \\
\hline Fontenay-Le-Comte & Les Genâts & 85 & $4 \times 4$ & sans objet & $6,2 \times 7,2$ env. & Nillesse, 1997, nº E7 [7/B] \\
\hline Fontenay-Le-Comte & Les Genâts & 85 & $4,5 \times 4,7$ & sans objet & 6,8 x 7,2 env. & Nillesse, 1997, nº E24 [7/B] \\
\hline Fontenay-Le-Comte & Les Genâts & 85 & $4 \times 4,5$ & sans objet & $6,8 \times 8$ env. & Nillesse, 1997, nº E26 [7/B] \\
\hline Fontenay-Le-Comte & Les Genâts & 85 & $4 \times 5$ & sans objet & $7,5 \times 9,5$ env. & Nillesse, $1997, \mathrm{n}^{\circ}$ E28 [7/C] \\
\hline La Chaize-le-Vicomte & La Chapellière & 85 & $4,7 \times 6$ & sans objet & 7,7 x 9,5 env. & $\begin{array}{c}\text { Maguer, 2005; Guérin, } 2003 \\
\text { Foyer central, [7/B] }\end{array}$ \\
\hline Marcé & Hélouine & 49 & $4,8 \times 5$ & sans objet & $9 \times 9$ env. & Nillesse, 2003, nº E14 [7/B] \\
\hline Marcé & Hélouine & 49 & $5,1 \times 11,5$ & sans objet & $9 \times 14$ env. & Nillesse, 2003, nº E7 [7/D] \\
\hline Marcé & Le Deffroux & 49 & $4,5 \times 4,5$ env. & sans objet & $7,50 \times 9$ env. & Nillesse, 2003, n ${ }^{\circ}$ E5 [7/B] \\
\hline Saint-Fulgent & La Petite Valinière & 85 & $3,5 \times 4$ & $9 \times 10$ & sans objet & Guérin, 2001, nº E1 [7/A?] \\
\hline Vivoin & La Gaudine & 72 & $3 \times 3$ & sans objet & $4 \times 4$ env. & $\begin{array}{l}\text { Guillier et al., 2006, no B1 } \\
{[7 / \mathrm{B}]}\end{array}$ \\
\hline Vivoin & La Gaudine & 72 & $3,5 \times 4$ & sans objet & 4,5 x 5 env. & $\begin{array}{c}\text { Guillier et al., 2006, no B2 } \\
{[7 / \mathrm{B}]}\end{array}$ \\
\hline Vivoin & La Pièce de Bildoux & 72 & $3 \times 3$ & sans objet & $4,2 \times 5$ env. & Maguer et al., 2003 [7/B] \\
\hline Yvré-L’Evêque & Le Grand Aunay & 72 & $4,5 \times 5,5$ & $10 \times 14$ & sans objet & Maguer et al., 2013 [7/A?] \\
\hline
\end{tabular}

Tableau 7 : quelques exemples de constructions élevées sur module porteur dans la région des Pays-de-la-Loire (dimensions exprimées en mètres).

Table 7: Some examples of constructions built on a load-bearing module in the region of the Pays-de-la-Loire (dimensions expressed in metres).

dans aucun des cas évoqués. La nature en matériau périssable de leur couverture, tel le chaume, pose des problèmes d'étanchéité au niveau de la toiture inférieure à l'endroit de la retombée d'eau s'écoulant de la toiture supérieure (une couverture de bardeau poserait-elle moins de problèmes à ce niveau?).
Le Groupe 8 est représenté par le seul bâtiment B14 (fig. 17, tabl. 6), une construction puissante, au plan complexe. Nous retenons un point de comparaison sur le site de La Tesserie à Couesmes en Indre-et-Loire (Quilliec et al., 2011, p. 287290, bâtiment A2). Le nombre et la variété de bâtiments et de constructions à poteaux laténiens sont exceptionnels dans 
la région. Les sites comparables, tous également exceptionnels, sont en nombre limité : La Bleure, Les Natteries et Les Genâts. Les deux derniers, aristocratiques, sont éloignés typologiquement de Bonchamp-lès-Laval. Celui de La Bleure, réinterprété (Maguer et al., 2009), serait un regroupement, au sein d'un vaste enclos de quatre ou cinq unités d'habitats disposés autour d'un espace commun. L'enclos de la phase 2 de Bonchamp-lès-Laval se rapprocherait plus en ce sens du site de La Bleure que d'une ferme indigène.

Les bâtiments gallo-romains sont peu représentés, avec quatre occurrences (tabl. 8). Deux relèvent de la phase 3 : B2 et B24, marquant une ferme gallo-romaine (fig. 24 et 25), et deux de la phase $4: B 1$ et B3, qui accompagnent un nouveau type d'habitat : la villa (fig. 28 et 29).

\section{Céramique et instrumentum : un catalogue restreint}

\section{La céramique gauloise et romaine (E. C.)}

Le mobilier céramique est peu abondant (tabl. 9). Celui de la phase 1 (fig. 10) signe une occupation de La Tène C2/ D1. La céramique de la phase 2 (fig. 22), attribuée à La Tène
D1/D2, est parfois redéposée dans les niveaux postérieurs; ces deux ensembles étant accompagnés de quelques importations d'amphores vinaires Dressel 1 italiques (14\% du nombre de restes). La céramique antique permet de déceler l'étendue chronologique de l'occupation, avec des dépôts étagés de la première moitié du i ${ }^{\text {er }}$ siècle (fig. 26/phase 3a) à la fin du $\mathrm{I}^{\text {er }}$ ou au début du $\mathrm{II}^{\mathrm{e}}$ siècle (fig. 27/phase 3b). Elle se caractérise par un nombre singulièrement élevé de céramiques modelées, phénomène que nous allons maintenant évoquer.

Présentation de la céramique non tournée du Haut-Empire

Sa proportion varie de $55 \%$ dans la phase $3 a$ (tabl. 2) à $64 \%$ du NMI dans la phase $3 \mathrm{~b}$ (tabl. 3). Nous nous interrogeons sur sa place dans le vaisselier domestique et sur l'homogénéité de son répertoire commercialisé en territoire Diablinte. Sa part au sein des vaisseliers locaux se situe autour de 10 à $20 \%$ du NMI du I $^{\text {er }}$ siècle jusqu'au II $^{e}$ siècle apr. J.-C. Des quantités comparables sont constatées dans le département de la Mayenne à La Petite Coyère à La Cropte (11 \% du NMI, Ledauphin, à paraître), à La Chesnaie à

Tableau 8 : Bonchamplès-Laval (53), les principales données relatives aux bâtiments antiques du site (dimensions exprimées en mètres, Longueur x largeur; surfaces en mètre carré; * : plan non significatif). Les plans sont orientés au nord.

Table 8: The main data relating to the GalloRoman buildings on the site (dimensions expressed in metres, Length $x$ width; surfaces in m2; *: plan not significant).

\begin{tabular}{|c|c|c|c|c|}
\hline Bâtiment & Chronologie & Dimensions, surface & Plan & Remarques \\
\hline $\begin{array}{c}\text { B1 } \\
\text { (fig. 29) }\end{array}$ & $\begin{array}{l}\text { gallo-romain } \\
\text { phase } 4\end{array}$ & $\begin{array}{l}7,1 \times 9,8 \mathrm{~m} \\
\text { surface } 69,5 \mathrm{~m}^{2}\end{array}$ & & $\begin{array}{l}\text { Bâtiment secondaire } \\
\text { (logement du } \\
\text { gardien?) }\end{array}$ \\
\hline $\begin{array}{c}\text { B2 } \\
\text { (fig. 25) }\end{array}$ & $\begin{array}{l}\text { gallo-romain } \\
\text { phase } 3\end{array}$ & $\begin{array}{l}9,4 \times 12,2 \mathrm{~m} \\
\text { surface } 114,7 \mathrm{~m}^{2}\end{array}$ & & Bâtiment porche? \\
\hline $\begin{array}{c}\text { B3* } \\
\text { (fig. 29) }\end{array}$ & $\begin{array}{l}\text { gallo-romain } \\
\text { phase } 4\end{array}$ & $3,5 \times \mathrm{X} \mathrm{m} * *$ & & $\begin{array}{l}\text { Bâtiment secondaire } \\
\text { (agricole ?) }\end{array}$ \\
\hline $\begin{array}{c}\text { B24 } \\
\text { (fig. 25) }\end{array}$ & $\begin{array}{l}\text { gallo-romain } \\
\text { phase } 3\end{array}$ & $\begin{array}{l}3 / 3,5 \times 4 / 5 \mathrm{~m} \\
\text { surface } 14 \mathrm{~m}^{2}\end{array}$ & & $\begin{array}{l}\text { Bâtiment annexe à } \\
\text { B2, appentis... }\end{array}$ \\
\hline
\end{tabular}

\begin{tabular}{|c|c|c|c|c|}
\cline { 2 - 5 } \multicolumn{1}{c|}{} & NR* & $\%$ & NMI $^{* *}$ & 16 \\
\hline Phase 1 & 126 & 7,7 & 23 & 1,5 \\
\hline Phase 2 & 147 & 9 & 65 & 30,2 \\
\hline Phase 3a & 298 & 18,2 & 111 & 51,6 \\
\hline Phase 3b & 1062 & 65,1 & 215 & 100 \\
\hline TOTAUX & 1633 & 100 & & \\
\hline
\end{tabular}

Tableau 9 : Bonchamp-lès-Laval (53), comptage de la céramique par grandes phases chronologiques, exprimé en nombre de restes $\left(^{*}\right.$ : $\mathrm{NR}$ ) et en Nombre minimum d'individus (** : NMI) ainsi qu'en pourcentage.

Table 9: Pottery totals by major chronological phases, expressed in number of remains $\left({ }^{*}: N R\right)$, in minimum number of individuals ( ${ }^{* *}:$ NMI) and as a percentage. 
La Selle-Craonnaise (22,5 \% du NMI, Coffineau 2006a), à La Carie II à Entrammes (entre 9 et $16 \%$, Coffineau, 2006b) et à La Garde à Moulay-Mayenne (Valais, 2005). Cette céramique peut atteindre $40 \%$ du NMI et $59 \%$ des tessons à La Davière à Mayenne (Valais, 2005). Exceptionnellement, à Cossé-le-Vivien, pour la période tibéro-claudienne, le taux est de $5,5 \%$ (Devals, 2004).

Ces vases reprennent les techniques de façonnage et de cuisson laténiennes (Chuniaud et al., 2002), mais n'en copient pas systématiquement les formes. Ces céramiques sont façonnées manuellement, montées par plaques, colombins ou moulées à l'aide d'un gabarit. Elles sont à pâte siliceuse. Une production particulière comporte une pâte vacuolaire, indiquant l'apport de végétaux dans l'argile avant cuisson. Elles peuvent être cuites dans un four ou une fosse aménagée. Les teintes varient du brun, brun-noir au noir uniforme. Enfin, leur surface peut être plus ou moins soigneusement lissée. Il n'est donc pas toujours aisé de les distinguer des productions gauloises.

Cependant, des variantes morphologiques sont observées au cours de la première moitié $\mathrm{du} \mathrm{I}^{\mathrm{er}}$ siècle Des pots à panse tronconique ou "cylindrique " apparaissent. Ils ont un col court et peu marqué et les bords deviennent moins développés, avec des lèvres arrondies (Le Grand-Coudray : fig. 26, $\mathrm{n}^{\circ} 11$ ), plus effilées (Le Grand-Coudray), triangulaires, qui peuvent être droites (Le Grand-Coudray : fig. 26, ${ }^{\text {os }} 8$, et 9). Ces formes plus élancées sont de modules variés avec des diamètres à l'ouverture variant de 8 à $25 \mathrm{~cm}$.

Les formes basses modelées retrouvées dans les contextes gallo-romains précoces sont des jattes à profil «en esse " (La Chesnaie, Le Grand-Coudray : fig. 26, n ${ }^{\circ}$ 15), à paroi oblique (La Chesnaie, La Carie) et à panse hémisphérique (La Chesnaie, Le Grand-Coudray : fig. 26, n ${ }^{\text {os }} 6$ et 14). Ce sont des vases fréquents dans les contextes de La Tène finale. Cependant, certaines jattes ont des variantes qui les différencient du répertoire laténien avec une lèvre oblique plus ou moins déversée (Le Grand-Coudray : fig. 26, $\mathrm{n}^{\circ} 13$ ) et triangulaire (Grand-Coudray).

Le même répertoire modelé se retrouve dans des contextes de la fin du $\mathrm{I}^{\text {er }}$ et du $\mathrm{II}^{\mathrm{e}}$ siècle apr. J.-C. à La Carie II, La Cropte, La Garde et La Davière. Ces céramiques sont à pâte siliceuse de couleur brune ou noire ou contenant de nombreuses vacuoles. Les pots globulaires encore présents ont une lèvre droite peu développée (La Garde). Mais ce sont les pots ayant un profil plus élancés qui deviennent majoritaires vers la fin du $\mathrm{I}^{\text {er }}$ siècle et pendant tout le $\mathrm{II}^{\mathrm{e}}$ siècle. Ils ont une panse plus ou moins tronconique et une lèvre courte, arrondie (La Carie II, La Garde, La Petite Coyère, Le Grand-Coudray : fig. 27, $\mathrm{n}^{\text {os }} 5$ et 6), effilée (La Carie II, La Garde, La Petite Coyère, Le Grand-Coudray) ou triangulaire (La Petite Coyère), qui peut être droite (Le Grand-
Coudray : fig. $27, \mathrm{n}^{\text {os }} 7$ et 8 ) ou rentrante. Les jattes à panse hémisphérique tendent à diminuer (Le Grand-Coudray : fig. $27, n^{\text {os }} 9$ et 10$)$ et celles à paroi oblique sont nombreuses (La Carie II, La Petite Coyère, La Garde, Le GrandCoudray : fig. $27, \mathrm{n}^{\circ} 12$ ). L'impact de la romanisation se manifeste par l'apparition des assiettes et des plats à bord droit ou légèrement rentrant (La Carie II, La Petite Coyère). Ces productions sont typologiquement semblables à celles de Mazières-en-Mauges (Berthaud et al., 2000) et de Jublains (Bocquet et al., 2004). De rares couvercles viennent clore le corpus (La Petite Coyère).

Pouvant parfois être confondue avec la vaisselle de la fin du second âge du Fer, la céramique non tournée du HautEmpire occupe une place prépondérante dans le vaisselier culinaire domestique des établissements ruraux du territoire Diablinte. Il s'agit de céramiques à feu héritées du corpus de la fin du second âge du Fer : pots ovoïdes et globulaires à lèvre simple déversée, jattes à profil "en esse ", à panse oblique. Ce vaisselier est agrémenté d'assiettes et de plats à cuire à la période gallo-romaine. Il s'agit de formes simples, fonctionnelles. Les argiles siliceuses locales et les techniques de modelage, apportent une bonne résistance aux chocs thermiques (Batigne, 1997 et 2001). Cette céramique modelée est le témoin d'un réseau économique local qui ne demande pas une infrastructure aussi importante que celle des ateliers spécialisés aux productions diffusées dans toute la Gaule. Il est possible que ce soit un artisanat saisonnier et plutôt familial, au savoir-faire certain. Un tel réseau économique local se retrouve en territoire Picton avec des productions aux mêmes caractéristiques typologiques et plastiques (Guitton et al., à paraître).

\section{Lìnstrumentum gaulois et romain (S.R.)}

Il est relativement abondant avec trente-sept éléments répartis dans plusieurs domaines (tabl. 10). Ce mobilier, essentiellement ferreux, illustre la continuité de l'occupation du site de La Tène finale (fig. 23) au Haut Empire (fig. 31). Le travail du bois est omniprésent sur le site, un type de matériaux mis en œuvre communément dans l'architecture des bâtiments à une période comme à l'autre. De plus, quelques objets illustrent le niveau social des habitants aux II ${ }^{\mathrm{e}}$ et $\mathrm{I}^{\mathrm{er}}$ siècle av. J.-C., jusqu'à la fin de la période augustéenne avec la présence d'un vase en lignite [29], d'un lingot de fer [7] et de fibules en alliage cuivreux [15 à 17].

\section{ConClusion : un, DEUX, TROIS...}

Sur le site du Grand-Coudray quatre phases principales ont été distinguées pour une durée de vie de près de trois siècles : deux phases pour la période laténienne et deux pour 


\begin{tabular}{|l|c|c|c|c|c|}
\hline Domaines & Préhistoire & La Tène & Gallo-romain & Indéterminé & Totaux \\
\hline Le domaine domestique & & 1 & 3 & 4 \\
\hline Le domaine économique & & 7 & 5 & 12 \\
\hline Le domaine personnel & & & 3 & 3 \\
\hline Le domaine immobilier/charronnerie & & 3 & 7 & 10 \\
\hline Varia & 1 & 2 & 4 & 1 & 8 \\
\hline Totaux & 1 & 13 & 22 & 1 & 37 \\
\hline
\end{tabular}

Tableau 10 : Bonchamp-lès-Laval (53), répartition de l'instrumentum en fonction des domaines de mobilier représentés et de leur chronologie.

Table 10: Distribution of the instrumentum as a function of the nature and chronology of the artefacts represented.

la période antique. Le fil conducteur qui les relie les unes aux autres, déjà en place à la phase 1 , marquera la trame de l'occupation sur toute sa durée : c'est au nord un enclos fossoyé (phases 1 à 3) puis maçonné (phase 4), qu'accompagnent au sud un axe de circulation, pérenne sur les quatre phases. Les éléments de la phase 1, issus de la fouille de 2012 (Guillier, 2014b), sont utilement complétés par les découvertes faites lors d'un récent diagnostic (Guillier, 2014a), à savoir un second enclos à l'est et au sud, enclos pourvu d'un portail monumental et qui ceinturerait l'enclos interne St 1152/1003.

Les enclos souvent de grandes dimensions, supérieures à 200 mètres pour la phase 1 , classent ce site dans la moyenne supérieure des occupations régionales (Maguer et al., 2009). Les fossés de la phase 1 sont peu marqués, sauf à l'est, contrairement à la phase 2 où, soulignés d'un talus massif, ils présentent des largeurs et profondeurs qui trahiraient un changement de statut, avec une empreinte plus ostentatoire que défensive. Le passage à l'époque antique voit l'enclos de la phase 2 toujours ouvert mais presque comblé et le tracé du cheminement sud modifié, mais leurs grands traits sont toujours là. Avec la création de la villa, dont nous avons mis au jour seulement un angle de la pars rustica, les fossés d'enclos sont définitivement abandonnés mais leurs tracés influent encore directement les nouvelles structures (fig. 30). Cette superposition, parfois exacte, de structures laténiennes puis antiques marque un fait que certains auteurs qualifient d'héritage ou de filiation (Gaudefroy, 2011).

La mise en valeur de l'accès est de l'enclos à la phase 1 ainsi que la quantité et la qualité des bâtiments et constructions à poteaux des phases laténiennes détonnent quelque peu localement et régionalement. Même si une bonne partie du site est hors de l'emprise de la fouille, il est possible d'envisager, au moins pour la phase 2 , du fait de la nature des bâtiments fouillés et leur organisation, la présence d'un habitat collectif (hameau, espace communautaire, habitat regroupé...) à l'image de celui de La Bleure près de Cholet
(Maguer et al., 2009), ce qui souligne d'un trait fort les singularités du site. Élément marqué d'un trait un peu plus fin, le mobilier est suffisamment caractérisé pour abonder dans la nature domestique de l'occupation. Sont dessinés en capitales quelques points particuliers : la présence d'un demi-produit en fer ou currency-bar et d'un fragment de vase en lignite ensevelis dans le fossé de l'enclos de la phase 1, qui posent déjà la question du statut (plutôt aisé?) du site. Ces deux objets s'inscrivent en caractères gras au sein d'un instrumentum laténien peu abondant. L'instrumentum antique est marqué par trois fibules de bronze tandis que le mobilier céramique associé présente un trait singulier avec une proportion remarquable régionalement de céramique modelée.

Enfin, que savons-nous du domaine dans lequel s'inscrit la villa? Jacques Naveau, en 1986, a eu le mérite incontesté d'émettre l'hypothèse de la présence d'une villa au nord du bourg de Bonchamp-lès-Laval et de proposer, à partir de l'observation des différents cadastres, la géométrie du domaine qui lui serait lié (fig. 2). Ce fundus présenterait un plan trapézoïdal régulier (largeur : 1,8 km; hauteur : de 1,8 à $2,2 \mathrm{~km}$ ), d'une surface d'environ 360 hectares. Sa situation, compte tenu des dimensions moyennes d'une villa antique et à partir des éléments exhumés, coïncide avec l'idée que nous pouvons nous faire de sa localisation. Le lieu-dit Martigné, serait basé sur le cognomen " Martinus » ou un des nombreux dérivés formés sur le nom divin " Mars ", mais n'excluons pas la racine celtique " mart-» (Evans, 1967, p. 365-366), qui a donné Martellus, Martella... En dernier lieu, qu'en est-il de la chronologie de la villa? Celle mise en évidence est tronquée par rapport à une réalité supposée : seule une fraction du site a été mise au jour, qui ne nous aide pas pour établir la chronologie générale du site. Dernier point, dans une charte du x $x^{e}$ siècle (Angot, 1910, vol. 4, p. 524), il est mentionné une seigneurie du Coudray. Pourrait-il s'agir du lieu-dit Le Grand-Coudray tout proche du site, matérialisant peut-être ainsi la continuité du domaine antique? 


\section{Remerciements}

Nous tenons à remercier toutes les personnes qui ont collaboré au bon déroulement des opérations: Guy San Juan et Nelly Le Meur (SRA); Claude Le Potier et Pierre Chevet (INRAP). Remercions l'équipe de l'Inrap qui s'est particulièrement investie dans la fouille de ce site, dans des conditions de travail souvent éprouvantes: Benoit Bazoge, Alain Béton, Pauline Carvalho, Marc Dumas, Fabrice Edin, Claire Goubely, Serge Kosseev, Dominique Guimard et Fabien Le Roux. Enfin, l'Inrap qui nous a accordé vingt jours pour la rédaction de cet article.

\section{Bibliographie}

Angot A., I 9 Io - Dictionnaire historique, topographique et bibliographique de la Mayenne, 4 vol., Laval, Goupil, 1900-1910, $3569 \mathrm{p}$.

BARON A., 2012 - Provenance et circulation des objets en roches noires ("lignite") à l'âge du Fer en Europe celtique (VIII - $I^{e r}$ siècle av. J.-C.), Oxford, BAR, IS, 2453, 2012.

Barthelemy-Sylvand C., Chambon M.-P. et Couvin F., 2005 "Les amphores ligériennes en région Centre (Carnute, Turon, Biturige), de la période augustéenne à la fin du Haut-Empire », in Société française d'étude de la céramique antique en Gaule, Actes du Congrès de Blois, p. 159-176.

Batigne C., I 997 - "Caractéristiques techniques gauloises dans les céramiques à feu gallo-romaines de Lyon : disparition et persistances ", in Société française d'étude de la céramique antique en Gaule, Actes du Congrès du Mans, p. 517-518.

Batigne C., 200 I - « Note sur les choix techniques des ateliers de céramique commune de Gaule du Nord pendant la période romaine ", in Société française d'étude de la céramique antique en Gaule, Actes du Congrès de Lille-Bavay, p. 207-208.

Bellanger P., 20 i I - "Guérande, ZAC de la Métairie de la Lande, La Lande, site $\mathrm{n}^{\circ}$ 2, Fouille préventive ", Bilan scientifique 2009, DRAC, SRA des Pays-de-la-Loire, p. 36-38.

Berranger M., 2009 - Le fer, entre matière première et moyen d'échange, en France, du vII au Ir siècle av. J.-C. Approches interdisciplinaires, Thèse de doctorat de l'université Paris I, 2 vol.

Berthaud G., Delage R., Mortreau M. et Simon L., 2000 Mazières-en-Mauges gallo-romain (Maine-et-Loire), un quartier à vocation artisanale et domestique, ARDA-Afan, Angers, 262 p.

Berthault F., I 997 - « Production d'amphores vinaires dans la région du Langon (Vendée) ", in Société française d'étude de la céramique antique en Gaule, Actes du Congrès du Mans, 1997, p. 209-216.

Bocquet A., Chuniaud K. et Naveau J., 2004 - « Le quartier antique de la Grande-Boissière à Jublains (Mayenne) ", Revue archéologique de l'Ouest, $\mathrm{n}^{\circ}$ 21, Rennes, p. 131-174.

Bouvet J.-P., Brodeur J., Chevet P., Mortreau M. et Siraudeau J., 2003 - "Un oppidum au château d'Angers (Maine -et-Loire) ", in Mandy B. et De Saulce A. (dir.), «Les
Marges de l'Armorique à l'âge du Fer, Archéologie et Histoire : culture matérielle et sources écrites. Actes du XXIII ${ }^{e}$ colloque de l'AFEAF ", Revue archéologique de l'Ouest, supplément $\mathrm{n}^{\circ} 10$, p. $173-187$.

Buchsenschutz O., Colin A., Firmin G., Fischer B., Guillaumet J.-P., Krausz S., Levery M., Marinval P., Orellana L. et Pierret A., 2000 - Le village celtique des Arènes à Levroux. Synthèses, $19^{\mathrm{e}}$ supplément à la Revue archéologique du Centre, Levroux 5. Levroux, FERAC/ADEL, 333 p. Chevet P., Guicheteau A., Gallien V., Hinguant S., Langlois J.-Y., Le Roux F., Mare E., Nillesse O., Pean E., Seris D. et ZaOur N., 20I 3 - «Contournement en sous-sol. Archéologie et LGV Bretagne - Pays de la Loire ", in Maine découvertes, 75, janvier-février 2013, p. 34-47.

Chuniaud C. et Mortreau M., 2002 - «Un ensemble céramique de la première moitié du II $^{\mathrm{e}}$ siècle sur le site de la Grande Boissière à Jublains (Mayenne) ", in Société française d'étude de la céramique antique en Gaule, Actes du Congrès de Bayeux, p. $159-176$.

Clement J.-P., Chantraine J. et Limasset J.-C., I987 - Notice explicative de la feuille de Loué à 1/50000 (357), Orléans, éditions du BRGM, 1987, 35 p.

Coffineau E., 2006a - "Le mobilier archéologique ", in Tourneur J., La Selle-Craonnaise (53) La Chesnaie, Rapport final d'opération, fouille archéologique, Inrap, CessonSévigné/SRA Pays de la Loire, Nantes 2006, p. 58-76.

Coffineau E., 2006b - Le mobilier archéologique », in Guillier G., Entrammes (53) - La Carie II (53), rapport final d'opération, fouille archéologique, Inrap Grand-Ouest, CessonSévigné/SRA Pays de la Loire, Nantes 2006, vol. 1 - texte : p. 56-60 et p. 81-86, vol. 2-annexes : pl. 36 à 43 et pl. 51 à 59.

Deffresigne-Tikonoff S. et Tikonoff N., 2005 - «L'habitat à la fin du deuxième âge du Fer en Meurthe-et-Moselle : présentation des données récentes ", Archaeologia Mosellana, 6, p. $103-150$.

Deloze V., 20 I 2 - " Matériaux de construction et de mouture du site gaulois et antique d'Entrammes " La Carie II » (Mayenne, France) ", in Marchand G. et Querré G., Actes du colloque Roches et Sociétés de la Préhistoire, entre massifs cristallins et bassins sédimentaires (Rennes, 28 au 30 avril 2010), PUR, coll. "Archéologie et Culture ", février 2012, p. 483-493.

Devals C., 2004-Cossé-le-Vivien, Guinefolle (site ñ 53.077.0083 EA), Rapport final de synthèse, fouille archéologique, Inrap, CessonSévigné/SRA Pays de la Loire, Nantes, 129 p., 18 phot, annexes.

Evans E., I 967 - Gaulish personal names, Oxford, Clarendon Press, $492 \mathrm{p}$.

Feugere M., I 985 - Les fibules en Gaule méridionale de la conquête à la fin $d u v^{e}$ s. apr. J.-C. Paris, éditions du CNRS, Revue archéologique de Narbonnaise, supplément 12, 509 p., illus.

Gaudedroy S., 20 I I - «Les sites de La Tène moyenne à La Tène finale sur les tracés linéaires en Picardie : questions méthodo- 
logiques et résultats scientifiques ", in BAYARD D., Buchez N. et Depaepe P., Quinze ans d'archéologie préventive sur les grands tracés linéaires en Picardie, Première partie, Revue archéologique de Picardie, 3-4, p. 201-266.

GuÉrIn F., 200 I - Saint-Fulgent : "La Petite Valinière ", 85.215.012 AH, Vendée, A87. Série fouille-15, DFS, 2001, 109 p.

GuÉRIN F., 2003 - La Chaize-le-Vicomte, "La Chapellière ", 85.046.015 AH, Vendée, A87. Série fouille, Inrap, DFS, 181 p., 144 fig.

Guicheteau A., 20 I I - Bonchamp-lès-Laval, Argentré, Mayenne, $L G V$ BPL section 10, Rapport final d'opération de diagnostic, Nantes, Inrap, avril 2011, 81 p.

GuILlier G., 2009 - Rapport d'opération de fouille préventive, commune d'Entrammes (Mayenne), "Le Clos des Primevères ", Inrap Grand-Ouest, Service régional de l'Archéologie des Pays de la Loire, avril 2009, 169 p., 142 fig. 17 phot. et annexes.

Guillier G., 20I4a - "Bonchamp-lès-Laval, Aires de l'A81 ", rapport d'opération, diagnostic archéologique, Inrap GrandOuest : Cesson-Sévigné/SRA Pays de la Loire, 87 p.

Guillier G., 20 I 4b - "Bonchamp-lès-Laval, Le Grand-Coudray, D'une ferme gauloise à une villa-romaine ", rapport d'opération, fouille archéologique, Inrap Grand-Ouest, CessonSévigné/SRA Pays de la Loire.

Guillier G., Auxiette G. et Cherel A.-F., 2006 "L'établissement rural de La Tène moyenne de La Gaudine à Vivoin (Sarthe) et ses activités de transformation ", Revue archéologique de l'Ouest, 23, p. 45-70.

Guillier G., Coffineau E. et Delage R., 20 i 2 - « Le site gaulois et antique de La Carie entre oppidum et ville romaine à Entrammes (Mayenne) ", Revue archéologique de l'Ouest, 29, p. $145-200$.

Guitton D. et Thebaud S., à paraittre - «Permanence de la céramique modelée en territoire picton du Haut-Empire à la fin du haut Moyen Âge : un phénomène d'ampleur lié à un terroir ", in Actes du colloque sur la "Céramique non tournée en Gaule romaine".

Joly M. et Mouton S. 2003 - Les productions céramiques en Bourgogne occidentale : le Nivernais au $\mathrm{I}^{\mathrm{er}}$ siècle apr. J.-C., in Société française d'étude de la céramique antique en Gaule, Actes du congrès de Saint-Romain-en-Gal, 2003, p. 255-277.

Lallemand D. et Tuffreau-Libre M., 2005 - " La céramique "type Besançon " en Gaule centrale ", in Société française d'étude de la céramique antique en Gaule, Actes du congrès de Blois, 2005, p. 63-82.

Laurelut C., Tegel W. et Vanmoerkerke J., 2004 - « Nouvelles réflexions concernant les bâtiments à porche de la fin de l'âge du Fer », in Lunula, Archeologica protohistorica, XII, Aalst, p. 137-144.

Le Boulanger F. et Simon L., 20 I 2 - «De la ferme antique à la nécropole de l'Antiquité tardive (milieu II ${ }^{\mathrm{e}}$ siècle - fin du ve siècle apr. J.-C.) ", Gallia, 69-1, p. 167-307.

Ledauphin A., à paraître - "La céramique romaine ", in PÉAN E., La Cropte (53) "La Petite Coyère », LGV Le Mans-Rennes, rapport final d'opération, fouille archéologique, Inrap GrandOuest : Cesson-Sévigné/SRA Pays de la Loire.

Le Goff E., I 998 - Carquefou : Le Clouët (Les Mazières), DFS de Sauvetage urgent, Nantes, Afan - SRA des Pays de la Loire, $138 \mathrm{p}$.

Le Nagard H., 2005 - "Le mobilier en lignite de l'âge du Fer dans le massif armoricain et ses marges ", in Les dossiers $d u$ CeRAA, 33, 2005, p. 55-77.

Maguer P., 2005 - «L'architecture des bâtiments de La Tène dans le sud du Maine-et-Loire et en Vendée : études de cas ", in Buchsenschutz O. et Mordant C., Architectures protohistoriques en Europe occidentale du Néolithique final à l'âge du Fer, Nancy : éditions du CTHS, 2005, p. 331-345.

Maguer P., Cherel A.-F. et Auxiette G., 2003 - « Nouvelles données sur les habitats de l'âge du Fer dans le nord de la Sarthe (commune de Vivoin, autoroute A28) ", in MANdy B. et De Saulce A., (dir.), "Les Marges de l'Armorique à l'âge du Fer, archéologie et histoire : culture matérielle et sources écrites. Actes du XXIII ${ }^{e}$ colloque de l'AFEAF ", Revue archéologique de l'Ouest, supplément $\mathrm{n}^{\circ} 10$, p. 213-234.

Maguer P. et Lusson D., 2009 - « Fermes, hameaux et résidences aristocratiques entre Loire et Dordogne ", in BERTrand I., Duval A., Gomez De Soto J. et Maguer P., Habitats et paysages ruraux en Gaule et regards sur d'autres régions du Monde celtique, Actes du XXXI ${ }^{\mathrm{e}}$ colloque international de l'AFEAF, (17-20 mai 2007, Vienne, F.), Tome I, p. 423-459.

Maguer P. et Robert G., 2013 - "La maison gauloise dans l'ouest et le centre de la France ", in Krausz S., Colin A., Gruel K., Ralston I et Dechezlepretre T., L'áge du fer en Europe, Mélanges offerts à Olivier Buchsenschutz, Ausonius, Mémoires 32, p. 247-258.

Manning W.H., I985 - Catalogue of the Romano-British iron tools, fittings and weapons in the British Museum. London, 1985, rééd. 1989.

Mary G. et Giordano R., I989 - Notice explicative de la feuille d'Évron (320) à 1/50 000, Orléans, éditions du BRGM, 30 p.

Menez Y., I985 - Les céramiques fumigées de l'Ouest de la Gaule, Cahiers de Quimper Antique, no 2, 128 p., 44 pl.

Menillet F., Plaine J., Manigault B. et Le Herisse A., I 988 - Notice explicative de la feuille Meslay-du-Maine à 1/50 000 (356), Orléans, éditions du BRGM, 1988, 79 p.

Mortreau M., 2007 - "Le mobilier céramique ", in Valais A., Aron (Mayenne), Le Panveau, Rapport final d'opération, fouille archéologique, Inrap, Cesson-Sévigné/SRA Pays de la Loire.

NAVEAu J., I992 - La Mayenne 53, Carte archéologique de la Gaule, Paris, Académie des Inscriptions et Belles-Lettres, 176 p.

NAVEAU J. (dir.), I 997 - «Recherches sur Jublains (Mayenne) et sur la cité des Diablintes ", Rennes, éd. RAO, coll. " Documents archéologiques de l'Ouest », 352 p.

Nillesse O., I 994 - «Les établissements ruraux gaulois dans le sud de la Vendée ", in Buchsenschutz O. et Méniel P. (éd.), Les ins- 
tallations agricoles de l'âge du Fer en Île-de-France, Paris: Presses de l'ENS (coll. Études d'Histoire et d'Archéologie, IV), p. 277-293.

Nillesse O., I 997 - L'établissement rural des Genâts, Fontenay-leComte (Vendée), DFS de sauvetage urgent, autoroute A83 NantesNiort, Nantes, SRA Pays-de-la-Loire/AFAN, volume 2, 197 p.

Nillesse O., 2003 - «Les établissements ruraux gaulois de Marcé (Maine-et-Loire) et la hiérarchisation des aedificia ", in MANDY B. et De Saulce, A. (dir.), «Les Marges de l'Armorique à l'Âge du Fer, Archéologie et Histoire : culture matérielle et sources écrites. Actes du XXIII ${ }^{e}$ colloque de l'AFEAF ", Revue archéologique de l'Ouest, supplément no 10, p. 149-172.

Nillesse O., 2006 - Établissement rural de la fin de l'âge du Fer et occupation gallo-romaine du Coq Hardy à Fontenay-le-Comte (Vendée), Rapport final d'opération, Inrap/SRA des Pays de la Loire, 2006, 108 p., 91 fig. et annexes.

Nillesse O., 2009 - «Activités, métiers, vie quotidienne dans les établissements ruraux de l'Ouest de la France à travers l'instrumentum (Hallstatt D/début du Haut-Empire) ", in Bertrand I., Duval A., Gomez De Soto J. et Maguer P., Habitats et paysages ruraux en Gaule et regards sur d'autres régions du Monde celtique, Actes du XXXI ${ }^{\mathrm{e}}$ colloque international de l'AFEAF, (17-20 mai 2007,Vienne, F.), Tome II, p. 45-83.

Petorin N., 2007 - Commune de Oisseau-le-Petit (72225045) "Les Noirâs ", Rapport final d'opération, Inrap/SRA des Paysde-la-Loire, Janvier 2007, 115 p., annexes.

Petorin N., 2010 - Angers, Maine-et-Loire, Beauséjour, établissement rural de la Tène finale, Rapport d'opération de fouille archéologique, Inrap/SRA des Pays de la Loire, 77 p., annexes.

Petorin N., 20I 3 - Pays-de-la-Loire, Aubigny, Vendée, La Pâquerie. Établissement rural, La Tène finale - I r s. A.D, Inrap GrandOuest, 401 p. et annexes.
Quilliec B. et Laruaz J.-M., 20 I I - « Un établissement rural de La Tène finale à Couesmes, La Tesserie (Indre-et-Loire) ", Revue archéologique du Centre de la France, 50, p. 175-313.

SAndoz G., I999 - Cholet : "La Bleure ", Maine-et-Loire, A87. Série fouille - 9, DFS, 199987 p., annexes.

Schweitz D., Toulier C., Ferdière A., Fehrnbac X. et Blanc P.-M., I986 - "L'atelier de potier de Mougon (Couzilles, Indre-et-Loire) ", Revue archéologique du Centre de la France, 25,1, p. 37-77.

Siraudeau J., I 988 - Corpus des amphores découvertes dans l'Ouest de la France: Amphores romaines des sites angevins et leurs contextes archéologiques, vol.2, Angers.

Thomas S., 2003 - Étude pétrographique et palynologique de mobilier en "lignite " protohistorique. Caractérisation et étude de provenance, Mémoire de DESS MSTA, Dijon : université de Bourgogne.

Tourneur J., 2006 - La Selle-Craonnaise "La Chesnaie ", (Paysde-la-Loire/Mayenne), Rapport final d'opération. Inrap/SRA des Pays de la Loire.

ValaIs A., 2005 - Moulay-Mayenne (53) déviation RN162, phase 3, rapport final d'opération, diagnostic archéologique, Inrap, Cesson-Sévigné/SRA Pays de la Loire, Nantes.

Valais A., 2007 - Aron, "Le Panveau ", 53 008.0018, rapport final d'opération, Inrap, Cesson-Sévigné/SRA Pays de la Loire, Nantes 2007, 130 p. et annexes.

Valais A., Meuret J.-C. et Nauleau J.-F., 2008 - " Le ClosHenry : une ferme de La Tène finale à Château-Gontier (Mayenne) ", Revue archéologique de l'Ouest, 25, p. 139-161.

Zusammenfassung: Vom latènezeitlichem Gehöft zur römischen Villenanlage: Der Fundplatz von Grand-Coudray bei Bonchamp-lèsLaval (Mayenne) - Die auf einen Teilbereich eines latènezeitlichen und gallo-römischen Fundplatzes beschränkte Ausgrabung im Nordosten der Stadt Laval hat es gestattet, zwei aufeinanderfolgende latènezeitliche Grabensysteme zu untersuchen, die nach Süden hin von einem Weg begrenzt wurden. Das Hauptinteresse dieser wenig spektakulären Ausgrabung galt den etwa 20 nachgewiesenen Pfostenbauten. Das geborgene keramische Fundmaterial ist gerade ausreichend, um eine erste chronologische Einordnung vorzunehmen. Dagegen haben die Metallobjekte einige ungewöhnliche Funde geliefert, darunter ein Eisenbarren sowie ein Fragment einer Vase aus Lignit. Die römische Epoche wird durch verschiedene eingetiefte Befunde repräsentiert, die exakt die vorhergehenden eisenzeitlichen Befunde überlagern. Die letzte Siedlungsphase, die an den Anfang des 2. Jh. n. Chr. zu stellen ist, wird durch die freigelegte Südwestecke der pars rustica einer römischen Villenanlage charakterisiert. Die römische Modelware, die im Keramikspektrum für den Fundplatz charakteristisch ist, weist einen für die Region ungewöhnlich hohen Anteil von nahezu $60 \%$ Vasen auf.

Resumen: Desde la granja galo hasta la villa romana: el sitio de Grand-Coudray en Bonchamp-lès-Laval (Mayenne) - La excavación parcial de un sitio de La Tène antigua situado al noreste de la ciudad de Laval ha puesto de relieve dos sistemas sucesivos de recintos galos, limitados al sur por un pequeño sendero. El principal interés de esta pequeña excavación es la presencia de una veintena de edificios instalados en estacas clavadas. El mobiliario de cerámica es sólo suficiente para permitir una primera hipótesis cronológica; sin embargo, el instrumentum reveló algunos objetos inusuales, un lingote de hierro y un fragmento de jarra de lignito. La época antigua se caracteriza por la excavación de estructuras que se superponen exactamente a las estructuras anteriores. La última fase de la ocupación, al principio del siglo II después de Jesús-Cristo, se define por la esquina suroeste de la pars rustica de una villa romana. La cerámica modelada antigua, característica del sito, presenta un porcentaje bastante inusual con casi $60 \%$ de jarras.

Schlüsselworte: Diablintes, Mayenne, Latènezeit, eisenzeitliche Einhegungen, Pfostenbauten, Portal, Frühe römische Kaiserzeit, Siedlung, villa, Keramik, Instrumentum.

Palabras clave: Diablintes, Mayenne, La Tène, recinto galo, edificios sobre estacas clavadas, hábitat, villa, ceramica, instrumentum. 